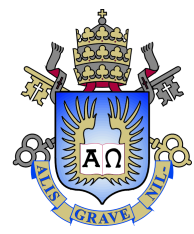

Alexandre Amorim Pereira Júnior

\title{
Detecção de sinais no enlace reverso de sistemas MIMO de larga escala com múltiplos usuários e células
}

Tese de Doutorado

Tese apresentada ao Programa de Pós-graduação em Engenharia Elétrica da PUC-Rio como requisito parcial para obtenção do grau de Doutor em Engenharia Elétrica.

Orientador: Prof. Raimundo Sampaio Neto 


\section{Pontifícia Universidade Católica \\ DO RIO DE JANEIRO}

Alexandre Amorim Pereira Junior

\section{Detecção de Sinais no Enlace Reverso de Sistemas MIMO de Larga Escala com Múltiplos Usuários e Células}

Tese apresentada como requisito parcial para obtenção do grau de Doutor pelo Programa de Pós-Graduação em Engenharia Elétrica da PUC-Rio. Aprovada pela Comissão Examinadora abaixo assinada.

Prof. Raimundo Sampaio Neto

Orientador

Centro de Estudos e Telecomunicações - PUC-Rio

Prof. Marco Antonio Grivet Mattoso Maia Centro de Estudos e Telecomunicações - PUC-Rio

Prof. Ernesto Leite Pinto IME

Prof. Cesar Augusto Medina Sotomayor IME

Dr. Fabian David Backx Instituto de Pesquisas da Marinha

Prof. José Antonio Apolinário Junior Exército Brasileiro

Prof. Márcio da Silveira Carvalho

Coordenador Setorial do Centro Técnico Científico - PUC-Rio

Rio de Janeiro, 24 de Abril de 2017 
Todos os direitos reservados. É proibida a reprodução total ou parcial do trabalho sem autorização da universidade, do autor e do orientador.

\section{Alexandre Amorim Pereira Júnior}

Graduou-se em Engenharia de Computação pelo Instituto Militar de Engenharia - IME (Rio de Janeiro, Brasil). Obteve o título de Mestre em Ciências em Engenharia Elétrica pelo Departamento de Engenharia Elétrica deste mesmo Instituto, especializando-se na área de concentração de processamento de sinais aplicado aos sistemas de comunicações. Trabalhou no gerenciamento de redes de computadores, sendo responsável pela gerência da Rede Corporativa Privativa do Exército e atualmente compõe o corpo docente do IME, atuando nos cursos de graduação em Engenharia de Comunicações, Eletrônica e de Computação.

Ficha Catalográfica

Amorim Pereira Júnior, Alexandre

Detecção de sinais no enlace reverso de sistemas MIMO de larga escala com múltiplos usuários e células / Alexandre Amorim Pereira Júnior; orientador: Raimundo Sampaio Neto. $-2017$.

v., 131 f: il. color. ; $30 \mathrm{~cm}$

Tese (doutorado) - Pontifícia Universidade Católica do Rio de Janeiro, Departamento de Engenharia Elétrica.

Inclui bibliografia

1. Engenharia Elétrica - Teses. 2. Sistemas MIMO de larga escala;. 3. Detecção multi-usuário;. 4. Detecção de enlace reverso;. 5. Detecção e decodificação iterativa;. 6. Contaminação por pilotos.. I. Sampaio Neto, Raimundo. II. Pontifícia Universidade Católica do Rio de Janeiro. Departamento de Engenharia Elétrica. III. Título. 


\section{Agradecimentos}

À Deus, sem o qual nada é possível, por me permitir trilhar esse caminho na jornada do auto-aperfeiçoamento e por estar sempre presente na minha vida.

Ao meu orientador, Professor Raimundo Sampaio Neto, pelos ensinamentos, orientações e disponibilidade durante o período que estivemos trabalhando juntos. Em especial, agradeço pela confiança na capacidade do seu orientado em realizar um trabalho de qualidade, mesmo nos momentos em que este orientado, em seus questionamentos mais interiores, duvidava dessas mesmas capacidade e qualidade.

Aos meus pais, Alexandre e Rosangela, pelo sólido alicerce moral, material e espiritual que sempre proveram, sem o qual seria impossível o desenvolvimento deste trabalho.

Às amigas Gisela e Melissa, por mais uma vez compreenderem as prolongadas ausências e nunca deixarem que nossa amizade fosse abreviada pela distância ou pelo tempo.

Por fim, a todos que ajudaram a concluir mais essa etapa. 


\section{Resumo}

Amorim Pereira Júnior, Alexandre; Sampaio Neto, Raimundo. Detecção de sinais no enlace reverso de sistemas MIMO de larga escala com múltiplos usuários e células. Rio de Janeiro, 2017. 131p. Tese de Doutorado - Departamento de Engenharia

Elétrica, Pontifícia Universidade Católica do Rio de Janeiro.

Este trabalho tem como finalidade estudar o problema da detecção de usuários no canal reverso de sistemas MIMO de larga escala, que são caracterizados pelo elevado número de elementos de transmissão e recepção, com foco na complexidade computacional e no desempenho em termos de taxa de erro destes sistemas. Inicialmente, os algoritmos de detecção da família Likelihood Ascent Search (LAS) são investigados e é desenvolvido um novo algoritmo de detecção, denominado de Random-List Based LAS (RLBLAS), capaz de atingir melhores taxas de erros com menor complexidade computacional do que os demais detectores considerados. Posteriormente, técnicas de detecção e decodificação iterativas (Iterative Detection and Decoding - IDD) em sistemas MIMO foram analisadas de forma a propor uma estratégia IDD de complexidade computacional reduzida a fim de viabilizar a sua aplicação em cenários massivos. Finalmente, o problema da contaminação por pilotos em sistemas MIMO multicelulares de larga escala, um dos principais limitadores do desempenho desse tipo de sistema, é estudado e estratégias de detecção com cooperação parcial entre as estações base componentes do sistema que visam mitigar os efeitos da contaminação por pilotos são propostas. As análises e afirmações realizadas durante a presente tese são sustentadas por resultados de simulações de Monte Carlo dos sistemas de comunicações em diversos cenários distintos, incluindo os casos em que são considerados os efeitos de correlação entre as antenas de transmissão/recepção, os efeitos de sombreamento e os erros de estimação dos estados dos canais de comunicações envolvidos.

\section{Palavras-chave}

Sistemas MIMO de larga escala; Detecção multi-usuário; Detecção de enlace reverso; Deteç̧ão e decodificação iterativa; Contaminação por pilotos. 


\section{Abstract}

Amorim Pereira Júnior, Alexandre; Sampaio Neto, Raimundo (Advisor). Reverse link large scale MIMO signal detection with multiple users and cells. Rio de Janeiro, 2017. 131p. Tese de Doutorado- Departamento de Engenharia Elétrica, Pontifícia Universidade Católica do Rio de Janeiro.

This work focuses on the multi-user multi-cellular large-scale MIMO reverse channel detection problem, where the number of transmitting and receiving antenna elements grows to the order of hundreds. In these scenarios, one major issue is the computational complexity of such systems. Therefore, this thesis aims to propose low-complexity techniques with good BER performance for the reverse channel detection of MIMO systems. Initially, the detection algorithms of the Likelihood Ascent Search (LAS) family are investigated and a new LAS based detector is proposed. This new detector, named Random-List Based LAS (RLB-LAS), is capable of achieving better BER with lower complexity then the other considered detectors. Next, iterative detection and decoding (IDD) techniques are analyzed in order to propose an IDD strategy applied to the detection and decoding of the reverse MIMO channel with reduced complexity to make possible its application to massive scenarios. Finally, the pilot contamination problem in multi-cellular large-scale MIMO systems, one of the major bounds on BER performance of these systems, are studied and some cooperative strategies are proposed in order to reduce the effects of this type of impairments. The analysis and statements of this thesis are supported by Monte Carlo simulation results of the considered systems in different scenarios, including the cases where the effects of transmitting and receiving antenna correlation, log-normal shadowing, and the estimation errors on the channel state information acquisition are considered.

\section{Keywords}

Large scale MIMO systems; Multiuser detection; Reverse link detection; Iterative detection and decoding; Pilot contamination. 


\section{Sumário}

1 Introdução 18

$\begin{array}{lll}1.1 & \text { Objetivos } & 23\end{array}$

2 Sistemas MIMO $\quad 26$

2.1 Introdução 26

2.2 O canal de comunicações sem fio 26

2.2.1 Desvanecimento de larga escala 27

2.2.2 Desvanecimento de pequena escala 28

2.3 Canal reverso de sistemas de comunicações MU-MIMO 31

2.3.1 Capacidade de informação para o canal reverso de sistemas MIMO 32

2.3.2 Correlação entre antenas e efeitos do sombreamento log-normal 35

2.4 Estimação de canal por mínimos quadrados 36

2.5 Estratégias clássicas de detecção em sistemas MIMO 37

2.5.1 Detector de máxima verossimilhança 38

2.5.2 Detector Zero forcing 39

2.5.3 Detecção por mínimo erro médio quadrático 39

$\begin{array}{ll}\text { 2.5.4 Detecção por filtro casado } & 40\end{array}$

2.5.5 Cancelamento de interferência serial ordenado (OSIC) 40

2.6 Conclusões 41

3 Estratégia de Busca por Verossimilhança Ascendente 43

3.1 Introdução 43

3.2 Procedimento LAS 43

3.3 Detectores baseados na busca LAS $\quad 58$

3.3.1 LAS Multiestágio $\quad 58$

3.3.2 Algoritmos LAS com Seleção de Saídas Múltiplas 61

3.3.2.1 Algoritmo LAS com Múltiplos Vetores de Entrada (MIV-LAS) 61

3.3.2.2 Algoritmo LAS com Múltiplos Conjuntos de Candidatos de Busca (MSCS-LAS) 62

3.3.3 Detector Random-List Based LAS 64

3.4 Comparação de Desempenho dos Detectores LAS 69

$\begin{array}{ll}3.5 \text { Conclusões } & 75\end{array}$

4 Detecção e Decodificação Iterativas em Sistemas MIMO $\quad 77$

4.1 Introdução $\quad 77$

4.2 Estratégia de Detecção e Decodificação Iterativa (Turbo) 78

4.2.1 Decodificador de Canal de Entradas e Saídas Suaves 81

4.2.2 Detector de entradas e saídas suaves PIC MF MIMO 84

$\begin{array}{lll}4.3 & \text { Resultados de simulação } & 87\end{array}$

$\begin{array}{lll}4.4 & \text { Conclusão } & 96\end{array}$

5 Contaminação por Pilotos e Estimação e Detecção Conjuntas $\quad 97$

$\begin{array}{lll}5.1 & \text { Introdução } & 97\end{array}$

5.2 Modelo multicelular e efeitos da contaminação por pilotos 99 
$\begin{array}{lll}\text { 5.2.1 } & \text { Modelo multicelular } & 99\end{array}$

5.2.2 Efeitos da contaminação por pilotos 100

5.3 Esquemas de estimação e detecção conjuntos 101

5.3.1 Estratégia de Estimação e Detecção conjunta 102

5.3.2 Esquemas de estimação e detecção propostos 105

$\begin{array}{lll}\text { 5.3.2.1 Esquema conjunto não cooperativo } & 106\end{array}$

$\begin{array}{lll}\text { 5.3.2.2 Esquema conjunto cooperativo } & 107\end{array}$

5.3.2.3 Esquema conjunto cooperativo com SCS aleatório 110

$\begin{array}{lll}5.4 & \text { Resultados de simulação } & 111\end{array}$

$\begin{array}{lll}5.5 \text { Conclusões } & 114\end{array}$

6 Conclusões e Trabalhos Futuros $\quad \mathbf{1 1 6}$

$\begin{array}{lll}6.1 \text { Conclusões } & 116\end{array}$

$\begin{array}{ll}\text { 6.2 Propostas para trabalhos futuros } & 118\end{array}$

$\begin{array}{lll}6.2 .1 & \text { Detector MF-RLB-LAS } & 118\end{array}$

6.2.2 Esquema de Detecção e Decodificação Iterativo 119

6.2.3 Estimação e Detecção conjuntas cooperativa em sistemas MIMO $\begin{array}{ll}\text { multicelulares } & 119\end{array}$

$\begin{array}{ll}\text { Referências bibliográficas } & 121\end{array}$

$\begin{array}{lll}\text { A } & \text { Demonstrações por indução } & 129\end{array}$ 


\section{Lista de figuras}

2.1 Desvanecimento de larga e pequena escala. Extraído de [8]. 27

2.2 Representação do sistema MIMO 31

2.3 Modelo simplificado de um sistema de comunicações 33

2.4 Curvas de capacidade para sistemas MIMO. 35

2.5 Esquema de detecção com cancelamento de interferência serial ordenado.

3.1 Curvas de BER de detectores SLAS com modulação BPSK. 49

3.2 Curvas de BER de detectores SLAS com modulação 4-QAM. 49

3.3 BER por SNR de detectores SLAS com modulação BPSK. $\quad 50$

3.4 BER por SNR de detectores SLAS com modulação 4-QAM. 50

3.5 Número máximo e médio de passos por SNR das buscas LAS do detector MF-SLAS em sistemas com modulação 4-QAM. 52

3.6 Número máximo e médio de passos por SNR das buscas LAS do detector MMSE-SLAS em sistemas com modulação 4-QAM. 52

3.7 Número médio de passos por $N_{r}=N_{t}=N$ dos detectores MFSLAS e MMSE-SLAS em sistemas MIMO com modulação 4-QAM. 53

3.8 Curvas do número médio de flops por bit transmitido pela SNR dos detectores MF-SLAS and MMSE-SLAS em sistemas com modulação 4-QAM.

3.9 Número médio de flops por $N_{t}$ dos detectores MF-SLAS e MMSESLAS para sistemas com $N_{r}=32$ e modulação 4-QAM.

3.10 Número médio de flops por $N_{r}$ dos detectores MF-SLAS e MMSESLAS para sistemas com $N_{t}=5$ e modulação 4-QAM.

3.11 Número médio de flops por $N_{t}=N_{r}=N$ dos detectores MF-SLAS e MMSE-SLAS para sistemas com modulação 4-QAM.

3.12 Ajuste de superfície para o detector MF-SLAS. 57

3.13 Ajuste de superfície para o detector MMSE-SLAS. 58

3.14 Curvas de BER pela SNR de detectores MLAS com modulação 4-QAM.

3.15 Curvas do número médio de flops por bit transmitido pela SNR de detectores MLAS com modulação 4-QAM.

3.16 Curvas de BER pela SNR de detectores MOS-LAS com modulação 4-QAM.

3.17 Curvas do número médio de flops por bit transmitido pela SNR de detectores MOS-LAS com modulação 4-QAM.

3.18 Curvas de BER pela SNR do detector MF-RLB-LAS com modulação 4-QAM.

3.19 Curvas do número médio de flops pela SNR de detectores MF-RLBLAS com modulação 4-QAM.

3.20 Curvas do número médio de flops por $N_{t}=N_{r}=N$ em escala log-log do detector MF-RLB-LAS com modulação 4-QAM.

3.21 Curvas de BER pela SNR dos detectores MF-RLB-LAS, MMSERLB-LAS, MMSE-MLAS, MF/ZF/MMSE-MIV-LAS e 5-MSCSLAS com modulação 4-QAM no cenário A e $N_{t}=N_{r}=20$. 
3.22 Curvas de BER pela SNR dos detectores MF-RLB-LAS, MMSESIC e MMSE-SIC-MB com modulação 4-QAM no cenário A e $N_{t}=N_{r}=20$.

3.23 Curvas do número médio de flops por bit transmitido pela $S N R$ de diversos detectores MIMO com modulação 4-QAM considerando o cenário A e $N_{t}=N_{r}=20$.

3.24 Curvas de BER pela SNR dos detectores MF-RLB-LAS, MMSE/ZF/MF-MIV-LAS e 5-MSCS-LAS com modulação 4-QAM no cenário $\mathrm{B}\left(\rho=0.2, \sigma_{k}=6 \mathrm{~dB}\right)$.

3.25 Curvas do número médio de flops por bit transmitido pela $S N R$ para os detectores MF-RLB-LAS, MMSE/ZF/MF-LAS e 5-MSCSLAS com modulação 4-QAM e $N_{t}=N_{r}=20$ considerando os cenários $\mathrm{A}$ e $\mathrm{B}\left(\rho=0.2, \sigma_{k}=6 d B\right)$.

3.26 Curvas do número médio de flops por bit transmitido por $N_{t}=N_{r}=N$ em escala log-log dos detectores MF-RLB-LAS, MMSE/ZF/MF-LAS e 5-MSCS-LAS com modulação 4-QAM considerando o cenário $\mathrm{B}\left(\rho=0.2, \sigma_{k}=6 d B\right)$.

4.1 Esquema de detecção e decodificação iterativo para sistemas MUMIMO.

4.2 Detector MIMO de entradas e saídas suaves com cancelamento de interferência paralelo. a) estrutura analítica, b) estrutura sintética.

4.3 BER versus $S N R_{B}$ de diversas iterações da detecção IDD turbo com o detector interno MF-1LAS para sistemas MIMO com $N_{r}=$ $N_{t}=20$ para canal conhecido e estimado no cenário A.

4.4 BER versus $S N R_{B}$ de diversas iterações da detecção IDD turbo com o detector interno MF-1LAS para sistemas MIMO com $N_{r}=$ $N_{t}=20$ para canal conhecido e estimado no cenário B com $\rho=0.2$ and $\sigma_{k}=6 d B$.

4.5 BER versus $S N R_{B}$ de diversas iterações da detecção IDD turbo com o detector interno 5-MSCS-LAS para sistemas MIMO com $N_{r}=N_{t}=20$ para canal conhecido e estimado no cenário A.

4.6 BER versus $S N R_{B}$ de diversas iterações da detecção IDD turbo com o detector interno MF-RLB-LAS para sistemas MIMO com $N_{r}=N_{t}=20$ para canal conhecido e estimado no cenário A.

4.7 BER versus $S N R_{B}$ de diversas iterações da detecção IDD turbo com o detector interno 5-MSCS-LAS para sistemas MIMO com $N_{r}=N_{t}=20$ para canal conhecido e estimado no cenário B com $\rho=0.2$ and $\sigma_{k}=6 d B$.

4.8 BER versus $S N R_{B}$ de diversas iterações da detecção IDD turbo com o detector interno MF-RLB-LAS para sistemas MIMO com $N_{r}=N_{t}=20$ para canal conhecido e estimado no cenário B com $\rho=0.2$ and $\sigma_{k}=6 d B$.

4.9 BER versus $S N R_{B}$ de diversos esquemas de detecção e decodificação para sistemas MIMO com $N_{r}=N_{t}=20$ sujeito às condições do cenário $A$ para canal estimado.

4.10 BER versus $S N R_{B}$ de diversos esquemas de detecção e decodificação para sistemas MIMO com $N_{r}=N_{t}=20$ sujeito às condições do cenário B com $\rho=0.2$ e $\sigma_{k}=6 d B$. 
4.11 Complexidade computacional total de diversos esquemas de detecção e decodificação para um sistema MIMO com $N_{r}=N_{t}=20$.

5.1 Diagrama de cooperação parcial no esquema de estimação/detecção conjunto

5.2 Exemplo de configuração de usuários para um sistema MIMO com $L=4$ e $K=4$.

5.3 Curvas de BER versus SNR para diversas estratégias de estimação e detecção em sistemas MIMO.

5.4 Curvas do número médio de flops por bit transmitido versus SNR para diversas estratégias de estimação e detecção em sistemas MIMO.114 


\section{Lista de tabelas}

2.1 Expoente de perda de percurso para ambientes distintos.

2.2 Condições do sistema de forma a considerar o desvanecimento plano na frequência e lento no tempo. 


\section{Lista de Abreviaturas}

3GPP - 3rd Generation Partnership Project

AWGN - Additive White Gaussian Noise

BCC - Binary Convolutional Code

BCJR - Decodificador de Bahl, Cocke, Jelinek e Raviv

BER - Bit Error Rate

BP - Belief Propagation

BPSK - Binary Shift Keying

CD - Carregamento Diagonal

CDMA - Code Division Multiple Access

EB - Estação Base

EM - Estação Móvel

fdp - Função Densidade de Probabilidade

FLOP - Floating-Point Operation

IDD - Iterative Detection and Decoding

IEEE - Institute of Electrical and Electronics Engineers

ISI - Intersymbol Interference

ISM - Industrial, Scientific and Medical

LAS - Likelihood Ascent Search

LDPC - Low-Density Parity Check

LLR - Log-Likelihood Ratio

LTE - Long Term Evolution

M-LAS - Multi-stage Likelihood Ascent Search

MAP - Máximo à Posteriori

MB-LR-SIC - Multi-Branch Lattice Reduction Successive Interference Cancellation

MF - Matched Filter

MIMO - Multiple-Input Multiple-Output

MIV-LAS - Multiple Input Vector Likelihood Ascent Search

ML - Maximum Likelihood

MMSE - Minimum Mean Squared Error

MOS-LAS - Multiple Output Selection Likelihood Ascent Search

MSCS-LAS - Multiple Search Candidate Set Likelihood Ascent Search

MSE - Mean Squared Error

MU-MIMO - Multi-User Multiple-Input Multiple-Output

OFDM - Orthogonal Frequency Division Multiplexing

OSIC - Ordered Sucessive Interference Cancellation

PAM - Pulse Amplitude Modulation

PEP - Pair-wise Error Probability

PIC - Parallel Interference Cancellation

QAM - Quadrature Amplitude Modulation 
RLB-LAS - Random-List Based Likelihood Ascent Search

RSC - Recursive Systematic Codes

RTS - Reactive Tabu Search

$\mathrm{Rx}$ - Receptor

SCS - Search Candidate Set

SD - Sphere Decoding

SIC - Serial Interference Cancellation

SIC-MB - Multi-Branch Successive Interference Cancellation

SINR - Signal to Interference Plus Noise Ratio

SISO - Single-Input Single-Output

SLAS - Sequential Likelihood Ascent Search

SNR - Razão Sinal-Ruído

$\mathrm{SNR}_{B}$ - Razão Sinal-Ruído de informação

STBC - Space-Time Block Code

TDD - Time Division Duplexing

Tx - Transmissor

UMTS - Universal Mobile Telecommunications System

ZF - Zero Forcing 


\section{Lista de Símbolos}

$\alpha^{t}(\mathbf{w})$ - Recursão avante do algoritmo de decodificação BCJR

$\mathcal{B}$ - Constelação de símbolos da modulação empregada

$\beta^{t}(\mathbf{w})$ - Recursão reversa do algoritmo de decodificação BCJR

$\beta_{k}$ - Coeficiente de sombreamento log-normal

$\Delta \Lambda$ - Variação da métrica de verossimilhança

$\gamma$ - Expoente de perda de percurso

$\mathscr{L}$ - Parâmetro de carregamento

$\boldsymbol{\lambda}_{i}^{1^{\prime}}$ - Matriz de LLRs a priori do $i$-ésimo decodificador da estratégia IDD

$\Lambda_{i}^{1^{\prime}}$ - LLRs a posteriori do detector MIMO da estratégia IDD destinada ao $i$-ésimo decodificador

$\lambda_{i}^{2}$ - LLRs a priori do detector MIMO da estratégia IDD calculada pelo $i$-ésimo decodificador

$\Lambda_{i}^{2}$ - LLRs a posteriori calculadas pelo $i$-ésimo decodificador da estratégia IDD $\Lambda_{i}^{2}\left(m^{t}\right)-$ LLR do bit de mensagem $m^{t}$

$\nu$ - Comprimento de restrição do código empregado na estratégia IDD

$\Lambda(\mathbf{d})$ - Métrica de verossimilhança

$\mathcal{N}(0,1)$ - Distribuição gaussiana real de média zero e variância unitária

$\phi(\mathbf{d})$ - Custo ML padronizado do vetor $\mathbf{d}$

$\psi$ - Número de símbolos da sequência piloto

$\boldsymbol{\Psi}$ - Matriz de sinais pilotos em cada célula

$\Psi_{0}$ - Matriz de sinais pilotos de todo o sistema multicelular

$\rho$ - Índice de correlação

$\rho_{r}$ - Índice de correlação entre antenas na recepção

$\rho_{t}$ - Índice de correlação entre antenas na transmissão

$\sigma_{n}^{2}$ - Variância de cada componente do vetor de ruído de recepção

$\sigma_{n, l}$ - Espalhamento de sombreamento do $n$-ésimo usuário da l-ésima célula

$\sigma_{k}-$ Espalhamento de sombreamento

$\tau$ - Número de símbolos transmitido por antena por quadro

$\tau_{p}$ - Número de símbolos das sequências pilotos

$\theta_{i, n, l}$ - Coeficiente de perda de percurso e sombreamento entre o $n$-ésimo usuário da $l$-ésima célula e a EB da $i$-ésima célula

$B$ - Número de bits por símbolo da modulação empregada

$\mathbf{b}_{i}$ - Sequência de bits codificados a ser transmitida pela $i$-ésima antena de transmissão

$\mathbf{b}_{i}^{t}$ - Saída do codificador referente à entrada $m_{i}^{t}$

$C_{e}$ - Capacidade ergódica de informação

$\mathcal{C N}(0,1)$ - Distribuição gaussiana complexa de média zero e variância unitária

d - Vetor de símbolos da decisão corrente do processo

\section{RLB-LAS}


$d_{0}$ - Distância de referência

$\mathbf{d}_{m}^{(0)}$ - Vetor de símbolos candidatos iniciais na $m$-ésima iteração do processo RLB-LAS

$\mathbf{d}(n)$ - Vetor de símbolos escolhidos no $n$-ésimo passo do algoritmo LAS

$E(\cdot)$ - Operador valor esperado

$\mathbf{e}_{p}$ - Vetor unitário cujo p-ésimo elemento é 1

$f_{0}$ - Banda de coerência

$f_{D}-$ Máximo desvio Doppler

$f_{\text {Doppler }}-$ Desvio Doppler

$\mathbf{g}(n)$ - $\mathbb{R}$-derivada conjugada da métrica de verossimilhança

$\mathbf{G}_{0 k}$ - Matriz de ganhos de canal entre o $k$-ésimo usuário e a EB, considerando os efeitos da correlação

$\mathbf{G}_{i, l}$ - Matriz de canal entre os usuários da l-ésima célula e as antenas da EB da $i$-ésima célula

$\mathbf{G}_{k}$ - Matriz de ganhos de canal entre o $k$-ésimo usuário e a EB, considerando os efeitos da correlação e do sombreamento

$\mathbf{H}$ - Matriz de coeficientes de canal

$\tilde{\mathbf{H}}$ - Matriz de coeficientes de canal estimada

$\mathbf{h}_{i}-i$-ésima coluna da matriz $\mathbf{H}$

$\mathbf{H}_{k}$ - Matriz de coeficientes de canal do $k$-ésimo usuário

$\mathbf{h}_{n_{r}, n_{t k}}$ - Ganho do canal entre a $n_{t k^{-}}$-ésima antena de transmissão e a $n_{r}$-ésima antena da EB

$H(\mathbf{x})$ - Entropia do vetor aleatório $\mathbf{x}$

$H(\mathbf{x} \mid \mathbf{y})$ - Entropia condicional do vetor aleatório $\mathbf{x}$ dado o vetor aleatório $\mathbf{y}$

I - Matriz identidade

$\mathbf{I}_{N_{r}}$ - Matriz identidade de dimensão $N_{r}$

$I(\mathbf{x}, \mathbf{y})$ - Informação mútua entre os vetores aleatórios $\mathbf{x}$ e $\mathbf{y}$

$K$ - Número de usuários servidos por célula

$\mathbf{K}_{\mathbf{y}}$ - Matriz covariância do vetor aleatório $\mathbf{y}$

$L_{f}(n)$ - Conjunto de índices do vetor de símbolos candidatos que terão seus símbolos correspondentes efetivamente trocados no $n$-ésimo passo do processo LAS

$L(n)$ - Conjunto de candidatos de busca do $n$-ésimo passo do algoritmo LAS

$\log (\cdot)$ - Operador logaritmo na base 10

$M$ - Número de símbolos da constelação utilizada

$\mathbf{m}_{i}$ - Sequência de bits de mensagem a ser transmitida pela $i$-ésima antena de transmissão

$m_{i}^{t}$ - Bit de entrada do codificador referente à $i$-ésima antena de transmissão no instante $t$ da estratégia IDD

$\mathbf{M}_{n}$ - Matriz de Hadamard de dimensões $(n \times n)$

$\mathbf{n}$ - Vetor de ruído de recepção

$N_{l}$ - Número de iterações do detector MSCS-LAS

$N_{p}$ - Número de iterações necessárias no processo RLB-LAS

$N_{p_{\text {min }}}$ - Número mínimo de iterações no processo RLB-LAS

$N_{r}$ - Número de antenas de recepção 
$N_{s}$ - Número médio de passos do processo LAS

$N_{t}$ - Número total de antenas de transmissão

$N_{t i}$ - Número de antenas de transmissão do $i$-ésimo usuário

$\mathbf{P}$ - Matriz de sinais piloto

$\overline{P L}(d)$ - Perda de percurso média

$P L(d)$ - Perda de percurso

$p(\mathbf{x})$ - fdp do vetor $\mathbf{x}$

$P_{t}$ - Potência do sinal transmitido

$P(\mathbf{x} \mid \mathbf{H}, \mathbf{y})$ - Probabilidade de transmitir o vetor $\mathbf{x}$ dada a matriz $\mathbf{H}$ e o vetor $\mathbf{y}$

$p(\mathbf{y} \mid \mathbf{H}, \mathbf{x})$ - fdp do vetor $\mathbf{x}$ dada a matriz $\mathbf{H}$ e o vetor $\mathbf{x}$

$R$ - Taxa do código empregado na estratégia IDD

$\mathbf{R}_{r_{x}}$ - Matriz correlação entre antenas receptoras

$\mathbf{R}_{t_{x_{k}}}$ - Matriz correlação entre as antenas do $k$-ésimo usuário na transmissão

$\mathbf{s}_{i}$ - Sequência de símbolos transmitida pela $i$-ésima antena de transmissão

$\mathbf{s}_{t}-$ Vetor de símbolos transmitidos no instante $t$

$T_{0}$ - Tempo de coerência

$T_{e}$ - Máximo atraso em excesso

$T_{m}$ - Número de símbolos de informação transmitidos

$T_{s}$ - Duração do símbolo

$W$ - Largura de banda do sinal transmitido

$\mathbf{w}_{i}^{t}$ - Vetor ordenado que define o estado da treliça do codificador referente à $i$-ésima antena de transmissão no instante $t$

$\mathbf{W}_{M F}$ - Filtro de detecção MF

$\mathbf{W}_{M M S E}$ - Filtro de detecção MMSE

$\mathbf{W}_{Z F}$ - Filtro de detecção ZF

$\mathbf{x}$ - Vetor de símbolos transmitidos

$\mathbf{x}_{k}$ - Vetor de símbolos transmitido pelo $k$-ésimo usuário

$\mathbf{Y}$ - Matriz de sinais recebidos

$\mathbf{y}$ - Vetor de sinal recebido

$\mathbf{Y}_{p}$ - Matriz de sinais recebidos referentes aos símbolos pilotos 


\section{Introdução}

As comunicações sem fio, por apresentar diversas características atrativas, como mobilidade, extensa área de serviço, infra-estrutura de enlaces reduzida, entre outras, foram eleitas pela sociedade moderna como sendo o método preferencial de troca de informações multimídia. Aliado a essas características, o conceito celular, empregado em diversas redes de comunicações sem fio, provê vantagens operacionais como possibilidade de reuso do espectro de radiofrequências disponíveis, reduzida potência de transmissão e áreas de cobertura teoricamente ilimitadas.

Todas essas vantagens mencionadas impulsionaram a popularização e o desenvolvimento de sistemas de comunicações sem fio afetando diretamente as demandas por capacidade de transmissão de tais sistemas. Por sua vez, o crescimento exponencial nas exigências por capacidade de transmissão das redes sem fio, observado nas últimas décadas, contribuiu para o aumento do esforço de pesquisa nas áreas de conhecimento correlatas como processamento digital de sinais, transmissão digital, protocolos de comunicações, eletrônica etc. Este esforço levou ao surgimento de tecnologias capazes de transmitir grandes quantidades de informação e à proliferação de dispositivos móveis capazes de processar grandes quantidades de dados, como smartphones e tablets.

Completando o círculo virtuoso dos sistemas de comunicações sem fio, a popularização e o emprego massivo dos dispositivos móveis e das redes sem fio, destacando-se as redes celulares, colocaram os sistemas sem fio em ênfase no cenário das comunicações modernas, amplificando ainda mais as demandas por capacidade dos sistemas de transmissão das gerações atuais e futuras.

Dado que o canal de comunicação sem fio possui espectro limitado, constituindo um recurso oneroso e escasso, as capacidades desejadas somente podem ser atingidas por meio do aumento da eficiência espectral dos sistemas de transmissão sem fio e do eficiente gerenciamento dos sinais interferentes, das imperfeições dos canais e do ruído de recepção. Neste contexto, as técnicas de múltiplas antenas, conhecidas como técnicas de entradas e saídas múltiplas (Multiple-Input Multiple-Output - MIMO), foram propostas como forma de aumentar a capacidade de transmissão dos sistemas sem fio e se tornaram 
bastante populares, sendo incorporadas a diversos serviços de usuário único e multi-usuário, como o WiMax, IEEE 802.11n [1], LTE, LTE-Advanced [2] e IEEE 802.11ac [3].

A emenda 5 ao padrão de camada física IEEE 802.11, IEEE 802.11n, que prevê a operação em ambas faixas de frequências de 2.4 e $5 \mathrm{GHz}$ do espectro de frequências da faixa ISM (Industrial, Scientific and Medical), alcança taxas de dados de até 540 Mbps empregando canais de 20 ou 40 $\mathrm{MHz}$, modulações de amplitude em quadratura 2/4/16/64-QAM, técnicas de multiplexação por divisão de frequências ortogonais (Orthogonal Frequency Division Multiplexing - OFDM) e MIMO com até 4 fluxos de dados [4]. Seguindo os avanços nas técnicas de acesso para sistemas sem fio, o padrão IEEE 802.11ac, aprovado no final de 2013, opera na faixa de $5 \mathrm{GHz}$ da banda ISM e fornece taxas de dados de até 7 Gbps. Para tanto, essa nova emenda possui as seguintes características: canais de 20,40,80, 160 ou $80+80 \mathrm{MHz}$, modulações 2/4/16/64/256-QAM, OFDM, MIMO com até 8 fluxos de dados, atendimento a múltiplos usuários com múltiplas antenas (Multiple User MIMO - MU-MIMO) permitindo até 4 usuários com 2 fluxos de dados por usuário, códigos corretores de erros binário convolucional (Binary Convolutional Codes - BCC) e de verificação de paridade de baixa densidade (Low-Density Parity Check - $L D P C$ ) [5]. Em relação às redes celulares, a padronização para a camada física da quarta geração das comunicações móveis, lançada pelo grupo 3rd Generation Partnership Project (3GPP), nomeada de Universal Mobile Telecommunications Systems Long Term Evolution (UMTS-LTE) release 10, e conhecida por LTE-Advanced (LTE-A), prevê taxas agregadas de até 1,5 Gbps para o canal de descida, ou seja, das estações base (EB) para as estações móveis (EM), e de até 500 Mbps para o canal de subida, i.e., das EM para as EB. No padrão LTE-A, são empregados canais com largura de banda de até $100 \mathrm{MHz}$, atendendo a sistemas de usuário único ou multi-usuários com múltiplas antenas chegando a 8 antenas transmissoras no canal de descida e 4 no canal de subida [2].

As elevadas taxas alcançadas nos sistemas MIMO são resultados dos ganhos de diversidade, de multiplexação espacial e de arranjo de antenas providos pelo aumento do número de elementos de transmissão e recepção. De forma a elevar ainda mais esses ganhos, é natural que sejam propostos sistemas de comunicações que empregam uma grande quantidade de antenas, chegando a ordem das centenas, os chamados sistemas MIMO massivos, ou de larga escala. Recentemente, diversos estudos teóricos têm sido publicados acerca das vantagens do emprego de tais sistemas massivos. Em [6], é apresentada uma análise de um sistema MU-MIMO multi-celular não cooperativo no qual 
uma EB serve, simultaneamente, um certo número limitado de usuários cujos terminais são providos de uma única antena de transmissão/recepção em uma mesma faixa de frequências. De acordo com [6], no limite em que o número de antenas das EB tende a infinito, considerando as interferências entre células distintas e os custos adicionais e erros associados à aquisição das informações de estado dos canais de comunicação, diversos aspectos positivos são observados: os efeitos do ruído de recepção e do desvanecimento rápido podem ser eliminados; a eficiência espectral do sistema torna-se independente da largura de banda empregada; a energia de transmissão mínima por bit pode ser reduzida tanto quanto se queira; e, como corroborado em [7], o processamento linear do vetor de sinais recebidos no canal de subida ou do vetor de sinais transmitidos no canal de descida é ótimo no sentido da menor taxa de erro de transmissão.

A suposição acerca do número limitado de usuários realizada em $[6,7]$ é razoável mesmo em um cenário no qual o número de antenas nas EB seja ilimitado. Considerando um sistema que emprega a duplexação por divisão no tempo (Time Division Duplexing - TDD) [8], este limite é governado pelo tempo necessário à obtenção das informações de estado dos canais entre a antena das EM e as antenas da EB e pelo tempo de coerência desses mesmos canais, que correspondem aos intervalos de tempo em que as respostas aos impulsos dos canais de comunicação permanecem praticamente constantes [8]. Usualmente, neste tipo de sistema, o tempo de coerência é dividido entre o envio de sinais pilotos no canal de subida com o intuito de adquirir as informações dos estados dos canais, a transmissão de dados por estes canais propriamente dita e, considerando que as respostas dos canais de subida e descida são essencialmente as mesmas, a transmissão de dados no canal de descida. Em [9] é defendido que o tempo necessário ao treinamento do sistema pelo envio de sinais pilotos é proporcional ao número de terminais servidos por cada $\mathrm{EB}$ e é independente do número de antenas na EB, justificando dessa forma que o número de terminais seja limitado pelo tempo de coerência dos canais envolvidos.

Um dos principais desafios ao se considerar sistemas MIMO de larga escala é a complexidade computacional dos detectores empregados. Algoritmos de detecção MIMO populares, como os algoritmos Sphere Decoding (SD) e suas variantes $[10,11]$ podem alcançar resultados em termos de taxa de erros de bits (Bit Error Rate - BER) similares aos algoritmos de máxima verossimilhança (Maximum Likelihood - ML), porém a um custo computacional elevado, o que os tornam inviáveis em cenários massivos. Outras estratégias de detecção, como o detector Zero Forcing (ZF) ou o de mínimo erro médio quadrático (Mini- 
mum Mean Squared Error - MMSE) [12], seguidos de técnicas de cancelamento de interferência serial ordenado (Ordered Sucessive Interference Cancellation OSIC) [13], oferecem bons resultados em termos de BER a custos computacionais de ordem cúbica com o número de antenas. Apesar de menos complexas, a complexidade cúbica ainda é fator impeditivo ao se considerar sistemas de larga escala. Dessa forma, detectores de baixa complexidade computacional devem ser empregados para a implementação prática de tais sistemas.

Outra questão de extrema relevância em relação aos ganhos propiciados pelos sistemas MIMO de larga escala em cenários multi-celulares diz respeito às interferências causadas entre os transmissores e receptores localizados em células distintas. As vantagens mencionadas anteriormente dos sistemas MIMO quando o número de antenas nas EB cresce indefinidamente são demonstradas em $[14,15]$ considerando que as células são isoladas umas das outras e que as EB possuem pleno conhecimento acerca dos estados dos canais de comunicação envolvidos. De forma a investigar os efeitos das interferências entre-células e do conhecimento parcial dos estados dos canais, diversos trabalhos vêm sendo realizados [16-18]. Especialmente no que se refere à aquisição das informações dos estados dos canais por meio do envio de sequências piloto, surge, em cenários multi-celulares, o problema conhecido por contaminação por pilotos (pilot contamination) [19]. Nestes cenários, a mesma faixa de frequências e as mesmas sequências pilotos são empregadas em todas as células componentes do sistema. Sendo assim, a estimação dos coeficientes dos canais entre as EB e os terminais de suas próprias células é corrompida pelos sinais transmitidos por terminais de outras células que empregam as mesmas sequências piloto. Portanto, quando as EB transmitem dados a seus terminais, elas, não intencionalmente, acabam interferindo seletivamente em terminais de outras células. Da mesma forma, quando as EB combinam seus sinais recebidos no canal de subida, elas também combinam coerentemente os sinais oriundos das outras células. É mostrado em [6] que este problema persiste mesmo no limite em que o número de antenas tende a infinito, o que gera um patamar inferior para a BER dos sistemas sujeitos a este tipo de interferência.

Apesar de outros problemas na realização dos sistemas MIMO de larga escala, como, por exemplo, a disposição física das antenas, a presente tese restringe-se aos problemas da complexidade dos detectores empregados e da contaminação por pilotos.

Nos últimos anos, algumas estratégias de detecção com baixa complexidade computacional foram apresentadas. Em [20], um detector MIMO originalmente empregado em sistemas de múltiplo acesso por divisão por código (Code Division Multiple Access - CDMA) em canais sujeitos a ruído aditivo gaussi- 
ano branco (Additive White Gaussian Noise - AWGN) foi aplicado em cenários MIMO de larga escala. Este detector, denominado de detector de busca por verossimilhança ascendente (Likelihood Ascent Search - LAS), efetua uma busca em um subespaço do espaço vetorial de vetores de símbolos transmitidos de forma que, a cada passo da busca, seja escolhido um vetor de símbolos candidato com maior valor de verossimilhança que o vetor do passo anterior até que se encontre um ponto fixo neste espaço vetorial. Posteriormente, o algoritmo LAS foi estendido em [21], dando origem ao chamado LAS multi-estágio (Multi-stage LAS - M-LAS) que apresentou melhoria na BER com aumento controlado na sua complexidade computacional. Outros algoritmos baseados no LAS foram propostos em [22], como o LAS com múltiplos vetores de entrada (Multiple Input Vector $L A S$ - MIV-LAS) e o LAS com múltiplos conjuntos de busca de candidatos (Multiple Search Candidate Set LAS - MSCS-LAS).

Além dos algoritmos baseados no LAS, outros detectores foram propostos: em [23] e [24] um algoritmo baseado em troca de mensagens, denotado por detector por propagação de crença (Belief Propoagation - BP), foi proposto e analisado em sistemas MIMO massivos. Este algoritmo considera uma representação em grafo de Tanner [25] do sistema MIMO na qual existem dois conjuntos de nós: nós de símbolo e nós de observação, que representam, respectivamente, as antenas de transmissão e recepção. São geradas informações extrínsecas em termos de razões de log-verossimilhança (Log-Likelihood Ratios - LLR) em cada conjunto de nós que são enviadas ao outro conjunto de nós em um processo iterativo até que seja tomada uma decisão final acerca dos símbolos transmitidos.

Em [26], estratégia de detecção para sistemas MIMO massivos foi apresentada, na qual um detector baseado em um algoritmo de busca denominado de busca tabu reativa (Reactive Tabu Search - RTS) é empregado em um sistema MIMO com codificação de blocos no espaço-tempo (Space-Time Block Code - STBC) não ortogonal de larga escala. A estratégia de busca tabu empregada em [26] utiliza um algoritmo de otimização combinatória que consiste em uma estratégia de escalada baseada em um conjunto de movimentos elementares e em uma heurística de forma a evitar tanto paradas em pontos sub-ótimos quanto a ocorrência de ciclos $[27,28]$. Neste algoritmo, ciclos são evitados pela proibição de movimentos que levariam a um estado já visitado anteriormente. Estes estados proibidos são armazenados em uma lista que deve ser grande o suficiente para evitar ciclos longos, porém não tão extensa de forma a não restringir a busca demasiadamente. O mecanismo reativo empregado estabelece um esquema adaptativo para o tamanho da lista de estados proibidos de acordo com as características do problema de otimização em questão [29]. 


\section{1 \\ Objetivos}

A presente tese enfoca o problema da complexidade computacional dos detectores empregados em sistemas MIMO de larga escala, bem como as interferências geradas a partir do emprego de sinais pilotos para a obtenção das informações acerca dos estados dos canais de comunicações envolvidos em sistemas multi-celulares. A seguir, serão apresentados os objetivos e contribuições principais da presente tese:

- proposição de nova estratégia de detecção para o canal de subida em sistema MIMO multi-usuário de larga escala com baixa complexidade computacional e melhor custo-benefício em termos de BER e complexidade computacional, avaliada pelo número médio de operações de pontoflutuante (Floating-poit Operations - FLOPS), do que o dos algoritmos propostos anteriormente;

- proposição e análise de estratégia de detecção e decodificação para sistemas MU-MIMO codificados considerando as características de complexidade computacional dos sistemas de larga escala;

- proposição e análise de estratégia de estimação de canal e detecção para o canal de subida em sistemas MU-MIMO multi-celulares considerando os efeitos de contaminação por sinais pilotos.

A fim de se alcançar o primeiro objetivo, foi proposto um novo algoritmo de detecção MIMO baseado na busca LAS denominado de Random-List Based LAS (RLB-LAS), o que gerou o artigo publicado em [30] no qual o algoritmo proposto é apresentado e seu desempenho em termos de BER e complexidade computacional é comparado a outras estratégias existentes por meio de simulações de Monte-Carlo em um cenário ideal. As análises realizadas em [30] foram estendidas para cenários mais realistas no trabalho apresentado em [31]. Em ambos trabalhos, o algoritmo proposto apresentou melhores resultados em comparação às estratégias já existentes.

No que diz respeito ao segundo objetivo da tese em tela, de forma a se aproximar da capacidade de informação dos canais sem fio, esquemas de codificação capazes de fornecer mecanismos de redundância e proteção contra os erros em rajada, interferências e ruído de recepção são usualmente empregados [32]. Dessa forma, estratégias de detecção e decodificação iterativa (Iterative Detection and Decoding - IDD), baseadas no princípio turbo [33], vêm sendo propostas com bons resultados [34-36], porém com complexidade computacional ainda proibitiva ao se tratar de sistemas MIMO de larga escala. 
Sendo assim, como parte dos trabalhos desta tese, foi submetido um artigo no qual é proposta uma nova estratégia de aproximação para o detector MIMO de entradas e saídas suaves (Sof-Input Soft-Output) utilizado no processo IDD que emprega um dos detectores MIMO de larga escala analisados durante o tratamento do primeiro objetivo elencado, aliado às operações de cancelamento paralelo de interferências entre símbolos transmitidos (Parallel Interference Cancellation - PIC).

Por fim, a questão da contaminação por pilotos é tratada de forma a verificar os impactos deste tipo de limitação dos sistemas MIMO de larga escala nos algoritmos propostos na presente tese. Em [16] é realizado um estudo teórico com base em um detector de máxima verossimilhança no qual são obtidas expressões analíticas para a probabilidade de erro símbolo a símbolo (Pair-wise Error Probability - PEP). Com base nessas expressões, este mesmo trabalho apresenta limites superiores e inferiores para esta probabilidade de erro e conclui que, caso o número de símbolos transmitidos por quadro seja maior que o número de EB, o patamar inferior na BER gerado pelas interferências oriundas da contaminação por pilotos pode ser eliminado por meio de um esquema de codificação apropriado. Vale ressaltar que as expressões analíticas da PEP, que constituem o ponto de partida das análises realizadas em [16], consideram a estimação dos canais e a detecção dos símbolos transmitidos propriamente dita de forma conjunta. Adicionalmente, o processo de estimação/detecção em todas as células é realizado cooperativamente e de maneira centralizada por uma central de processamento que conhece os sinais recebidos em todas as EB do sistema.

Em consonância com o objetivo central desta tese, que está relacionado à complexidade computacional dos sistemas MIMO de larga escala com o intuito de propor técnicas capazes de permitir a implementação de tais sistemas, foi proposta uma estratégia de estimação e detecção conjunta e semi-cooperativa, baseada no detector RLB-LAS, para o canal de subida de sistemas MIMO multi-celulares, a fim de mitigar os efeitos da contaminação por pilotos presentes nesses sistemas de comunicação.

A presente tese está organizada em seis capítulos, conforme se segue.

No Capítulo 2 uma visão geral dos sistemas de comunicações MIMO é apresentada, incluindo os modelos matemáticos do sistema de comunicações e dos canais considerados, aspectos relacionados à capacidade de informação desses canais e estratégias de estimação e detecção comumente empregadas em tais sistemas.

O Capítulo 3 é dedicado à estratégia de busca LAS e ao detector RLB-LAS proposto. Nele, o procedimento LAS é descrito detalhadamente 
em sua versão aplicada a sinais complexos, outros detectores baseados na busca LAS pré-existentes são apresentados, o detector RLB-LAS proposto é pormenorizado e resultados de simulações que comparam o desempenho dos diversos esquemas de detecção analisados são apresentados.

No Capítulo 4 o emprego de codificação em sistemas MIMO de larga escala é abordado e uma estratégia IDD aplicável a esses sistemas é proposta. Adicionalmente, resultados de simulações que ilustram o desempenho dos esquemas analisados são apresentados de forma a validar o emprego da estratégia IDD nos cenários avaliados.

O problema da contaminação por sinais pilotos é detalhado no Capítulo 5. Neste capítulo, os efeitos das interferências oriundas do processo de estimação dos coeficientes dos canais entre as antenas dos transmissores e receptores é ilustrado e uma nova estratégia de estimação e detecção conjunta que utiliza a cooperação parcial entre as EB do sistema com o intuito de minimizar os efeitos dessa contaminação é proposta.

Por fim, no Capítulo 6, as conclusões da presente tese são sumarizadas e as sugestões de continuação a título de trabalhos futuros são apresentadas. 


\section{2}

\section{Sistemas MIMO}

\section{1}

\section{Introdução}

Neste capítulo, um modelo para o canal reverso de sistemas MIMO é detalhado, o método de estimação por mínimos quadrados da matriz complexa de coeficientes dos canais entre as antenas do transmissor e do receptor é apresentado e estratégias clássicas de detecção em sistemas MIMO são descritas. Inicialmente, na Seção 2.2, os modelos matemáticos usualmente adotados para descrever as variações dos canais de comunicações sem fio são apresentados. Em seguida, o sistema de comunicações MIMO é modelado e expressões para a capacidade de informação desses sistemas são derivadas na Seção 2.3. A estimação por mínimos quadrados das matrizes de coeficientes de canal empregadas na detecção dos sinais transmitidos nos sistemas MIMO é descrita na Seção 2.4 e, por fim, na Seção 2.5, métodos clássicos de detecção para o canal reverso de sistemas MIMO, como detecção por máxima verossimilhança, Zero Forcing, mínimo erro quadrático médio e filtro casado são apresentados.

\section{2}

\section{O canal de comunicações sem fio}

O desempenho dos sistemas de transmissão é diretamente afetado pelas imperfeições introduzidas pelos canais de comunicações nos quais estes sistemas operam. Dessa forma, o conhecimento dos efeitos desses canais sobre o sinal transmitido é de fundamental importância para o projeto de sistemas de transmissão eficientes. Especificamente, para sistemas que empregam o ar como meio de comunicação, a tarefa de descrever as pertubações impostas pelo meio utilizado é dificultada, uma vez que a resposta ao impulso desses canais é, em geral, variante com o tempo. A seguir, uma breve descrição dessas variações e dos modelos estatísticos empregados para descrevê-las é apresentada.

A Figura 2.1, retirada de [8], ilustra a potência recebida de um sinal transmitido em um sistema de comunicações rádio. Pode ser observado que a potência recebida varia rapidamente enquanto o receptor se move, porém sua média local varia de forma bem mais lenta com a distância entre o transmissor 


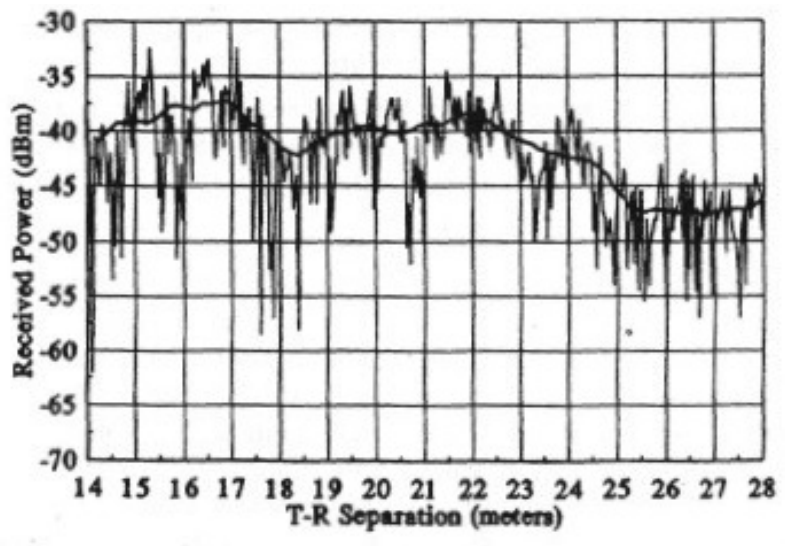

Figura 2.1: Desvanecimento de larga e pequena escala. Extraído de [8].

(Tx) e o receptor $(\mathrm{Rx})$. Sendo assim, para fins de análise, esse decaimento, chamado de desvanecimento, é separado em dois tipos: desvanecimento de pequena escala e desvanecimento de larga escala.

\subsection{1}

\section{Desvanecimento de larga escala}

O desvanecimento de larga escala está relacionado com as características do canal cujos efeitos são percebidos ao longo de médias e grandes distâncias entre o transmissor e o receptor quando comparadas ao comprimento de onda do sinal transmitido. Ele está relacionado às perdas de potência do sinal ao se aumentar a separação entre Tx e Rx, denominadas perdas de percurso. Além da perda com a distância, outro fator que influi no desvanecimento de larga escala são as obstruções, naturais, como o relevo e a vegetação, ou feitas pelo homem, como prédios e casas. Esses obstáculos criam áreas de "sombra" nas quais a potência do sinal transmitido é substancialmente degradada, fato pelo qual este fenômeno é chamado de sombreamento.

Tanto os modelos teóricos quanto os baseados em medições de campo para o desvanecimento de larga escala indicam que a potência média do sinal recebido decresce de forma logarítmica com a separação Tx-Rx [8]. Portanto, a perda de percurso média para uma separação Tx-Rx arbitrária, $\overline{P L}(d)$, pode ser expressa como:

$\mathrm{Ou}$

$$
\overline{P L}(d) \propto\left(\frac{d}{d_{0}}\right)^{\gamma}
$$

$$
\overline{P L}(d)[d B]=\overline{P L}\left(d_{0}\right)+10 \gamma \log \left(\frac{d}{d_{0}}\right)
$$

em que $d$ é a distância entre Tx e $\mathrm{Rx}, \gamma$ é o expoente de perda de percurso, que indica a taxa com a qual a perda de percurso cresce com a distância, $d_{0}$ é uma 
distância de referência, geralmente próxima ao transmissor, na qual a perda de percurso é determinada por meio de medições de campo e log refere-se ao logaritmo na base 10. O valor de $\gamma$ depende das características específicas do ambiente no qual o sistema de comunicações opera, e. g., a perda de percurso de um sinal que é transmitido em meio urbano, em termos gerais, possuirá um expoente de perda de percurso maior que um sinal que é transmitido em meio rural. a Tabela 2.1 lista valores típicos para o expoente de perda de percurso em diversos ambientes rádio-móveis distintos.

Tabela 2.1: Expoente de perda de percurso para ambientes distintos.

\begin{tabular}{|c|c|}
\hline Ambiente & Expoente de perda de percurso, $\gamma$ \\
\hline Espaço livre & 2 \\
\hline Rádio celular em área urbana & 2.7 a 3.5 \\
\hline Dentro de edificações com linha de visada & 1.6 a 1.8 \\
\hline Dentro de edificações sem linha de visada & 4 a 6 \\
\hline Dentro de fábricas sem linha de visada & 2 a 3 \\
\hline \hline
\end{tabular}

As equações (2-1) e (2-2) acima não consideram os efeitos do sombreamento. Este fenômeno faz com que a potência do sinal recebido em dois locais distintos com mesma distância Tx-Rx seja consideravelmente diferente. Um modelo comumente adotado para descrever essas discrepâncias é o modelo lognormal para o sombreamento. De acordo com este modelo, a perda de percurso em uma localidade particular, $P L(d)$, é uma variável aleatória cuja função densidade de probabilidade (fdp) segue uma distribuição log-normal (gaussiana se $P L(d)$ for dada em dB) com média dada por $(2-2)[37,38]$, i.e.

$$
P L(d)[d B]=\overline{P L}\left(d_{0}\right)+10 \gamma \log \left(\frac{d}{d_{0}}\right)+X_{\sigma}
$$

sendo $X_{\sigma}$ uma variável aleatória gaussiana de média zero e desvio padrão $\sigma$. Dessa forma, a potência do sinal recebido em uma determinada localidade pode ser calculada pela seguinte expressão:

$$
P_{r}(d)[d B]=P_{t}[d B]-P L(d)[d B]
$$

em que $P_{t}[d B]$ é a potência do sinal transmitido.

\subsection{2}

\section{Desvanecimento de pequena escala}

O desvanecimento de pequena escala descreve flutuações rápidas nas componentes em fase e quadratura do sinal recebido em curtos períodos de tempo 
ou pequenos deslocamentos espaciais. Estas variações rápidas são causadas por interferências entre as componentes do sinal recebido que percorrem diferentes percursos entre o transmissor e o receptor, chegando ao destino com diferentes fases e amplitudes. São três os principais efeitos do desvanecimento de pequena escala:

1. variações rápidas na potência do sinal recebido em pequenos intervalos de tempo ou pequenos deslocamentos;

2. modulação (variação) na frequência do sinal transmitido causada pela variação no desvio Doppler das diferentes componentes de multi-percurso do sinal;

3. dispersão temporal causada pelos diferentes atrasos de cada componente de multi-percurso que pode resultar em interferência entre símbolos (Inter Symbol Interference - ISI).

Este tipo de desvanecimento é responsável por espalhar o sinal recebido tanto no tempo quanto na frequência. O espalhamento temporal altera a amplitude das componentes frequenciais do sinal transmitido. Caso todas essas componentes sejam modificadas igualmente, então é dito que o desvanecimento é plano. Alternativamente, caso as componentes frequenciais sejam alteradas de forma distinta, é dito que o desvanecimento é seletivo em frequência. Um parâmetro que pode ser empregado na classificação do desvanecimento como plano ou seletivo em frequência é a banda de coerência, $f_{0}$, de um determinado canal, que indica a faixa de frequências na qual um canal pode ser considerado plano, ou seja, a largura de faixa de um canal em que as componentes de frequência de um sinal que trafegue por ele são alteradas essencialmente da mesma forma [39]. Se $f_{0}$ for maior que a largura de banda do sinal transmitido, $W$, então o desvanecimento pode ser considerado plano. O desvanecimento também pode ser caracterizado no domínio do tempo: ele é considerado plano caso a duração do símbolo, $T_{s}$, for muito maior que a dispersão temporal do canal, medida pelo máximo atraso em excesso $(X d B)$, $T_{e}$, i.e., o intervalo de tempo em que a energia das componentes de multi-percurso cai em $X d B$ abaixo do valor máximo no perfil de atraso de potência do canal, que consiste em uma média espacial da potência das respostas ao impulso do canal como função do atraso em excesso.

Caso um sistema de comunicações esteja sujeito a um canal que produza o desvanecimento seletivo em frequência, a ISI pode ocorrer. Considerando o domínio do tempo, neste caso, $T_{s}$ é da mesma ordem (ou menor) que $T_{e}$. Sendo assim, algumas componentes de multi-percurso de símbolos passados são 
recebidas durante o período destinado à detecção do símbolo atual, causando assim a ISI. No domínio da frequência, nesses casos, a largura de banda do sinal transmitido é maior que $f_{0}$ e, consequentemente, o canal afetará de forma distinta as componentes frequenciais do sinal.

A banda de coerência e o máximo atraso em excesso são parâmetros que descrevem a dispersividade temporal dos canais localmente. O desvio Doppler e o tempo de coerência são parâmetros empregados na avaliação das variações temporais (ou dispersividade em frequência) dos canais sem fio causadas pelo movimento dos objetos no entorno dos transmissores e receptores ou pelo movimento relativo entre Tx e Rx. O desvio Doppler, $f_{\text {Doppler }}$, é uma medida do alargamento do espectro de frequências do sinal causado pela taxa de mudança temporal do canal móvel e é diretamente proporcional à velocidade relativa do receptor na direção de propagação do sinal transmitido. $f_{\text {Doppler }}$ é dado por:

$$
f_{\text {Doppler }}=f_{D} \cos (\theta)
$$

onde $\theta$ representa o ângulo entre a direção do movimento relativo entre Tx e Rx e a direção de propagação da onda eletromagnética. $f_{D}$ é o máximo desvio Doppler, também conhecido por taxa de desvanecimento, e pode ser calculado como:

$$
f_{D}=\frac{v}{\lambda}
$$

onde $\lambda$ é o comprimento de onda da portadora e $v$ é a velocidade relativa do receptor.

O tempo de coerência do canal, $T_{0} \approx \frac{1}{f_{D}}$, é o parâmetro no domínio do tempo equivalente ao desvio Doppler e representa o intervalo de tempo em que a resposta ao impulso do canal permanece inalterada. Sendo assim, o desvanecimento pode ser considerado lento caso $T_{s}<<T_{0}$ (no domínio do tempo) ou $W>>f_{D}$ (no domínio da frequência). Considerando $W \approx \frac{1}{T_{s}}$, o desvanecimento pode ser considerado lento caso $f_{D} T_{s}<<1$.

$\mathrm{Na}$ presente tese, o desvanecimento é considerado lento no tempo e plano na frequência, i.e., considera-se que a resposta ao impulso dos canais permanecem constantes durante o intervalo de símbolo e todas as componentes frequenciais são afetadas igualmente pelo canal. A Tabela 2.2 sumariza as condições, em termos de parâmetros do canal e do sinal transmitido, de forma a considerar o desvanecimento plano e lento.

Encerrando esta breve descrição do canal de comunicação sem fio, vale ressaltar que nas comunicações rádio-móveis, a distribuição Rayleigh é usualmente empregada na descrição estatística da variação temporal da envoltória do sinal recebido em um sistema sujeito ao desvanecimento plano [8]. A distribuição Rayleigh possui fdp dada por: 
Tabela 2.2: Condições do sistema de forma a considerar o desvanecimento plano na frequência e lento no tempo.

\begin{tabular}{|c|c|c|}
\hline Desvanecimento & Plano na frequência & Lento no tempo \\
\hline Domínio do tempo & $T_{s}>>T_{e}$ & $T_{s}<<T_{0}$ \\
\hline Domínio da frequência & $W<<f_{0}$ & $W>>f_{D}$ \\
\hline \hline
\end{tabular}

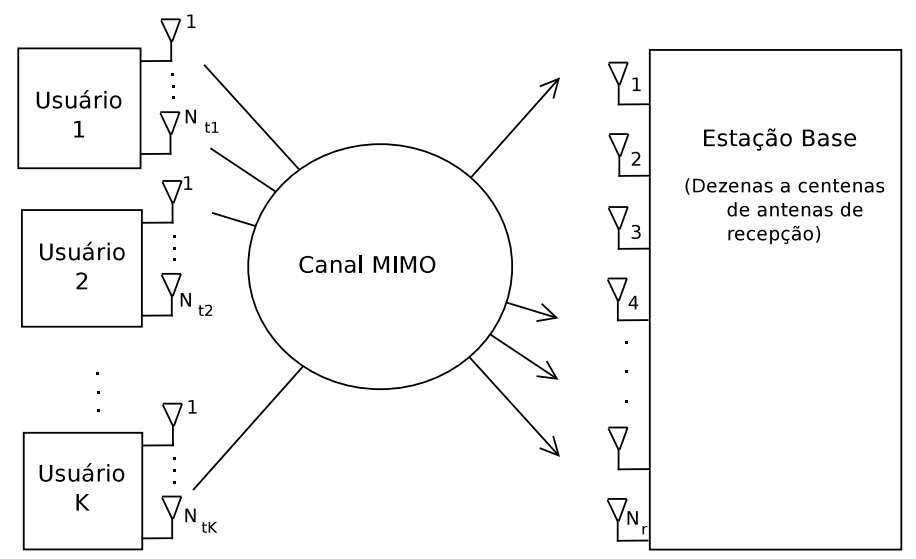

Figura 2.2: Representação do sistema MIMO

$$
p(r)=\left\{\begin{array}{cl}
\frac{r}{\sigma^{2}} \exp \left(-\frac{r^{2}}{2 \sigma^{2}}\right) & , 0 \leq r \leq \infty \\
0 & , r<0
\end{array}\right.
$$

em que $\sigma^{2}$ é a média temporal da potência do sinal recebido antes da detecção.

\section{3}

\section{Canal reverso de sistemas de comunicações MU-MIMO}

Considere o canal reverso de um sistema MIMO no qual $K$ usuários munidos de $N_{t i}$ antenas de transmissão, em que o índice $i$ identifica o respectivo usuário, enviam símbolos a uma EB com $N_{r}$ antenas, como ilustrado na Figura 2.2. Seja $N_{t}=\sum_{i=1}^{K} N_{t i}$ o número total de antenas de transmissão. Todos os usuários transmitem símbolos de um alfabeto $\mathcal{B}$. Assume-se que as amostras complexas dos sinais em banda base estão disponíveis no receptor da EB.

Seja $\mathbf{x}_{k} \in \mathbb{C}^{N_{t k} \times 1}, \mathbf{x}_{k}=\left[x_{k 1}, x_{k 2}, \cdots, x_{k N_{t k}}\right]^{T}$, o vetor de símbolos transmitidos pelo $k$-ésimo usuário no qual $x_{k i}$ é o símbolo transmitido na sua $i$-ésima antena que satisfaz a seguinte restrição de potência de transmissão: $E\left(\left|x_{k i}\right|^{2}\right)=1$, onde $E(\cdot)$ representa o operador valor esperado. Seja $\mathbf{H}_{k} \in$ $\mathbb{C}^{N_{r} \times N_{t k}}$ a matriz de coeficientes de canal entre o $k$-ésimo usuário e a EB de tal forma que seus elementos, $h_{n_{r}, n_{t k}}$, representam o ganho complexo do canal entre a $n_{t k}$-ésima antena de transmissão e a $n_{r}$-ésima antena da EB. No presente trabalho, assume-se condições de espalhamento suficientes para considerar as 
entradas de $\mathbf{H}_{k}$ variáveis aleatórias complexas independentes e identicamente distribuídas gaussianas de média zero e variância unitária, $\mathcal{C N}(0,1)$. O vetor de sinal recebido na $\mathrm{EB}, \mathbf{y}$, pode ser escrito da seguinte forma:

$$
\mathbf{y}=\mathbf{H}_{1} \mathbf{x}_{1}+\mathbf{H}_{2} \mathbf{x}_{2}+\cdots+\mathbf{H}_{K} \mathbf{x}_{K}+\mathbf{n}
$$

em que $\mathbf{n} \in \mathbb{C}^{N_{r} \times 1}$ é o vetor de ruído de recepção, modelado por um vetor aleatório gaussiano complexo de média zero e matriz covariância $K_{n}=$ $E\left[\mathbf{n n}^{H}\right]=\sigma_{n}^{2} \mathbf{I}_{N_{r}}$, sendo $\mathbf{I}_{N_{r}}$ a matriz identidade de dimensão $N_{r}$. De acordo com este modelo, a envoltória do sinal recebido possui distribuição Rayleigh, em consonância com o discutido na seção anterior.

Considerando a restrição de potência de transmissão mencionada, i.e., assumindo que os símbolos são transmitidos com energia média unitária, a razão sinal ruído (Signal to Noise Ratio - SNR) por antena de recepção em dB é dada por $10 \log \left(\frac{N_{t}}{\sigma_{n}^{2}}\right)$. A expressão em (2-8) pode ser convenientemente escrita como:

$$
\mathbf{y}=\mathbf{H x}+\mathbf{n}
$$

sendo $\mathbf{H}=\left[\mathbf{H}_{1} \mathbf{H}_{2} \cdots \mathbf{H}_{K}\right]$ e $\mathbf{x}=\left[\mathbf{x}_{1}^{T} \mathbf{x}_{2}^{T} \cdots \mathbf{x}_{K}^{T}\right]^{T}$. O operador $(\cdot)^{T}$ representa transposição.

\subsection{1}

\section{Capacidade de informação para o canal reverso de sistemas MIMO}

A Figura 2.3 ilustra um sistema de comunicações simples no qual uma fonte de informação gera uma mensagem, $\mathcal{W}$, que é transformada em um vetor de símbolos a ser transmitido, $\mathbf{x}$, que por sua vez constitui a entrada de um canal de comunicações. Esta entrada produz o vetor aleatório, y, na saída do canal de forma que cada possível vetor de entrada distinto induz uma determinada distribuição de probabilidade para o vetor y. Neste cenário, erros de transmissão podem ocorrer uma vez que diferentes vetores de entrada podem resultar no mesmo vetor de saída do canal. A probabilidade de ocorrência desses erros pode ser arbitrariamente reduzida pela escolha da transmissão de apenas um subconjunto do espaço vetorial formado pelos possíveis vetores de entrada de forma que vetores neste subconjunto sejam diferentes o suficiente para que, com alta probabilidade, um vetor de saída do canal seja produzido apenas por um único vetor de entrada. A máxima taxa de bits que essa transmissão com baixa probabilidade de erro pode ser realizada é chamada de capacidade do canal. Foi mostrado em [40] que mensagens podem ser transmitidas com probabilidades de erro arbitrariamente pequenas a taxas não superiores à capacidade do canal.

A fim de chegar-se a expressões para a capacidade do canal reverso dos 


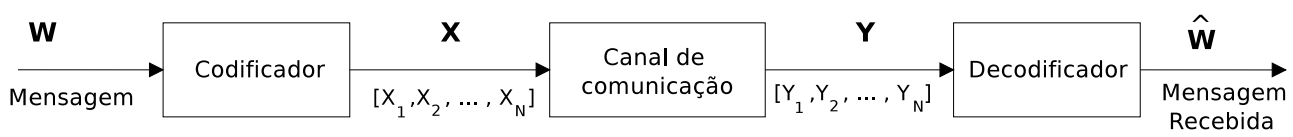

Figura 2.3: Modelo simplificado de um sistema de comunicações

sistemas MIMO, parte-se do conceito de informação mútua entre dois vetores aleatórios, $I(\mathbf{x} ; \mathbf{y})$, que representa uma medida da quantidade de informação que um vetor aleatório possui acerca do outro. A capacidade de informação de um canal, $C$, pode então ser definida como a máxima informação mútua entre seus vetores de entrada e saída dentre todas as possíveis distribuições do vetor de entrada, $p(\mathbf{x})[41]$, i.e.,

$$
C=\max _{p(\mathbf{x})}\{I(\mathbf{x} ; \mathbf{y})\} .
$$

Considerando a matriz de coeficientes do canal, $\mathbf{H}$, conhecida e a independência entre o vetor de entrada e o vetor de ruído de recepção, $\mathbf{n}, I(\mathbf{x} ; \mathbf{y})$ pode ser avaliada pela redução na incerteza, medida pela entropia, de $\mathbf{x}$ devido ao conhecimento de $\mathbf{y}$, i.e.,

$$
\begin{aligned}
I(\mathbf{x} ; \mathbf{y}) & =H(\mathbf{x})-H(\mathbf{x} \mid \mathbf{y}) \\
& =H(\mathbf{y})-H(\mathbf{y} \mid \mathbf{x}) \\
& =H(\mathbf{y})-H(\mathbf{n})
\end{aligned}
$$

em que $H(\cdot)$ representa a entropia. De acordo com as equações (2-10)-(2-13), o problema de maximização em (2-10) equivale à maximização de $H(\mathbf{y})$, que é realizada pela escolha de $\mathbf{y}$ como um vetor aleatório gaussiano. Sendo assim, $H(\mathbf{y})$ e $H(\mathbf{n})$ serão dados por:

$$
\begin{aligned}
& H(\mathbf{y})=\log _{2}\left[\operatorname{det}\left(\pi e \mathbf{K}_{\mathbf{y}}\right)\right] \\
& H(\mathbf{n})=\log _{2}\left[\operatorname{det}\left(\pi e \mathbf{K}_{\mathbf{n}}\right)\right]
\end{aligned}
$$

em que $\mathbf{K}_{\mathbf{y}}$ e $\mathbf{K}_{\mathbf{n}}$ são as matrizes covariância de $\mathbf{y}$ e $\mathbf{n}$, respectivamente. De (2-9), considerando que o receptor conhece a matriz de coeficientes de canal, $\mathbf{H}, \mathbf{K}_{\mathbf{y}}$ pode ser calculada da seguinte forma:

$$
\begin{aligned}
\mathbf{K}_{\mathbf{y}} & =E\left[\mathbf{y} \mathbf{y}^{H}\right] \\
& =E\left[(\mathbf{H x}+\mathbf{n})(\mathbf{H} \mathbf{x}+\mathbf{n})^{H}\right] \\
& =\mathbf{H K}_{\mathbf{x}} \mathbf{H}^{H}+\mathbf{K}_{\mathbf{n}},
\end{aligned}
$$


sendo $\mathbf{K}_{\mathbf{x}}$ a matriz covariância de $\mathbf{x}$. Sendo assim, de (2-14) e (2-15), tem-se que a expressão para a capacidade de informação do canal MIMO é dada por:

$$
\begin{aligned}
C & =\max _{p(\mathbf{x})}\left\{\log _{2}\left[\operatorname{det}\left(\pi e\left(\mathbf{H K}_{\mathbf{x}} \mathbf{H}^{H}+\mathbf{K}_{\mathbf{n}}\right)\right)\right]-\log _{2}\left[\operatorname{det}\left(\pi e \mathbf{K}_{\mathbf{n}}\right)\right]\right\} \\
& =\max _{p(\mathbf{x})}\left\{\log _{2}\left[\operatorname{det}\left(\mathbf{H} \mathbf{K}_{\mathbf{x}} \mathbf{H}^{H}\left(\mathbf{K}_{\mathbf{n}}\right)^{-1}+\mathbf{I}_{N_{r}}\right)\right]\right\} .
\end{aligned}
$$

Caso o transmissor conhecesse antecipadamente a matriz de coeficientes do canal, ele poderia aplicar uma transformação no vetor de entrada de forma a alterar $\mathbf{K}_{\mathbf{x}}$ com o objetivo de maximizar a expressão de capacidade em (2-20). Entretanto, assumiu-se que apenas o receptor possui conhecimento da matriz H, impossibilitando a referida maximização. Considerando a potência média total de transmissão igual a $N_{t}$ e que o vetor de símbolos transmitidos possui componentes descorrelatadas, $\mathbf{K}_{\mathbf{x}}=\mathbf{I}$. Além disso, $\mathbf{K}_{\mathbf{n}}=\sigma_{n}{ }^{2} \mathbf{I}$ uma vez que o ruído é considerado branco. Sendo assim, $C$ é dada por:

$$
C=\log _{2}\left[\operatorname{det}\left(\frac{S N R}{N_{t}} \mathbf{H H}^{H}+\mathbf{I}_{N_{r}}\right)\right] .
$$

Até este ponto, foi considerado que o receptor possui conhecimento da matriz de ganhos de canal $\mathbf{H}$. Na prática, $\mathbf{H}$ é uma matriz aleatória cujas amostras variam de acordo com o modelo de canal descrito anteriormente. Sendo assim, define-se a capacidade ergódica, $C_{e}$ como o valor esperado da capacidade do canal no tempo [42]:

$$
C_{e}=E\left\{\log _{2}\left[\operatorname{det}\left(\frac{1}{\sigma_{n}^{2}} \mathbf{H} \mathbf{H}^{H}+\mathbf{I}_{N_{r}}\right)\right]\right\} .
$$

A Figura 2.4 apresenta curvas de capacidade ergódica em termos do número de bits por uso do canal (bps/Hz) versus SNR (dB) para diversos canais MIMO com diferentes números de antenas de transmissão e recepção. As curvas apresentadas nesta figura são o resultado das médias das curvas de capacidade obtidas por meio de 10000 ensaios de simulações de Monte Carlo nas quais a matriz de coeficientes de canal foi amostrada de acordo com o modelo descrito na Seção 2.3. Para cada amostra da matriz de coeficientes de canal, a capacidade foi calculada de acordo com a equação (2-21). Verifica-se que a capacidade ergódica de informação aumenta com o aumento do número de elementos de transmissão. Ademais, existe uma SNR mínima necessária para atingir uma capacidade específica dado um determinado sistema, e.g., em um sistema MIMO com 20 antenas de transmissão e 20 antenas de recepção $(20 \times 20)$, a SNR mínima para se atingir uma capacidade de 20 bps/Hz é de $3,4 d B$. 


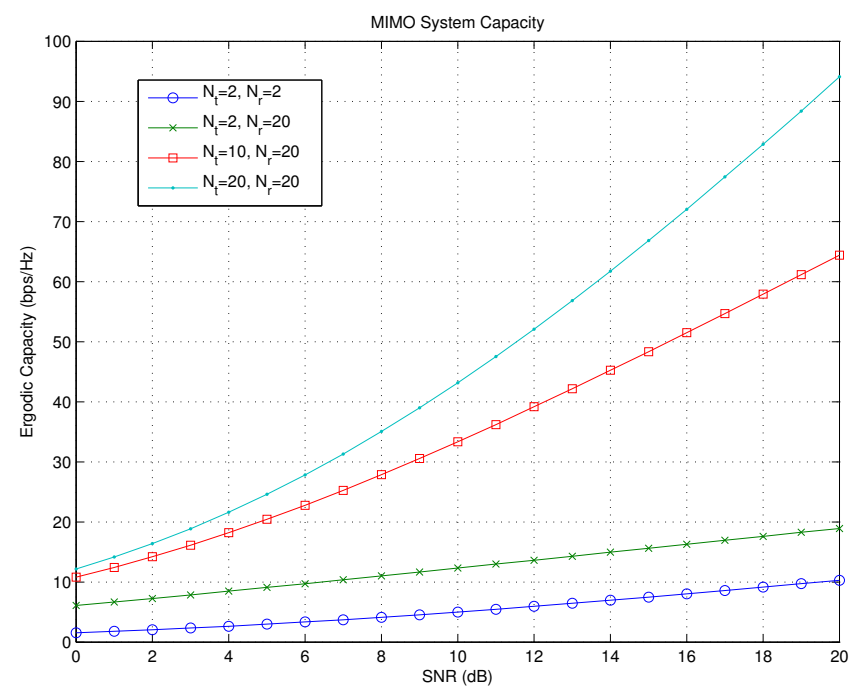

Figura 2.4: Curvas de capacidade para sistemas MIMO.

\subsection{2}

\section{Correlação entre antenas e efeitos do sombreamento log-normal}

O modelo matemático descrito anteriormente representa canais de comunicação entre as antenas de transmissão e recepção descorrelatados e identicamente distribuídos sujeitos ao desvanecimento Rayleigh. No decorrer desta tese, este cenário será denotado por cenário A. Apesar deste cenário prover indicadores acerca do comportamento dos diferentes detectores e um ambiente mais simples de forma a facilitar as derivações analíticas, a fim de comparar o desempenho dos distintos detectores para o canal reverso dos sistemas MIMO em condições mais realistas, faz-se necessária a inclusão dos efeitos de correlação e sombreamento log-normal ao modelo já apresentado. Este novo cenário, que inclui esses efeitos, será denotado por cenário B.

Os efeitos oriundos da correlação entre antenas, tanto no transmissor quanto no receptor, podem ser considerados empregando o modelo de Kronecker para os canais de comunicação [43]. Neste modelo, a matriz de ganhos de canal entre o $k$-ésimo usuário e a $\mathrm{EB}, \mathrm{G}_{\mathbf{0} k} \in \mathbb{C}^{N_{r} \times N_{t k}}$, é dada por:

$$
\mathbf{G}_{\mathbf{0} k}=\mathbf{R}_{r_{x}}^{1 / 2} \mathbf{H}_{k} \mathbf{R}_{t_{x_{k}}}^{1 / 2}
$$

em que $\mathbf{R}_{r_{x}}$ e $\mathbf{R}_{t_{x_{k}}}$ denotam as matrizes de correlação entre as antenas da EB na recepção e entre as antenas do $k$-ésimo usuário na transmissão, respectivamente. Na equação $(2-23)$, o operador $(\cdot)^{1 / 2}$ representa a seguinte relação matricial:

$$
\mathbf{R}=\mathbf{R}^{1 / 2} \mathbf{R}^{1 / 2^{H}}
$$

As matrizes de correlação empregadas acima possuem a seguinte forma: 


$$
\mathbf{R}=\left[\begin{array}{ccccc}
1 & \rho & \rho^{4} & \cdots & \rho^{\left(N_{a}-1\right)^{2}} \\
\rho & 1 & \rho & \cdots & \vdots \\
\rho^{4} & \rho & 1 & \cdots & \vdots \\
\vdots & \vdots & \vdots & \ddots & \vdots \\
\rho^{\left(N_{a}-1\right)^{2}} & \cdots & \rho^{4} & \rho & 1
\end{array}\right]
$$

em que $N_{a}$ é o número de antenas e $\rho$ é o índice de correlação entre antenas adjacentes.

Os efeitos do sombreamento log-normal podem ser incluídos pela inclusão de uma nova variável aleatória para cada usuário, $\beta_{k}$, que afetará sua matriz de coeficientes de canal. Sendo assim, a matriz de coeficientes de canal entre as antenas do $k$-ésimo usuário e as antenas da EB que inclui os efeitos tanto da correlação entre antenas quanto do sombreamento, $\mathbf{G}_{k}$, é expressa por [8]:

$$
\mathbf{G}_{k}=\sqrt{\beta_{k}} \mathbf{G}_{\mathbf{0} k}
$$

em que $\beta_{k}$ é uma variável aleatória log-normal dada por:

$$
\beta_{k}=10^{\frac{\sigma_{k} \mathcal{N}_{k}(0,1)}{10}} \text {. }
$$

Na equação (2-27), $\sigma_{k}$ é o espalhamento de sombreamento (shadowing spread) dado em dB e $\mathcal{N}_{k}(0,1)$ representa uma variável aleatória real gaussiana de média zero e variância unitária.

\section{4}

\section{Estimação de canal por mínimos quadrados}

Uma das estratégias mais empregadas para a estimação da matriz de coeficientes de canais dos sistemas MIMO consiste no envio de vetores de sinais conhecidos previamente pelos transmissor e receptor chamados de sinais pilotos. De posse do sinal recebido oriundo dessa transmissão e do conhecimento dos sinais pilotos, o estimador por mínimos quadrados estima a matriz de coeficientes de canais da seguinte forma [44]:

$$
\tilde{\mathbf{H}}=\mathbf{Y}_{p} \boldsymbol{\Phi}^{\dagger}
$$

em que $\mathbf{Y}_{p}$ é a matriz de dimensões $\left(N_{r} \times \psi\right)$ dos sinais recebidos referentes aos sinais pilotos transmitidos, $\psi$ é o número de símbolos transmitidos em cada sequência piloto, $\Phi$ é a matriz de dimensões $\left(N_{t} \times \psi\right)$, em que $\psi \geq N_{t}$, dos sinais pilotos e $\boldsymbol{\Phi}^{\dagger}$ é a matriz pseudo-inversa de Moore-Penrose da matriz $\boldsymbol{\Phi}$, dada por:

$$
\boldsymbol{\Phi}^{\dagger}=\boldsymbol{\Phi}^{H}\left(\boldsymbol{\Phi} \boldsymbol{\Phi}^{H}\right)^{-1} .
$$

Cabe ressaltar que a matriz de coeficientes de canal estimada, $\tilde{\mathbf{H}}$, diferirá 
da matriz de canal real, $\mathbf{H}$, apenas devido aos efeitos do ruído de recepção modificado, $\mathbf{N}^{\prime}$, como se segue:

$$
\begin{aligned}
\tilde{\mathbf{H}} & =\mathbf{Y}_{p} \boldsymbol{\Phi}^{\dagger} \\
& =[\mathbf{H} \boldsymbol{\Phi}+\mathbf{N}] \boldsymbol{\Phi}^{H}\left(\boldsymbol{\Phi} \boldsymbol{\Phi}^{H}\right)^{-1} \\
& =\mathbf{H} \boldsymbol{\Phi} \boldsymbol{\Phi}^{H}\left(\boldsymbol{\Phi} \boldsymbol{\Phi}^{H}\right)^{-1}+\mathbf{N} \boldsymbol{\Phi}^{H}\left(\boldsymbol{\Phi} \boldsymbol{\Phi}^{H}\right)^{-1} \\
& =\mathbf{H}+\mathbf{N}^{\prime}
\end{aligned}
$$

em que $\mathbf{N}$ é a matriz de dimensões $\left(N_{r} \times \psi\right)$ de vetores de ruído de recepção e $E\left[\mathbf{N}^{\prime H} \mathbf{N}^{\prime}\right]=N_{r} \sigma_{n}^{2}\left(\boldsymbol{\Phi} \boldsymbol{\Phi}^{H}\right)^{-1}$.

Nas simulações realizadas durante os trabalhos referentes à presente tese que empregaram a matriz de coeficientes de canal estimada, as matrizes de pilotos utilizadas foram formadas pelas $N_{t}$ primeiras linhas da matriz de Hadamard [45], de dimensões $\left(2^{\left\lceil\log _{2} N_{t}\right\rceil} \times 2^{\left\lceil\log _{2} N_{t}\right\rceil}\right)$, obtida a partir da seguinte recursão:

Inicia-se com a matriz de dimensões $(2 \times 2)$

$$
\mathbf{M}_{2}=\left[\begin{array}{ll}
-1 & -1 \\
-1 & +1
\end{array}\right] \text {. }
$$

A matriz de Hadamard de dimensões $(2 n \times 2 n)$ é obtida a partir da matriz de Hadamard de dimensões $(n \times n)$ conforme:

$$
\mathbf{M}_{2 n}=\left[\begin{array}{cc}
\mathbf{M}_{n} & \mathbf{M}_{n} \\
\mathbf{M}_{n} & -\mathbf{M}_{n}
\end{array}\right]
$$

\section{5}

\section{Estratégias clássicas de detecção em sistemas MIMO}

Nesta seção, algumas estratégias clássicas de detecção em sistemas MIMO serão apresentadas. Nestes detectores, as matrizes de coeficientes de canal serão consideradas conhecidas pelo receptor. Inicialmente, o detector ótimo em termos da minimização da BER, o detector por máxima probabilidade a posteriori (MAP), será apresentado. Para cenários em que as probabilidades de transmissão a priori de cada símbolo são iguais (símbolos equiprováveis), como os abordados no presente trabalho, o detector MAP reduz-se ao detector de máxima verossimilhança (ML), conforme será descrito em seguida. Além destes, detectores lineares que objetivam a redução da complexidade computacional do processo de detecção serão apresentados.

\subsection{1}




\section{Detector de máxima verossimilhança}

Considere o sinal recebido conforme a equação (2-9). Sabe-se que o detector que minimiza a probabilidade de erro de símbolo é o detector MAP [46], dado por:

$$
\begin{aligned}
\hat{\mathbf{x}}_{\text {MAP }} & =\underset{\mathbf{x}}{\operatorname{argmax}} P(\mathbf{x} \mid \mathbf{H}, \mathbf{y}) \\
& =\underset{\mathbf{x}}{\operatorname{argmax}} p(\mathbf{y} \mid \mathbf{H}, \mathbf{x}) P(\mathbf{x}) .
\end{aligned}
$$

Empregando-se o modelo do sistema apresentado na Seção 2.3, $p(\mathbf{y} \mid \mathbf{H}, \mathbf{x})$ é a fdp de um vetor aleatório complexo gaussiano circularmente simétrico, dada por:

$$
p(\mathbf{y} \mid \mathbf{H}, \mathbf{x})=\frac{1}{\pi^{N_{r}} \sigma_{n}^{2 N_{r}}} \exp \left\{-\frac{\|\mathbf{y}-\mathbf{H} \mathbf{x}\|^{2}}{\sigma_{n}^{2}}\right\} .
$$

Sendo assim, o detertor MAP pode ser escrito como:

$$
\hat{\mathbf{x}}_{M A P}=\underset{\mathbf{x}}{\operatorname{argmax}} \sigma_{n}^{2} \ln P(\mathbf{x})-\|\mathbf{y}-\mathbf{H x}\|^{2} .
$$

Para o caso em que os símbolos a serem transmitidos são equiprováveis, o detector MAP é equivalente ao detector ML,

$$
\hat{\mathbf{x}}_{M L}=\underset{\mathbf{x}}{\operatorname{argmax}} p(\mathbf{y} \mid \mathbf{H}, \mathbf{x}) .
$$

Considerando (2-38), este detector reduz-se a um detector de mínima distância dado por:

$$
\begin{aligned}
\hat{\mathbf{x}}_{M L} & =\underset{\mathbf{x}}{\operatorname{argmin}}\|\mathbf{y}-\mathbf{H} \mathbf{x}\|^{2} \\
& =\underset{\mathbf{x}}{\operatorname{argmin}}\|\mathbf{H} \mathbf{x}\|^{2}-2 \operatorname{Re}\left\{\mathbf{y}^{H} \mathbf{H} \mathbf{x}\right\} .
\end{aligned}
$$

É importante notar que tanto o problema de maximização requerido pelo detector MAP quanto o problema de minimização requerido pelo detector ML exigem $M^{N_{t}}$ avaliações de uma determinada métrica, em que $M$ é o tamanho da constelação de símbolos empregada. Dessa forma, a complexidade computacional destes detectores cresce exponencialmente com o número de antenas de transmissão e polinomialmente (da ordem de $N_{t}$ ) com $M$. 


\subsection{2}

\section{Detector Zero forcing}

O objetivo principal do detector zero forcing (ZF) é minimizar a interferência entre os símbolos transmitidos empregando o processamento linear do sinal recebido. Considerando-se $N_{t} \leq N_{r}$, este detector realiza essa tarefa empregando a matriz pseudo-inversa de Moore-Penrose da matriz de coeficientes de canal como filtro de detecção, $\mathbf{W}_{Z F}$ :

$$
\mathbf{W}_{Z F}=\left(\mathbf{H}^{H} \mathbf{H}\right)^{-1} \mathbf{H}^{H} \text {. }
$$

Empregando-se essa estratégia, a saída do filtro de detecção, $\tilde{\mathbf{x}}_{Z F}$, é dada por:

$$
\begin{aligned}
\tilde{\mathbf{x}}_{Z F} & =\mathbf{W}_{Z F} \mathbf{y} \\
& =\left(\mathbf{H}^{H} \mathbf{H}\right)^{-1} \mathbf{H}^{H}(\mathbf{H} \mathbf{x}+\mathbf{n}) \\
& =\mathbf{x}+\tilde{\mathbf{n}}
\end{aligned}
$$

em que $\tilde{\mathbf{n}}=\left(\mathbf{H}^{H} \mathbf{H}\right)^{-1} \mathbf{H}^{H} \mathbf{n}$. Finalmente, o vetor de símbolos detectados, $\hat{\mathbf{x}}_{Z F}$, é dado por:

$$
\hat{\mathbf{x}}_{Z F}=Q\left(\tilde{\mathbf{x}}_{Z F}\right),
$$

em que a função $Q$ mapeia cada elemento do vetor de estimativas oriundo do filtro de detecção para o símbolo mais próximo pertencente à constelação empregada. Cabe ressaltar que, apesar de cancelar a interferência entre os símbolos transmitidos, o vetor de ruído de recepção é alterado gerando um novo vetor de ruído, $\tilde{\mathbf{n}}$, com componentes correlatadas, o que torna este tipo de detecção sub-ótima.

\subsection{3}

\section{Detecção por mínimo erro médio quadrático}

Na detecção por mínimo erro médio quadrático, um filtro linear é aplicado ao sinal recebido de forma a minimizar o erro médio quadrático (Mean Squared Error - MSE), da seguinte forma:

$$
\mathbf{W}_{M M S E}=\underset{\mathbf{W}}{\operatorname{argmin}} E\left[\|\mathbf{x}-\mathbf{W} \mathbf{y}\|^{2}\right] .
$$

A resolução deste problema de minimização, considerando o modelo da Seção 2.3, resulta no filtro MMSE dado por [44]:

$$
\mathbf{W}_{M M S E}=\left(\mathbf{H}^{H} \mathbf{H}+\sigma_{n}^{2} \mathbf{I}_{N_{t}}\right)^{-1} \mathbf{H}^{H} .
$$

De forma análoga ao realizado na detecção ZF, o vetor de estimativas MMSE, $\tilde{\mathbf{x}}_{M M S E}=\mathbf{W}_{M M S E} \mathbf{y}$, é quantizado de acordo com a constelação de símbolos empregada, gerando o vetor detectado $\hat{\mathbf{x}}_{M M S E}$ : 


$$
\hat{\mathbf{x}}_{M M S E}=Q\left(\tilde{\mathbf{x}}_{M M S E}\right) .
$$

Um aspecto positivo deste detector é que, além de minimizar o erro médio quadrático, a filtragem MMSE também maximiza a razão sinal-ruído mais interferência (Signal to Interference plus Noise Ratio - SINR). Em relação à sua complexidade computacional, bem como a do detector ZF, pode-se afirmar que, devido à necessidade da operação de inversão de matrizes, ambos detectores possuem complexidade proporcional a $N_{t}^{3}$.

\subsection{4}

\section{Detecção por filtro casado}

Na detecção por filtro casado (Matched Filter - MF), o filtro de detecção é tomado igual à matriz hermitiana da matriz de coeficientes de canal, i.e.,

$$
\mathbf{W}_{M F}=\mathbf{H}^{H} \text {. }
$$

Este tipo de detecção maximiza a SNR media porém não trata as interferências oriundas dos outros símbolos sendo transmitidos. Por outro lado, a detecção MF possui menor complexidade computacional que os outros detectores lineares uma vez que não necessita da inversão de matrizes.

\subsection{5}

\section{Cancelamento de interferência serial ordenado (OSIC)}

O desempenho da detecção dos sistemas MIMO pode ser melhorado por meio de técnicas de cancelamento de interferência, como as técnicas de cancelamento de interferência serial ordenado (OSIC). Nesta estratégia, um banco de detectores é empregado em série de forma que cada detector realiza a detecção de um símbolo transmitido e, em seguida, efetua a subtração da componente de sinal referente ao símbolo que acabou de ser detectado do sinal recebido antes de passar para a detecção do próximo símbolo, conforme ilustrado na Figura 2.5.

Nesta figura, $\hat{x}_{i}$ é o $i$-ésimo símbolo detectado que, dependendo do ordenamento empregado para a detecção, pode ser diferente da $i$-ésima componente do vetor de símbolos transmitidos $\mathbf{x}$ da equação (2-9). Além disso, $\mathbf{h}_{i}$ é o vetor de coeficientes de canal entre a antena de transmissão correspondente ao $i$-ésimo símbolo a ser detectado e as antenas da EB. Em cada passo, se a detecção foi realizada sem erros, a interferência gerada pelo símbolo que foi detectado é eliminada da detecção dos próximos símbolos. Caso contrário, o erro de detecção é propagado para as demais detecções. Sendo assim, é importante que os símbolos a serem detectados inicialmente sejam aqueles com menor pro- 


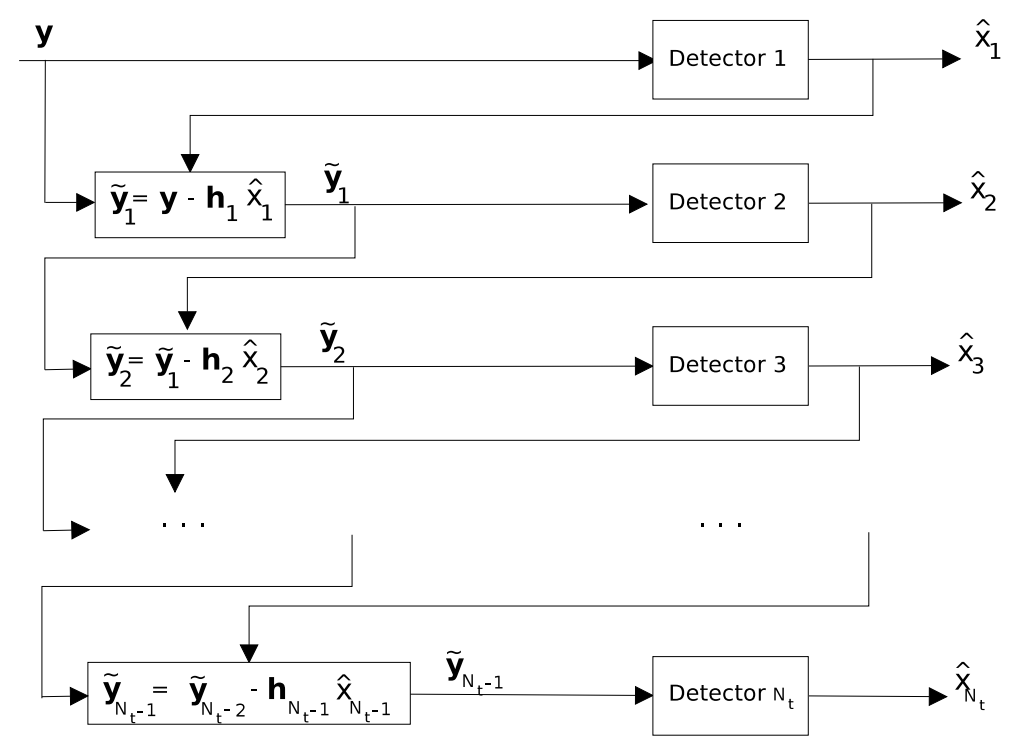

Figura 2.5: Esquema de detecção com cancelamento de interferência serial ordenado.

babilidade de erro, evidenciando o papel da estratégia de ordenamento neste tipo de detecção.

Diversas estratégias de ordenamento podem ser empregadas, sendo as mais intuitivas as que priorizam os símbolos com maior SNR ou SINR. Outra estratégia popular é a de detectar primeiramente os símbolos com maior norma do vetor de coeficientes de canal respectivo, uma vez que a potência do sinal recebido referente a um determinado símbolo é proporcional à norma do vetor de canal entre a respectiva antena de transmissão e a EB. Em [47] é proposto um detector MIMO, denominado Multi-Branch Lattice Reduction SIC (MBLR-SIC), baseado no detector proposto em [48], que efetua diversas detecções OSIC com diferentes estratégias de ordenamento e escolhe o melhor resultado como decisão final.

\section{6}

\section{Conclusões}

Neste capítulo os modelos de canais comumente adotados em sistemas de comunicação sem fio foram apresentados. Além disso, um modelo matemático para descrever o canal reverso em sistemas MU-MIMO foi descrito e dois cenários de estudo foram definidos: o primeiro, denotado por cenário $\mathrm{A}$, não considera os efeitos de correlação entre elementos transmissores e receptores, nem os efeitos do sombreamento log-normal dos usuários do sistema. Já no segundo, nomeado de cenário B, esses efeitos deletérios são incorporados ao modelo.

Expressões para a capacidade de informação para o canal reverso de 
sistemas MIMO foram apresentadas e verificou-se que a capacidade ergódica de informação desses sistemas aumenta com o aumento do número de antenas, tanto no transmissor quanto no receptor, justificando assim o aumento do número de elementos de transmissão/recepção nos sistemas MIMO.

Por fim, o método de estimação por mínimos quadrados da matriz de coeficientes de canal foi descrito e estratégias de detecção clássicas para o canal reverso de sistemas MIMO foram apresentadas.

No próximo capítulo, a técnica de detecção por busca por verossimilhança ascendente (LAS) será apresentada e diversos algoritmos propostos para emprego em sistemas MIMO de larga escala baseados nesta técnica serão descritos. Em especial, o algoritmo Random-List Based LAS, desenvolvido durante a presente tese, será detalhado e seus resultados de desempenho em termos de BER e complexidade computacional serão comparados aos resultados dos demais detectores por meio de simulação de Monte Carlo. 


\section{3}

\section{Estratégia de Busca por Verossimilhança Ascendente}

\section{1}

\section{Introdução}

Neste capítulo, a estratégia de busca por verossimilhança ascendente ( $L i$ kelihood Ascent Search - LAS) é apresentada e diversos algoritmos baseados nessa estratégia são detalhados, incluindo o detector Random-List Based LAS (RLB-LAS), desenvolvido durante o curso do presente trabalho. Além disso, de forma a comparar o desempenho dos algoritmos analisados em termos de BER e a complexidade computacional, avaliada por meio do número médio de operações de ponto-flutuante (Floating-Point Operations - flops), alguns resultados de simulações de Monte Carlo são apresentados. Destaca-se que o algoritmo RLB-LAS obteve melhores resultados do que os demais detectores analisados, tanto em termos de BER quanto referentes à complexidade computacional.

Inicialmente, uma abordagem alternativa à apresentada em [20], desenvolvida durante esta tese, é descrita. Diferentemente de [20], que trabalha em um sistema real equivalente ao sistema em banda base de variáveis complexas, a abordagem aqui apresentada opera diretamente nas amostras complexas dos símbolos transmitidos. Em seguida, na Seção 3.3, diversos algoritmos baseados na busca LAS são descritos. Posteriormente, resultados de simulações são apresentados na Seção 3.4 visando a comparação do desempenho em termos de BER dos detectores analisados e das suas complexidades computacionais em termos do número médio de flops. Finalmente as conclusões são apresentadas na Seção 3.5.

\section{2}

\section{Procedimento LAS}

Um detetor para sistemas MIMO de larga escala operando com uma constelação de símbolos BPSK (Binary Shift Keying) foi introduzido em [20]. Este detector consiste em uma busca em um espaço de vetores de símbolos transmitidos na qual a cada passo da busca o vetor solução escolhido possui valor da função de verossimilhança maior que o vetor de símbolos escolhido no passo anterior. Esta busca segue até que se chegue a um ponto fixo, que é eleito 
como o vetor de símbolos detectados. Ainda em [20] foi proposto um mecanismo de extensão deste detector para sistemas que empregam modulações por amplitude de pulso (Pulse Amplitude Modulation - PAM ) ou modulações de amplitude em quadratura (Quadrature Amplitude Modulation - QAM ) retangulares. Nesta tese desenvolve-se uma alternativa a este mecanismo que pode ser empregada em sistemas que operam com qualquer constelação de símbolos complexos. A diferença fundamental das duas abordagens é que em [20] a detecção é realizada no espaço vetorial de bits transmitidos, e na estratégia adotada no presente trabalho a detecção é feita no espaço vetorial de símbolos transmitidos.

Considerando o modelo do sistema descrito no capítulo anterior, o detector de máxima verossimilhança (ML), conforme equação (2-42), escolhe o vetor de símbolos, $\mathbf{d}$, que maximiza a seguinte métrica:

$$
\Lambda(\mathbf{d})=\mathbf{d}^{H} \mathbf{H}^{H} \mathbf{y}+\mathbf{y}^{H} \mathbf{H d}-\mathbf{d}^{H} \mathbf{H}^{H} \mathbf{H d},
$$

em que $\mathbf{y}$ representa o vetor de sinais recebidos e $\mathbf{H}$ é a matriz de coeficientes de canal. Esta métrica de verossimilhança pode ser escrita como:

$$
\Lambda(\mathbf{d})=\mathbf{d}^{H} \mathbf{y}_{e f f}+\mathbf{y}_{e f f}^{H} \mathbf{d}-\mathbf{d}^{H} \mathbf{H}_{e f f} \mathbf{d},
$$

sendo

$$
\begin{gathered}
\mathbf{y}_{\text {eff }}=\mathbf{H}^{H} \mathbf{y}, \\
\mathbf{H}_{\text {eff }}=\mathbf{H}^{H} \mathbf{H} .
\end{gathered}
$$

Seja $\mathbf{d}(n) \in \mathcal{B}^{N_{t}}$ o vetor de símbolos escolhido no $n$-ésimo passo do algoritmo de busca LAS, onde $\mathcal{B}$ é o alfabeto de símbolos da modulação empregada, que contém $M$ símbolos complexos distintos, e $N_{t}$ é o número total de símbolos transmitidos. O objetivo do detector LAS, a cada passo da busca, é encontrar um novo vetor de símbolos, $\mathbf{d}(n+1)$ tal que $\Lambda(\mathbf{d}(n+1))>\Lambda(\mathbf{d}(n))$. O algoritmo efetua um novo passo até que se chegue a um ponto fixo, ou seja, até que não exista nenhum outro vetor candidato com maior métrica de verossimilhança do que o vetor atual. Obviamente, caso esta busca não sofresse nenhuma restrição, o resultado deste detector seria igual ao resultado de uma detecção ML, uma vez que todo o espaço vetorial de vetores de símbolos transmitidos seria investigado. Porém, a busca irrestrita não geraria ganho em redução de complexidade. De forma a reduzir a complexidade desta busca, o conjunto de possíveis vetores de símbolos a serem escolhidos no próximo passo é reduzido com base nos chamados conjuntos de candidatos de busca (Search Candidate Sets - SCS).

Seja $L(n)$ o conjunto de candidatos de busca do $n$-ésimo passo do 
algoritmo LAS, tal que $L(n) \subseteq\left\{1,2,3, \cdots, N_{t}\right\}, L(n) \neq \emptyset$. Este conjunto define quais os índices dos símbolos do vetor de símbolos escolhido do passo atual que podem ser alterados para a escolha do vetor de símbolos do próximo passo. Por exemplo, seja um sistema que transmita um vetor de 3 símbolos de uma constelação formada pelo conjunto de símbolos $\left\{s_{1}, s_{2}, s_{3}, s_{4}\right\}$. Caso o vetor de símbolos escolhido no passo atual seja o vetor $\left[s_{1}, s_{1}, s_{2}\right]^{T}$ e o SCS do passo atual seja o conjunto unitário $\{2\}$, apenas os vetores $\left[s_{1}, s_{2}, s_{2}\right]^{T}$, $\left[s_{1}, s_{3}, s_{2}\right]^{T}$ e $\left[s_{1}, s_{4}, s_{2}\right]^{T}$ poderão ser examinados como possíveis candidatos a serem escolhidos no próximo passo da busca.

O vetor de símbolos candidatos escolhido no início da busca, $\mathbf{d}(0)$, pode ser tomado aleatoriamente ou obtido pela saída de um outro detector mais simples. Quando o vetor inicial é escolhido pelo resultado de uma detecção por filtro casado, o detector LAS resultante é chamado de MF-LAS. Analogamente, os detectores LAS que empregam os resultados da detecção ZF e MMSE como vetores de símbolos candidatos iniciais são denominados de ZF-LAS e MMSELAS, respectivamente.

Define-se a variação da métrica de verossimilhança da equação (3-2) no n-ésimo passo por:

$$
\Delta \Lambda \triangleq \Lambda(\mathbf{d}(n+1))-\Lambda(\mathbf{d}(n))
$$

Esta variação pode ser escrita em termos do gradiente da métrica de verossimilhança $\Lambda(\mathbf{d}(n))$ e do vetor diferença entre símbolos no passo $n, \Delta \mathbf{d}(n)=$ $\mathbf{d}(n+1)-\mathbf{d}(n)$, como se segue.

Seja $\mathbf{g}(n)$ a $\mathbb{R}$-derivada conjugada [49] da métrica de verossimilhança avaliada em $\mathbf{d}(n)$, i.e.:

$$
\begin{aligned}
& \mathbf{d}(n) \text {, i.e.: } \mathbf{g}(n)=\frac{\partial(\Lambda(\mathbf{d}(n)))}{\partial\left(\mathbf{d}^{*}(n)\right)} \\
& =\frac{\partial\left(\mathbf{d}^{H}(n) \mathbf{y}_{e f f}\right)}{\partial\left(\mathbf{d}^{*}(n)\right)}+\frac{\partial\left(\mathbf{y}_{\text {eff }}^{H} \mathbf{d}(n)\right)}{\partial\left(\mathbf{d}^{*}(n)\right)}-\frac{\partial\left(\mathbf{d}^{H}(n) \mathbf{H}_{e f f} \mathbf{d}(n)\right)}{\partial\left(\mathbf{d}^{*}(n)\right)} \\
& =\mathbf{y}_{\text {eff }}-\mathbf{H}_{\text {eff }} \mathbf{d}(n) .
\end{aligned}
$$

Considerando (3-2), a equação (3-5) pode ser escrita como:

$$
\begin{aligned}
& \Delta \Lambda= \\
= & \mathbf{d}^{H}(n+1) \mathbf{y}_{\text {eff }}+\mathbf{y}_{\text {eff }}^{H} \mathbf{d}(n+1)-\mathbf{d}^{H}(n+1) \mathbf{H}_{\text {eff }} \mathbf{d}(n+1) \\
& -\mathbf{d}^{H}(n) \mathbf{y}_{\text {eff }}-\mathbf{y}_{\text {eff }}^{H} \mathbf{d}(n)+\mathbf{d}^{H}(n) \mathbf{H}_{\text {eff }} \mathbf{d}(n) \\
= & {\left[\mathbf{d}^{H}(n+1)-\mathbf{d}^{H}(n)\right] \mathbf{y}_{e f f}+\mathbf{y}_{\text {eff }}^{H}[\mathbf{d}(n+1)-\mathbf{d}(n)] } \\
& -\mathbf{d}^{H}(n+1) \mathbf{H}_{\text {eff }} \mathbf{d}(n+1)+\mathbf{d}^{H}(n) \mathbf{H}_{\text {eff }} \mathbf{d}(n) .
\end{aligned}
$$


Adicionando e subtraindo o termo $\mathbf{d}^{H}(n) \mathbf{H}_{e f f} \mathbf{d}(n+1)$ na expressão acima, tem-se:

$$
\begin{aligned}
& \Delta \Lambda= \\
= & \Delta \mathbf{d}^{H}(n) \mathbf{y}_{\text {eff }}+\mathbf{y}_{\text {eff }}^{H} \Delta \mathbf{d}(n)-\left[\mathbf{d}^{H}(n+1)-\mathbf{d}^{H}(n)\right] \mathbf{H}_{e f f} \mathbf{d}(n+1) \\
& -\mathbf{d}^{H}(n) \mathbf{H}_{e f f}[\mathbf{d}(n+1)-\mathbf{d}(n)] \\
= & \Delta \mathbf{d}^{H}(n) \mathbf{y}_{\text {eff }}+\mathbf{y}_{\text {eff }}^{H} \Delta \mathbf{d}(n)-\Delta \mathbf{d}^{H}(n) \mathbf{H}_{e f f} \mathbf{d}(n+1) \\
& -\mathbf{d}^{H}(n) \mathbf{H}_{e f f} \Delta \mathbf{d}(n) \\
= & \Delta \mathbf{d}^{H}(n)\left[\mathbf{y}_{\text {eff }}-\mathbf{H}_{\text {eff }} \mathbf{d}(n+1)\right]+\left[\mathbf{y}_{\text {eff }}^{H}-\mathbf{d}^{H}(n) \mathbf{H}_{\text {eff }}^{H}\right] \Delta \mathbf{d}(n) .
\end{aligned}
$$

Considerando $\mathbf{d}(n+1)=\mathbf{d}(n)+\Delta \mathbf{d}(n)$ e aplicando (3-6), a equação (3-8) pode ser reduzida a:

$$
\begin{aligned}
& \Delta \Lambda(\Delta \mathbf{d}(n))= \\
= & \Delta \mathbf{d}^{H}(n)\left[\mathbf{y}_{\text {eff }}-\mathbf{H}_{\text {eff }}(\mathbf{d}(n)+\Delta \mathbf{d}(n))\right]+\mathbf{g}^{H}(n) \Delta \mathbf{d}(n) \\
= & \Delta \mathbf{d}^{H}(n)\left[\mathbf{g}(n)-\mathbf{H}_{e f f} \Delta \mathbf{d}(n)\right]+\mathbf{g}^{H}(n) \Delta \mathbf{d}(n) \\
= & \Delta \mathbf{d}^{H}(n) \mathbf{g}(n)+\left[\Delta \mathbf{d}^{H}(n) \mathbf{g}(n)\right]^{H}-\Delta \mathbf{d}^{H}(n) \mathbf{H}_{e f f} \Delta \mathbf{d}(n) \\
= & 2 \operatorname{Real}\left\{\Delta \mathbf{d}^{H}(n) \mathbf{g}(n)\right\}-\Delta \mathbf{d}^{H}(n) \mathbf{H}_{e f f} \Delta \mathbf{d}(n) .
\end{aligned}
$$

Neste ponto, dados $\mathbf{y}_{\text {eff }}, \mathbf{H}_{\text {eff }}$ e $\mathbf{d}(n)$, o objetivo é obter $\mathbf{d}(n+1)$ a partir de $\mathbf{d}(n)$, tal que $\Delta \Lambda(\Delta \mathbf{d}(n))$ em (3-9) seja o maior possível. Considerando $L(n)$ o SCS do $n$-ésimo passo conforme discutido anteriormente, seja $L_{f}(n) \subseteq$ $L(n)$ o conjunto de índices do vetor de símbolos que terão seus símbolos correspondentes efetivamente trocados, após o exame de todos os possíveis vetores de símbolos candidatos definidos por $L(n)$. Sendo assim, (3-9) pode ser escrita como:

$$
\begin{aligned}
& \Delta \Lambda(\Delta \mathbf{d}(n))= \\
= & \text { 2Real }\left\{\sum_{i \in L_{f}(n)} \Delta d_{i}^{*}(n) g_{i}(n)\right\}- \\
& \sum_{i \in L_{f}(n)} \sum_{j \in L_{f}(n)} \Delta d_{i}^{*}(n) h_{e f f_{i, j}} \Delta d_{j}(n)
\end{aligned}
$$

em que $\Delta d_{i}(n), g_{i}(n)$ e $h_{e f f_{i, j}}$ denotam a $i$-ésima componente de $\Delta d(n)$ e de $\mathbf{g}(n)$, e o $(i, j)$-ésimo elemento de $\mathbf{H}_{e f f}$, respectivamente.

Uma vez que os elementos de $\mathbf{d}(n+1)$ e de $\mathbf{d}(n)$ pertencem a uma constelação de símbolos $\mathcal{B}$, os possíveis valores de $\Delta d_{i}(n)$ são limitados. Dessa forma, a fim de encontrar o novo vetor de símbolos $\mathbf{d}(n+1)$, o algoritmo LAS busca, considerando apenas os valores possíveis de $\Delta d_{i}(n)$, o vetor diferença 
$\Delta \mathbf{d}(n)_{\max }=\left[\Delta d_{1}(n)_{\max }, \Delta d_{2}(n)_{\max }, \cdots, \Delta d_{N t}(n)_{\max }\right]^{T}$ que gera o maior aumento na métrica de verossimilhança, sendo $\Delta d_{i}(n)_{\max }=0$ caso $i \notin L(n)$, já que o símbolo correspondente a um índice que não pertença ao SCS não pode ser trocado. De (3-10), $\Delta \mathbf{d}(n)_{\max }$ é dado por:

$$
\begin{aligned}
\Delta \mathbf{d}(n)_{\text {max }} \triangleq & \underset{\Delta \mathbf{d}(n)}{\operatorname{argmax}}\{\Delta \Lambda(\Delta \mathbf{d}(n))\} \\
= & \underset{\Delta \mathbf{d}(n)}{\operatorname{argmax}}\left\{2 \operatorname{Real}\left\{\sum_{i \in L(n)} \Delta d_{i}^{*}(n) g_{i}(n)\right\}\right. \\
& \left.-\sum_{i \in L(n)} \sum_{j \in L(n)} \Delta d_{i}^{*}(n) h_{e f f_{i, j}} \Delta d_{j}(n)\right\} .
\end{aligned}
$$

Uma vez encontrado $\Delta \mathbf{d}(n)_{\max }$, caso $\Delta \Lambda\left(\Delta \mathbf{d}(n)_{\max }\right)>0, \mathbf{d}(n+1)$ é obtido somando-se $\Delta \mathbf{d}(n)_{\max }$ a $\mathbf{d}(n)$ e $\mathbf{g}(n)$ é atualizado conforme se segue:

$$
\begin{aligned}
\mathbf{g}(n+1) & =\mathbf{y}_{\text {eff }}-\mathbf{H}_{e f f}\left[\mathbf{d}(n)+\Delta \mathbf{d}(n)_{\max }\right] \\
& =\mathbf{g}(n)-\mathbf{H}_{e f f} \Delta \mathbf{d}(n)_{\max } \\
& =\mathbf{g}(n)-\sum_{i \in L_{f}(n)} \mathbf{h}_{e f f_{i}} \Delta d_{i}(n)_{\max }
\end{aligned}
$$

em que $\mathbf{h}_{e f f_{i}}$ é a $i$-ésima coluna de $\mathbf{H}_{e f f}$. Caso $\Delta \Lambda\left(\Delta \mathbf{d}(n)_{\max }\right) \leq 0$, faz-se $\mathbf{d}(n+1)=\mathbf{d}(n)$ e repete-se o processo de maximização em (3-11) para o próximo passo da busca. Caso todos os possíveis SCS sejam empregados sem que haja mudanças no vetor de símbolos candidatos, considera-se que chegouse a um ponto fixo e o vetor de símbolos candidatos atual é escolhido como resultado da detecção LAS.

Observa-se em (3-11) que a busca pelo $\Delta \mathbf{d}(n)$ que maximiza a expressão envolve $M^{|L(n)|}-1$ possíveis vetores e, portanto, possui complexidade proporcional à $\mathcal{O}\left(M^{|L(n)|}\right)$. De forma a reduzir esta complexidade, o número de elementos em cada SCS é normalmente reduzido. Para o caso em que $|L(n)|=1$, temos o algoritmo denominado de Sequential LAS (SLAS)[20], no qual $L(n)$ representa o índice do símbolo componente do vetor de símbolos candidatos a ser testado para possível troca. A sequência de SCS, $L(n)$, pode ser determinada de forma que os índices de símbolos a serem verificados sejam escolhidos de forma circular ou aleatória. Diz-se que uma sequência de SCS é circular quando ela é periódica, de período igual a $N_{t}$ e, a cada período, todos os índices são testados para possível troca de símbolos. Como exemplo, seja um sistema que transmita um vetor com 3 símbolos $\left(N_{t}=3\right)$. A sequência de SCS $L(n)=\left\{i \mid i=\left(n\right.\right.$ modulo $\left.\left.N_{t}\right)+1\right\}$ é uma sequência de SCS circular na qual testa-se, no primeiro passo da busca, o símbolo da segunda posição do vetor de símbolos candidatos, depois o símbolo da terceira, em seguida, o da primeira e, 
no quarto passo, retorna-se à segunda posição do vetor de símbolos candidatos. Essa busca continua até que todas as posições do vetor de símbolos candidatos sejam testadas sem que haja alteração deste vetor.

A seguir alguns resultados de desempenho em termos de curvas de BER e número médio de flops por bit transmitido versus SNR para o detector SLAS são apresentados. Estas curvas foram obtidas por meio de simulações de Monte Carlo de um sistema MIMO com $N_{t}$ antenas transmissoras e $N_{r}$ antenas receptoras $\left(N_{t} \times N_{r}\right)$ no qual empregou-se o detector SLAS. Estes resultados são uma média de 1000 ensaios independentes, cada um com a transmissão de 10 vetores de símbolos sujeitos a um canal com desvanecimento plano e lento, de acordo com o cenário A, detalhado no capítulo 2. Nas simulações efetuadas, definiu-se a SNR (em dB) como $S N R(d B)=10 \log \left(\frac{N_{t}}{\sigma_{n}^{2}}\right)$, em que $\sigma_{n}^{2}$ é a variância de cada componente do vetor de ruído de recepção. O número de flops foi calculado com o auxílio da biblioteca de funções do Matlab Lightspeed Matlab toolbox [50].

Nas Figuras 3.1 e 3.2, são apresentadas as curvas de BER por SNR para os detectores MF-SLAS, ZF-SLAS e MMSE-SLAS empregando-se as modulações BPSK e 4-QAM, respectivamente, onde foi mantido $N_{t}=N_{r}=N$. Além destas curvas, resultados de BER de um sistema com uma única antena de transmissão e uma antena de recepção (Single-Input Single-Output - SISO) sujeito a um canal AWGN são apresentados a título de comparação. Pode ser observado nessas figuras que conforme $N$ aumenta, a BER do detector SLAS se aproxima dos resultados do sistema SISO AWGN. Este fato ilustra a capacidade do algoritmo SLAS em remover os efeitos do desvanecimento e a interferência espacial oriunda dos símbolos transmitidos nas outras antenas ao passo em que o número de antenas componentes do sistema cresce, o que está em consonância com os resultados teóricos dos sistema MIMO de larga escala discutidos em [6]. Este comportamento é uma característica de todos os detectores baseados na busca LAS, conforme será evidenciado adiante. Por outro lado, pode ser notado, ao se comparar os resultados da Figura 3.1 aos da Figura 3.2, que este efeito é reduzido com o aumento do número de símbolos da constelação empregada, ou seja, ao passo em que $M$ cresce, são necessárias mais antenas para que os resultados do detector SLAS se aproximem das curvas de BER do cenário SISO AWGN. Além disso, observa-se que ao se empregar a modulação 4-QAM, a escolha do vetor de símbolos candidatos inicial é mais relevante no resultado final do detector SLAS, uma vez que as diferenças entre as curvas de BER dos detectores MF-SLAS, ZF-SLAS e MMSE-SLAS são mais acentuadas no sistema que emprega a modulação 4-QAM do que no sistema que emprega a modulação BPSK. 

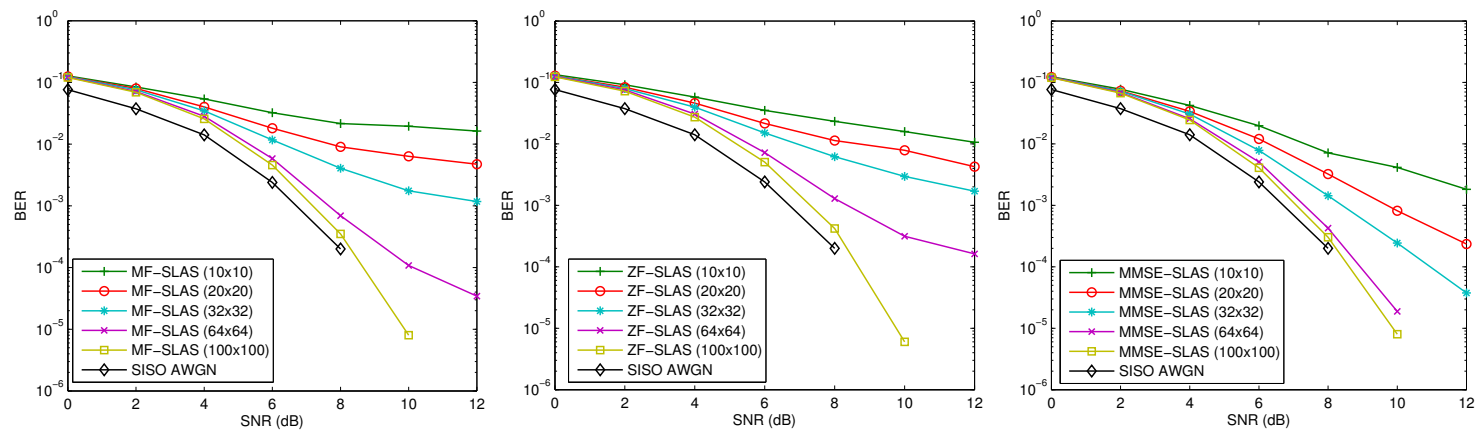

Figura 3.1: Curvas de BER de detectores SLAS com modulação BPSK.
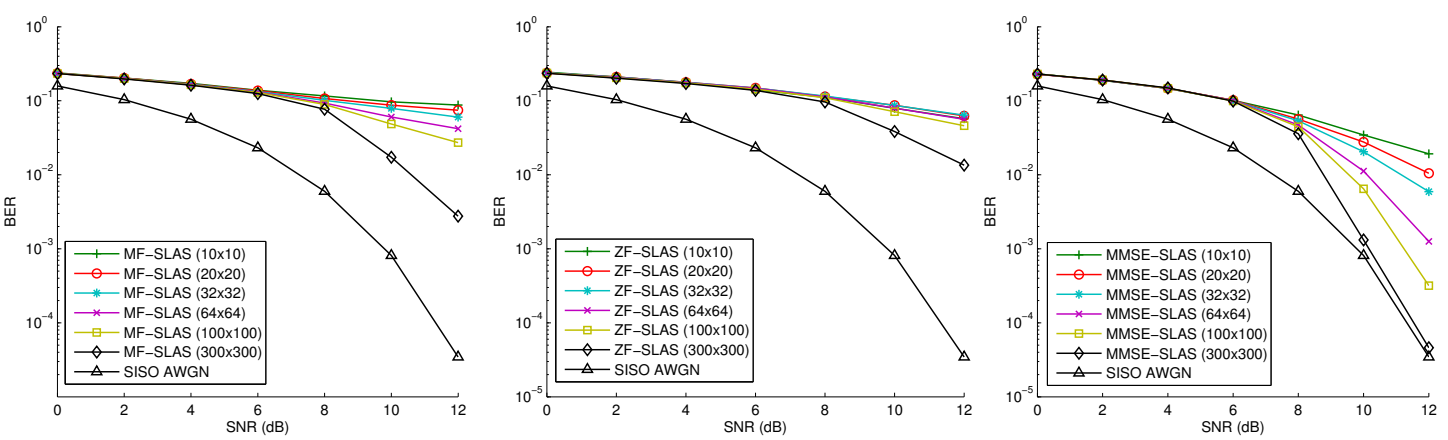

Figura 3.2: Curvas de BER de detectores SLAS com modulação 4-QAM.

As curvas de BER dos detectores MF-SLAS, ZF-SLAS e MMSE-SLAS para os sistemas MIMO $(10 \times 10)$, $(64 \times 64)$ e $(300 \times 300)$ são apresentadas nas Figuras 3.3 e 3.4 para fins de comparação. Os resultados ilustrados na primeira figura foram obtidos empregando-se a modulação BPSK, enquanto que os da segunda foram obtidos empregando-se a modulação 4-QAM. Como pode ser visto, independentemente da modulação utilizada, o detector MMSESLAS atingiu melhores resultados em termos de BER do que os demais detectores SLAS. Cabe ressaltar que, para sistemas com um número de antenas grande o suficiente, o detector MF-SLAS obteve melhores resultados do que o detector ZF-LAS. Este fato explica-se ao observar que, sob condições de elevado ruído/interferência, o detector ZF obtém piores resultados que o detector MF [51].

A seguir, a complexidade computacional do detector SLAS é analisada. Além dos custos da obtenção do vetor de símbolos candidatos inicial $\mathbf{d}(0)$, esta complexidade é influenciada por quatro componentes: $i$ ) cálculo inicial de $\mathbf{g}(0)$ de acordo com $(3-6)$; ii) atualização de $\mathbf{g}(n)$ a cada passo conforme (3-12); iii) número de passos efetuados até que se chegue a um ponto fixo; e $i v)$ número de operações realizadas em cada passo. O cálculo de $\mathbf{g}(0)$ requer a 


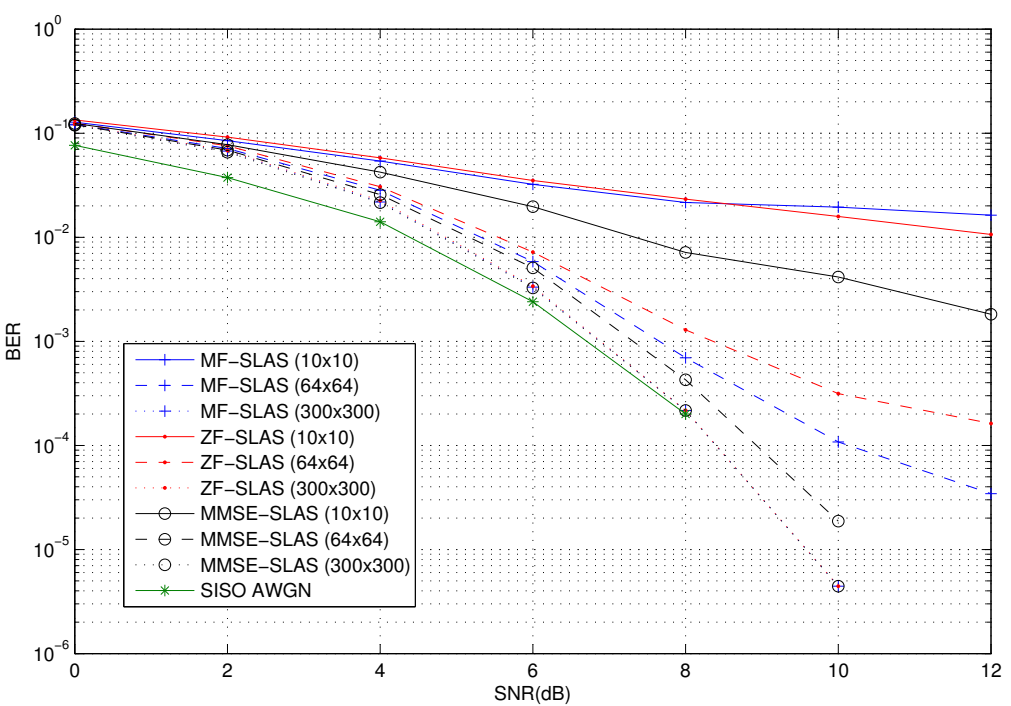

Figura 3.3: BER por SNR de detectores SLAS com modulação BPSK.

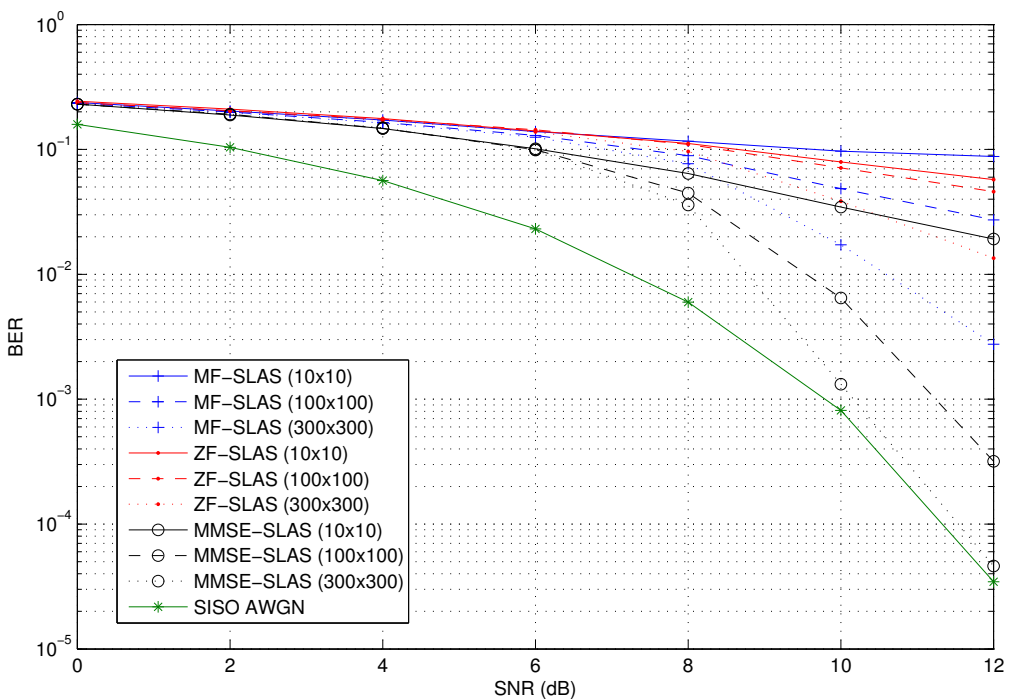

Figura 3.4: BER por SNR de detectores SLAS com modulação 4-QAM. 
avaliação de $\mathbf{H}^{H} \mathbf{H}$ para cada realização do canal, que possui complexidade da ordem de $\mathcal{O}\left(N_{t}^{2} N_{r}\right)$. A atualização de $\mathbf{g}(n)$ necessita apenas de $\mathcal{O}\left(N_{t}\right)$ operações. Já o número de passos até se chegar a um ponto fixo na busca LAS não é determinístico e varia de acordo com o sinal recebido, o vetor de símbolos candidatos inicial utilizado e os SCS empregados. Sendo assim, o número médio de passos da busca LAS até que se chegue a um ponto fixo foi avaliado por meio de simulações, que serão descritas a seguir. Observou-se que este número médio não é maior que $c_{1} N_{t} N_{r}$ em que $c_{1}$ é uma constante que depende da SNR e do vetor de símbolos candidatos inicial. Em cada passo da busca, o detector SLAS avalia $(M-1)$ possíveis valores de $\Delta \Lambda(\Delta \mathbf{d}(n))$, cada um necessitando de um número constante de operações para ser calculado. Dessa forma, considerando que $M<N_{t} N_{r}$, a complexidade total do detector SLAS é da ordem de $\mathcal{O}\left(N_{t}^{2} N_{r}\right)$, o que gera uma complexidade por símbolo transmitido da ordem de $\mathcal{O}\left(N_{t} N_{r}\right)$.

As Figuras 3.5 e 3.6 ilustram os resultados de simulações realizadas com o intuito de avaliar o número de passos necessários a se alcançar um ponto fixo na busca LAS realizada pelo detector SLAS. Estas figuras apresentam curvas do número médio de passos por SNR para os detectores MF-SLAS e MMSE-SLAS em sistemas que empregam a modulação 4-QAM nos quais $N_{t}=N_{r}=N$. O detector ZF-SLAS não foi avaliado, uma vez que seus resultados de BER foram similares, e até piores nos casos em que $N$ é grande, aos resultados do MFSLAS, que possui menor complexidade computacional para a obtenção do vetor de símbolos candidatos inicial. Além do número médio de passos, também são apresentadas curvas das médias do número máximo de passos necessários em cada busca LAS para a transmissão de um quadro composto por 10 vetores de símbolos. Pode ser observado desses resultados que, para o detector MF-SLAS, o número médio de passos manteve-se praticamente constante ao se variar a SNR, enquanto que, para o detector MMSE-SLAS, ele decresce ligeiramente. Além disso, observa-se que a média do número máximo de passos não se afasta de forma exagerada da curva do número médio de passos, o que é uma característica desejável para o detector, uma vez que um número máximo de passos muito elevado para uma determinada detecção poderia gerar variações grandes no tempo de detecção de cada vetor de símbolos.

A fim de avaliar a ordem de grandeza do número médio de passos em função do número de antenas $N$, a Figura 3.7 apresenta as curvas do número médio de passos, e da média do número máximo de passos, por $N_{t}=N_{r}=N$ em uma escala log-log para os detectores MF-SLAS e MMSE-SLAS para a SNR igual a $10 d B$. Além dessas curvas, são plotadas no mesmo gráfico curvas quadráticas e lineares para comparação. Assumindo que o número médio de 


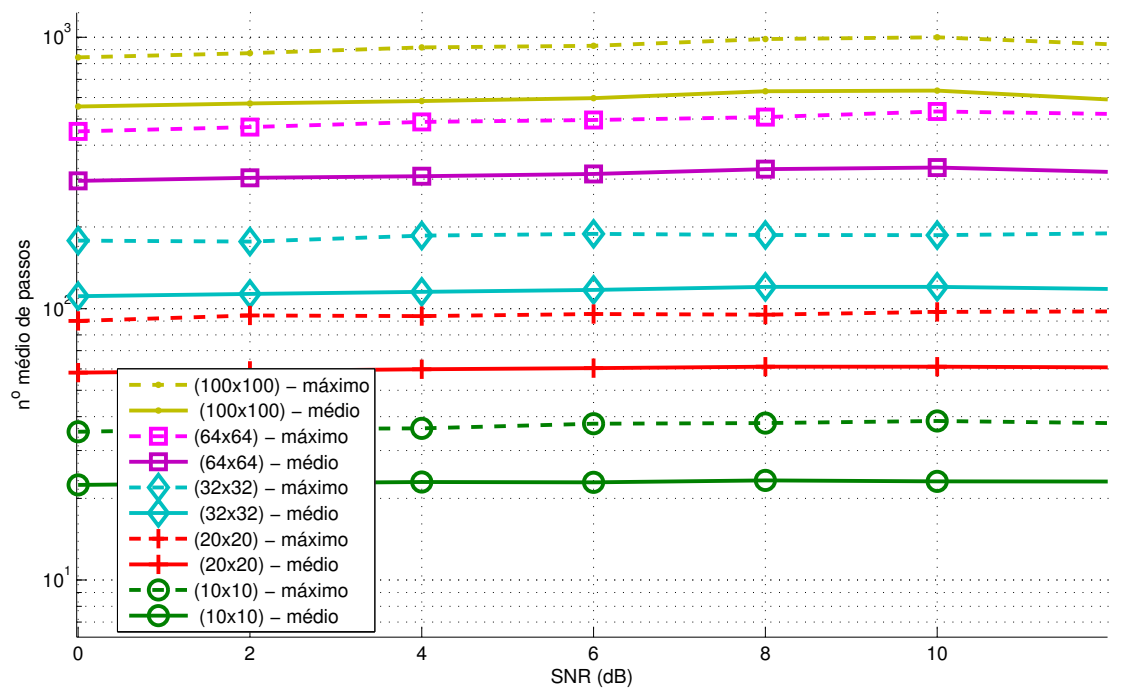

Figura 3.5: Número máximo e médio de passos por SNR das buscas LAS do detector MF-SLAS em sistemas com modulação 4-QAM.

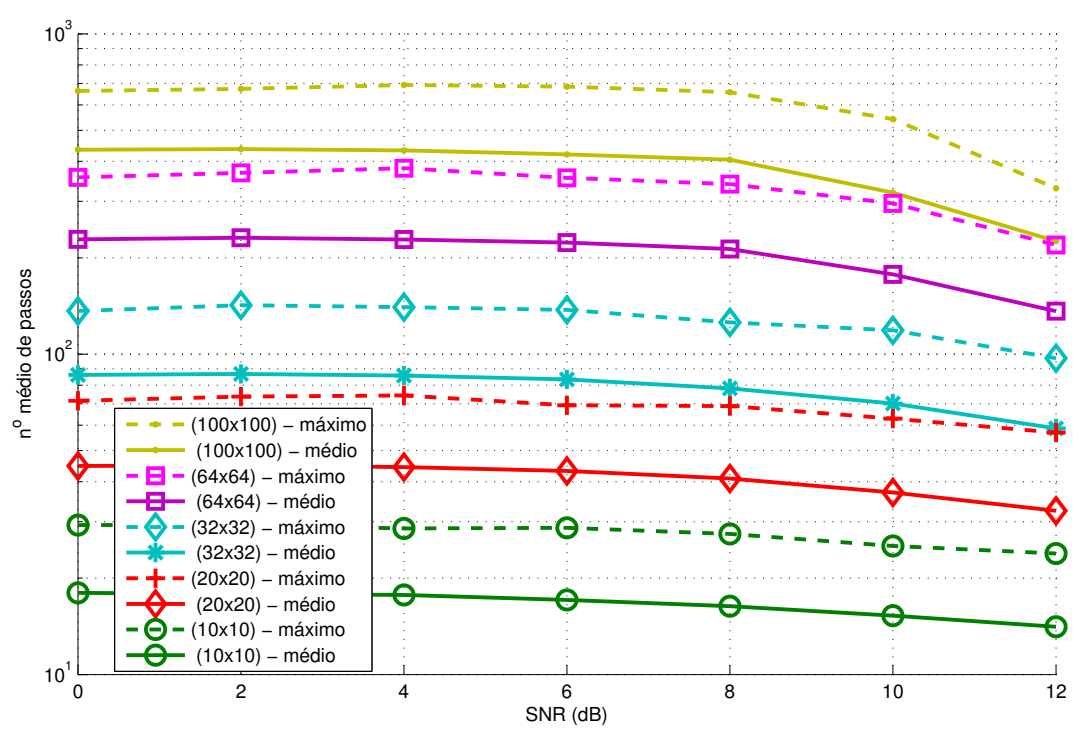

Figura 3.6: Número máximo e médio de passos por SNR das buscas LAS do detector MMSE-SLAS em sistemas com modulação 4-QAM. 
passos, $N_{s}$ seja da forma:

$$
N_{s}=c_{1} N^{k}
$$

essas curvas em escala log-log podem ser empregadas para estimar o expoente $k$ por meio da observação das suas inclinações da seguinte forma: aplicando o operador $\log (\cdot)$ em $(3-13)$, tem-se:

$$
\begin{gathered}
\log \left(N_{s}\right)=\log \left(c_{1}\right)+\log \left(N^{k}\right) \\
\log \left(N_{s}\right)=k \log (N)+\log \left(c_{1}\right) .
\end{gathered}
$$

Portanto, pela comparação das inclinações das curvas do número médio de passos por $N$ e das curvas lineares e quadráticas da Figura 3.7, pode-se concluir que o número médio de passos em cada busca do detector SLAS com $N_{t}=N_{r}=N$ não é maior que $c_{1} N^{2}$, em que $c_{1}$ é uma constante, conforme mencionado anteriormente. Verifica-se ainda a partir dessas curvas que o número médio de passos efetuados pelo detector MF-SLAS é maior do que o do detector MMSE-SLAS.

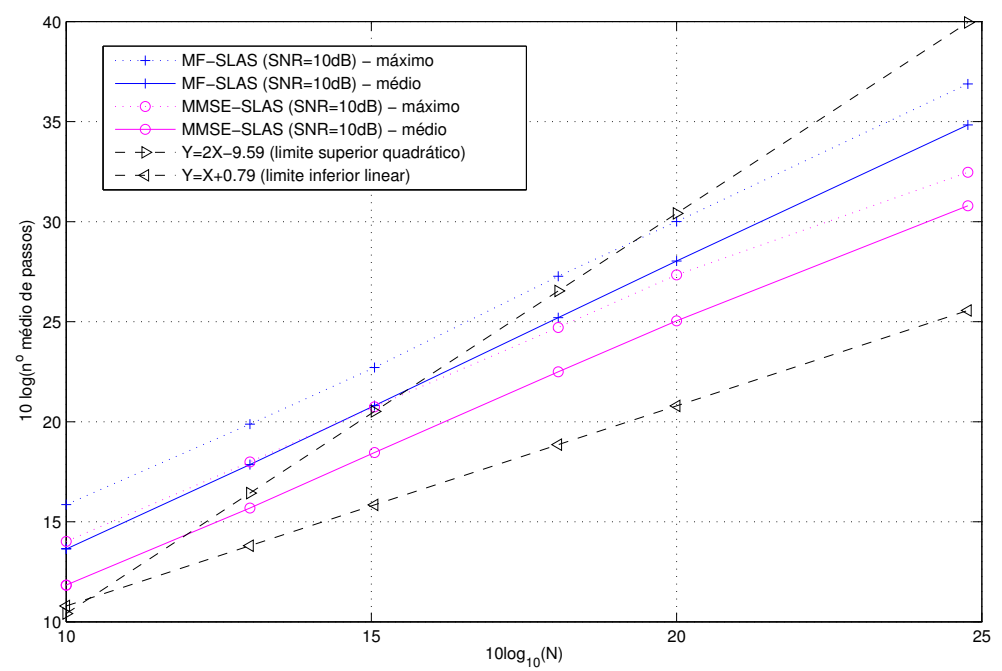

Figura 3.7: Número médio de passos por $N_{r}=N_{t}=N$ dos detectores MFSLAS e MMSE-SLAS em sistemas MIMO com modulação 4-QAM.

A complexidade computacional total do detector SLAS pode ser analisada por meio da observação do número médio de flops por bit transmitido, como ilustrado nas Figuras 3.8 até 3.11. Na Figura 3.8, curvas do número médio de flops por bit transmitido pela SNR são apresentadas para os detectores MF-SLAS e MMSE-SLAS. Embora, como visto anteriormente, o número de passos possa variar com a SNR, o número médio de flops destes detectores não depende da SNR, como pode ser observado nesta figura. Este fato explica-se 
uma vez que a complexidade total destes detectores é influenciada por fatores que dependem da SNR, como o próprio número de passos da busca, e por fatores que independem da SNR, como o número de operações necessárias para obter o vetor de símbolos candidatos inicial. Como a parcela da complexidade que independe da SNR no detector SLAS é bem maior que a que depende da SNR, especialmente para sistemas com muitas antenas, aliado ao fato de que o número de passos não varia drasticamente com a SNR, a complexidade total do detector tende a tornar-se independente da SNR.
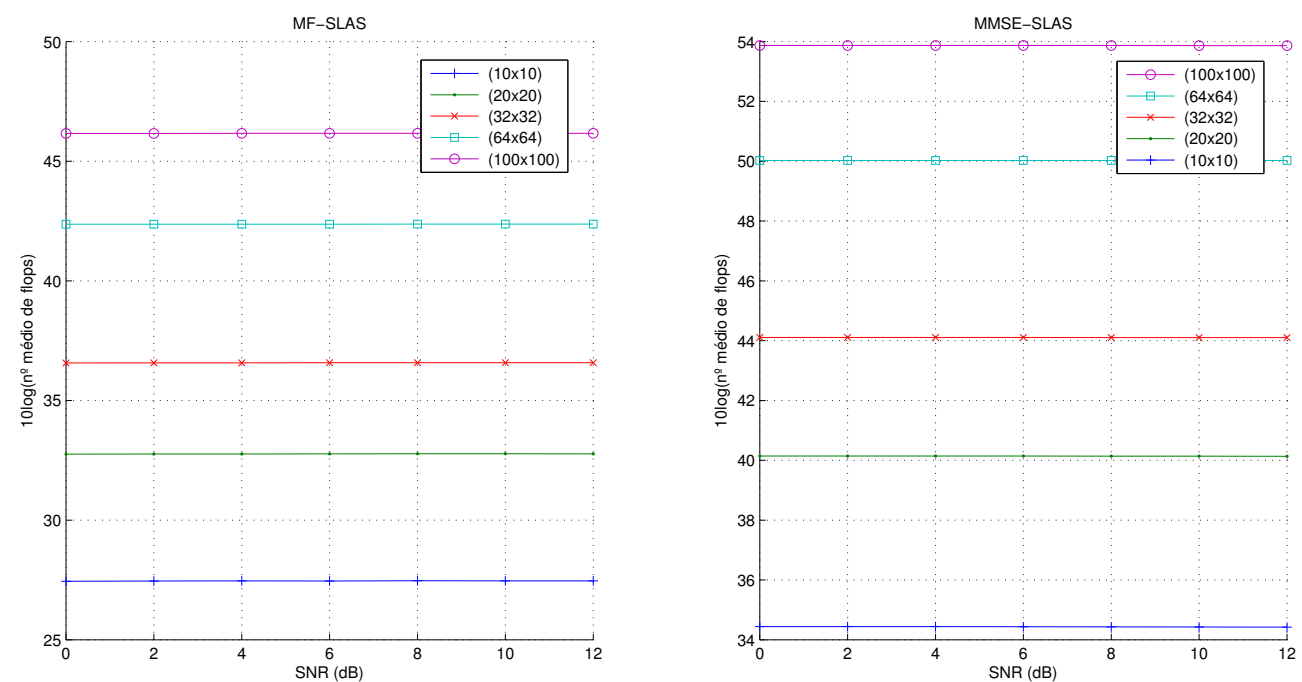

Figura 3.8: Curvas do número médio de flops por bit transmitido pela SNR dos detectores MF-SLAS and MMSE-SLAS em sistemas com modulação 4-QAM.

Os resultados apresentados na Figura 3.9 foram obtidos em simulações nas quais o número de antenas receptoras foi mantido constante, $N_{r}=32$. Pode ser notado que o detector MF-SLAS apresentou menor complexidade do que o MMSE-SLAS. Cabe ressaltar que nestas simulações os filtros de detecção MF e MMSE foram reavaliados a cada transmissão, ou seja, a matriz de coeficientes de canal varia a cada uso do canal. Nesta figura, além dos resultados das simulações, representados pelos marcadores, são apresentadas as curvas obtidas por meio de ajustes lineares desses resultados. Estas curvas foram obtidas empregando-se a ferramenta aberta de ajuste de curvas do Matlab, cftool. As linhas tracejadas representam os limites superiores e inferiores de um intervalo de confiança de $95 \%$ para o resultado do ajuste efetuado. Analogamente ao realizado em (3-14), assumindo que o número médio de flops é proporcional a $N_{t}^{k}$, o expoente $k$ pode ser deduzido pela inclinação da curva apresentada na Figura 3.9. Para o detector MF-SLAS, o limite superior do intervalo de confiança de $95 \%$ apresenta uma inclinação de $k_{M F}=0.9364$, portanto, 
a complexidade total desse detector não é maior que $\mathcal{O}\left(N_{t}\right)$. Para o caso MMSE-SLAS, tanto o limite superior quanto o limite inferior apresentam inclinações maiores que $1\left(k_{M M S E}^{\text {sup }}=1.364\right.$ e $\left.k_{M M S E}^{\text {inf }}=1.096\right)$. Sendo assim, a complexidade total do MMSE-SLAS para valores fixos de $N_{r}$ é maior que $\mathcal{O}\left(N_{t}\right)$.

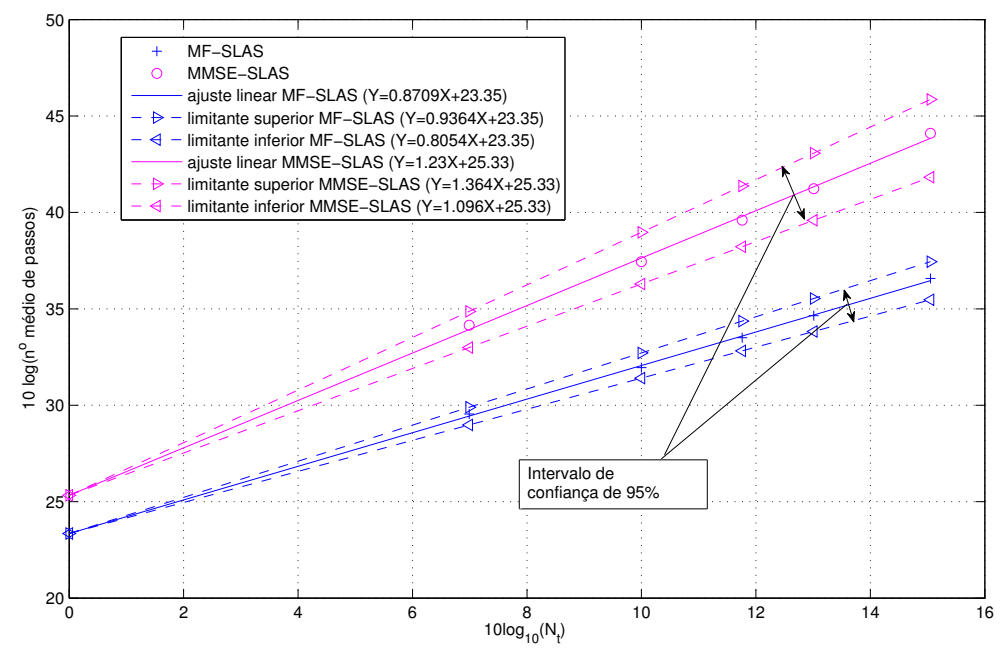

Figura 3.9: Número médio de flops por $N_{t}$ dos detectores MF-SLAS e MMSESLAS para sistemas com $N_{r}=32$ e modulação 4-QAM.

A Figura 3.10 apresenta resultados similares, porém, neste caso, $N_{t}=5$ foi mantido constante durante a simulação. As curvas resultantes dos limites do intervalo de confiança indicam que tanto o detector MF-SLAS quanto o MMSE-SLAS apresentam complexidades computacionais menores que $\mathcal{O}\left(N_{r}\right)$ $\left(k_{M F}^{u p p e r}=0.9227\right.$ e $\left.k_{M M S E}^{u p p e r}=0.5066\right)$. Esta complexidade de ordem linear só é possível para o detector MMSE-SLAS, a despeito da inversão de matrizes, pois manteve-se fixo o valor de $N_{t}$. Apesar de ter apresentado menores valores de complexidade para o intervalo de SNR considerado, a maior inclinação da curva ajustada do detector MF-SLAS indica que, para um valor fixo de $N_{t}$, este detector eventualmente ficará mais complexo que o MMSE-SLAS à medida em que o número de antenas de recepção for aumentado. Destaca-se que a diferença de complexidade entre os detectores MMSE-SLAS e MF-SLAS, para valores pequenos de $N_{r}$, aumenta com $N_{t}$ devido à diferença de complexidade na obtenção dos resultados das detecções MMSE e MF empregados como vetores de símbolos candidatos iniciais.

A Figura 3.11 apresenta os resultados de número médio de flops por bit transmitido por $N_{t}=N_{r}=N$. Neste caso, as curvas ajustadas e seus intervalos de confiança indicam que ambos os detectores SLAS apresentam complexidade menor que $\mathcal{O}\left(N^{2}\right)$ quando os números de antenas transmissoras e receptoras 


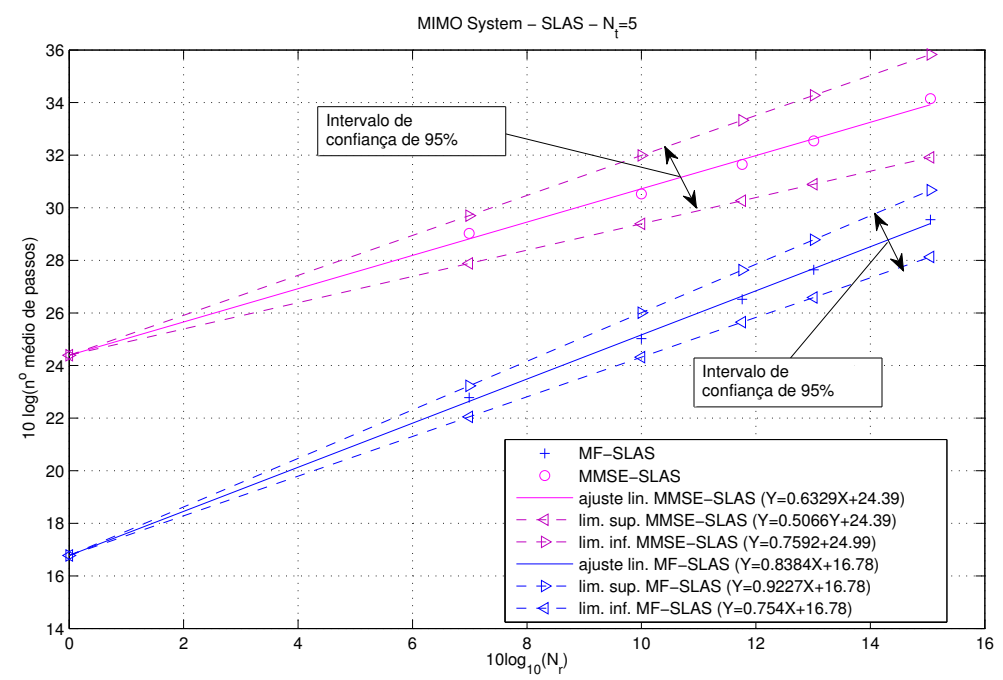

Figura 3.10: Número médio de flops por $N_{r}$ dos detectores MF-SLAS e MMSESLAS para sistemas com $N_{t}=5$ e modulação 4-QAM.

são mantidos iguais, uma vez que $k_{M F}^{\text {sup }}=1.958$ e $\left.k_{M M S E}^{\text {sup }}=1.982\right)$. Neste caso, a complexidade do detector MF-SLAS mantém-se menor do que a do MMSE-SLAS mesmo quando $N$ cresce.

Finalizando a análise de complexidade do detector SLAS, realizouse simulações em que os números de antenas transmissoras e receptoras foram variados de forma independente. Os resultados dessas simulações foram empregados como entrada da ferramenta de ajuste de superfície do Matlab, sftool, cujos resultados são apresentados nas Figuras 3.12 e 3.13 para os detectores MF-SLAS e MMSE-SLAS, respectivamente, com modulação 4QAM. De forma similar ao realizado anteriormente, assume-se que o número médio de flops é proporcional a $N_{t}^{k_{1}} N_{r}^{k_{2}}$. Nos resultados do ajuste de superfície apresentados nas figuras, as variáveis $x=10 \log \left(N_{t}\right)$ e $y 1=10 \log \left(N_{r}\right)$ são as entradas do procedimento de ajuste e $z 1=10 \log \left(n^{\circ}\right.$ médio de flops) a sua saída. Como pode ser observado, os parâmetros ajustados sugerem que a complexidade do detector MF-SLAS não é maior do que $\mathcal{O}\left(N_{t} N_{r}\right)\left(k_{1}=0.9334\right.$, $\left.k_{2}=0.9422\right)$ e que a complexidade do MMSE-SLAS é maior do que $\mathcal{O}\left(N_{t} N_{r}\right)$ $\left(k_{1}=1.209, k_{2}=0.7526\right)$. 


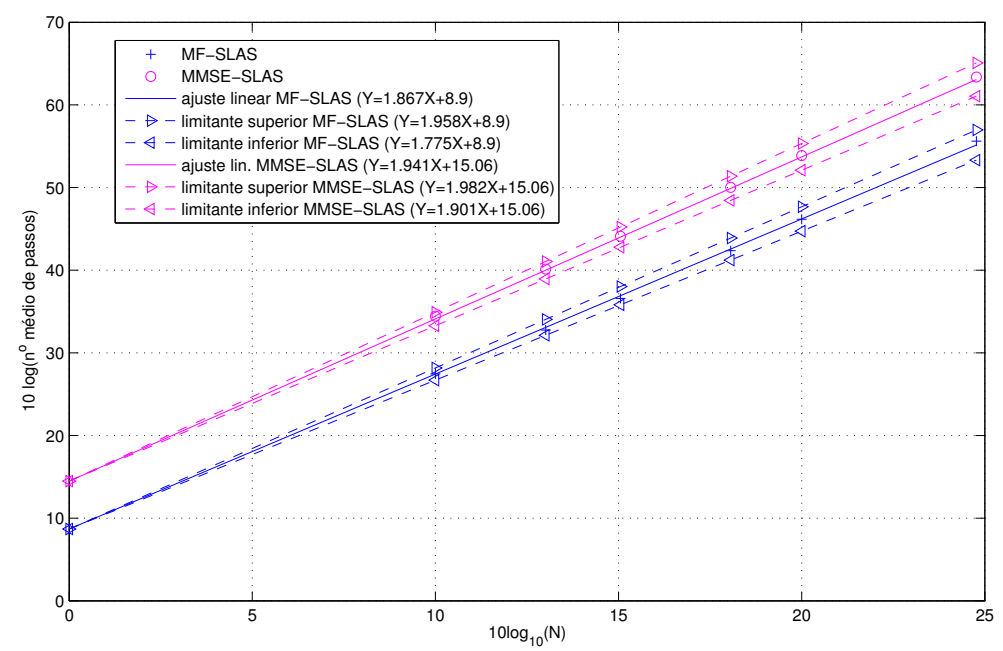

Figura 3.11: Número médio de flops por $N_{t}=N_{r}=N$ dos detectores MFSLAS e MMSE-SLAS para sistemas com modulação 4-QAM.

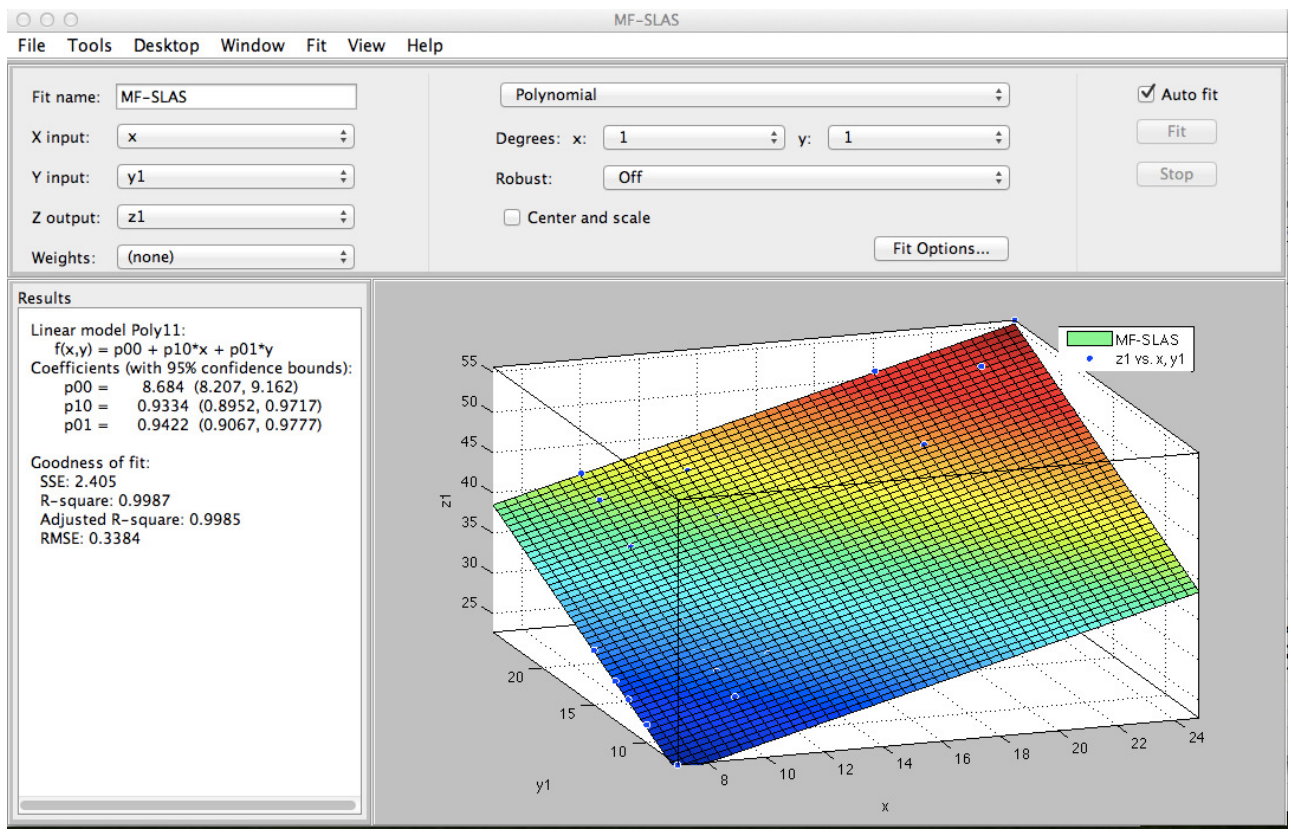

Figura 3.12: Ajuste de superfície para o detector MF-SLAS. 


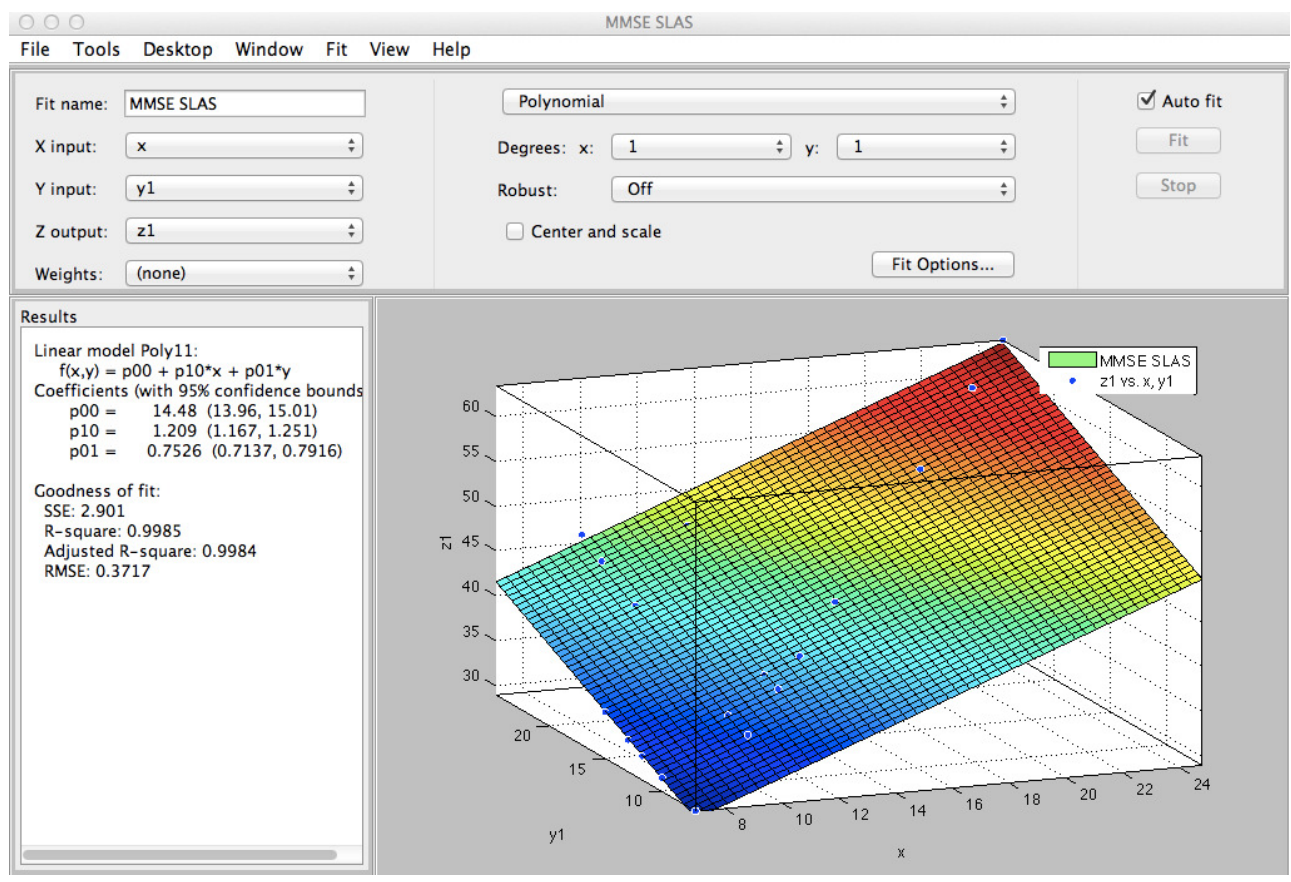

Figura 3.13: Ajuste de superfície para o detector MMSE-SLAS.

\section{3}

\section{Detectores baseados na busca LAS}

Motivados pela redução na complexidade computacional com bons resultados em termos de BER dos detectores SLAS, diversos detectores baseados na estratégia LAS foram desenvolvidos. Nesta seção, alguns destes detectores são descritos e, na próxima seção, seus desempenhos em termos de BER e número médio de operações serão comparados.

\subsection{1}

\section{LAS Multiestágio}

Em [21], o detector Multistage LAS (MLAS) foi proposto. Este detector consiste essencialmente em uma sequência de buscas LAS em série, cada qual empregando conjuntos de candidatos de busca com cardinalidade crescente, sendo a primeira busca LAS (primeiro estágio) com SCS unitários, i.e., a diferença entre o vetor de símbolos candidato em um passo durante a busca e o vetor do próximo passo é de apenas 1 símbolo $(|L(n)|=1)$. Uma vez terminada a busca LAS do primeiro estágio, a sua saída é tomada como entrada da busca LAS do segundo estágio, no qual emprega-se SCS com cardinalidade 2, ou seja, atualização de 2 símbolos em cada passo da busca LAS $(|L(n)|=2)$. Terminada a busca do segundo estágio, sua saída constitui a entrada do próximo estágio $(|L(n)|=3)$, e assim sucessivamente.

Diferentemente do procedimento de busca LAS descrito para o algoritmo 
SLAS, as buscas LAS efetuadas no detector MLAS não seguem um SCS prédeterminado. Para o SLAS, a sequência de índices de símbolos do vetor de símbolos candidato a serem testados para possível troca é pré-determinada pela sequência de conjuntos $L(n)$. Caso a troca do símbolo na posição determinada em $L(n)$ gere uma diferença positiva na métrica de verossimilhança $(\Delta \Lambda(\Delta \mathbf{d}(n))>0)$, este símbolo é trocado e, caso contrário, mantém-se o símbolo daquela posição e passa-se para o próximo passo da busca. Já no algoritmo empregado no MLAS, a cada passo da busca, o algoritmo troca os símbolos (1 símbolo no primeiro estágio, 2 no segundo etc.) que irão provocar o maior aumento na métrica de verossimilhança. Caso este aumento máximo não seja maior que zero, significa que a busca encontrou um ponto de máximo local e o algoritmo MLAS passa para o próximo estágio.

A título de exemplo, considere o primeiro estágio do detector MLAS. Neste estágio, assumindo que o $p$-ésimo símbolo seja atualizado no passo $(n+1)$, o vetor diferença $\Delta \mathbf{d}(n)$ pode ser escrito como:

$$
\Delta \mathbf{d}(n)=\Delta d_{p}(n) \mathbf{e}_{p}
$$

em que $\mathbf{e}_{p}$ é o vetor unitário com o $p$-ésimo elemento igual a 1 e os demais iguais a 0 .

Empregando as equações (3-15), (3-10) e (3-11), a variação na métrica de verossimilhança é dada por:

$$
\Delta \Lambda\left(\Delta d_{p}(n)\right)=2 \operatorname{Real}\left\{\Delta d_{p}^{*}(n) g_{p}(n)\right\}-\left\|\Delta d_{p}(n)\right\|^{2} h_{e f f_{p, p}}
$$

em que $\Delta d_{p}(n)$ é calculado pela seguinte maximização:

$$
\Delta d_{p}(n)=\underset{\Delta d_{p}}{\operatorname{argmax}} \Delta \Lambda\left(\Delta d_{p}\right)
$$

Cabe relembrar que, conforme observado anteriormente, os possíveis valores de $\Delta d_{p}$ dependem da constelação de símbolos empregada e da $p$-ésima entrada do vetor de símbolos candidatos atual, $\mathbf{d}(n)$. Por exemplo, para a constelação 4-QAM formada pelos símbolos $[1+j, 1-j,-1-j,-1+j]$, se o símbolo da $p$-ésima posição de $\mathbf{d}(n)$ for $d_{p}(n)=1+j$, os possíveis valores de $\Delta d_{p}$ são $[-2,-2 j,-2-2 j]$.

A posição $s$ do símbolo que será realmente escolhido para atualização no passo atual é encontrada pela maximização:

$$
s=\underset{p \in\left[1, \cdots, N_{t}\right]}{\operatorname{argmax}} \Delta \Lambda\left(\Delta d_{p}(n)\right) .
$$

Se em determinado passo da busca $\Delta \Lambda\left(\Delta d_{s}(n)\right)$ não for positivo, o primeiro estágio termina e o algoritmo passa ao segundo estágio.

Desenvolvimento similar pode ser realizado para os demais estágios do 
algoritmo MLAS. Para o segundo estágio, que consiste na atualização de dois símbolos do vetor de símbolos candidatos a cada passo, as equações (3-15)-(318) se tornam:

$$
\begin{gathered}
\Delta \mathbf{d}(n)=\Delta d_{p}(n) \mathbf{e}_{p}+\Delta d_{q}(n) \mathbf{e}_{q} \\
\Delta \Lambda\left(\Delta d_{p}(n), \Delta d_{q}(n)\right)= \\
=2 \operatorname{Real}\left\{\Delta d_{p}^{*}(n) g_{p}(n)+\Delta d_{q}^{*}(n) g_{q}(n)-\Delta d_{p}^{*}(n) h_{e f f_{p, q}} \Delta d_{q}(n)\right\}- \\
\left\|\Delta d_{p}(n)\right\|^{2} h_{e f f_{p, p}}-\left\|\Delta d_{q}(n)\right\|^{2} h_{e f f_{q, q}}
\end{gathered}
$$

nas quais $\Delta d_{p}(n)$ e $\Delta d_{q}(n)$ são calculadas por meio da maximização conjunta

$$
\left[\Delta d_{p}(n), \Delta d_{q}(n)\right]=\underset{\left(\Delta d_{p}, \Delta d_{q}\right)}{\operatorname{argmax}} \Delta \Lambda\left(\Delta d_{p}, \Delta d_{q}\right) .
$$

Os índices $s$ e $t$ das posições que serão efetivamente atualizadas são dados por:

$$
(s, t)=\underset{(p, q) \in\left[(1,1), \cdots,\left(N_{t}, N_{t}\right)\right]}{\operatorname{argmax}} \Delta \Lambda\left(\Delta d_{p}(n), \Delta d_{q}(n)\right) .
$$

$\mathrm{O}$ detector MLAS atinge melhores resultados (mais próximos ao detector ML) conforme o número de estágios cresce. Por outro lado, no k-ésimo estágio, o problema de encontrar as posições do vetor de símbolos candidatos a serem efetivamente atualizadas envolve a avaliação da métrica de verossimilhança para $N_{t}^{k}(M-1)$ vetores distintos. Sendo assim, a complexidade total por símbolo transmitido do detector MLAS é, pelo menos, da ordem de $\mathcal{O}\left(N_{t}^{K-1}(M-1)\right)$. A fim de limitar essa complexidade, em [21], foi considerado o detector MLAS com 3 estágios $(k=3)$.

As Figuras 3.14 e 3.15 apresentam curvas de BER e número médio de flops por bit transmitido, respectivamente, para o detector MLAS aqui apresentado. Estas curvas foram obtidas por meio da média de 1000 ensaios independentes de simulações de Monte Carlo da transmissão de um quadro de 10 vetores de símbolos 4-QAM em um canal de acordo com o cenário A, detalhado no Capítulo 2. Estes resultados mostram que, como no caso SLAS, ao passo em que o número de antenas aumenta, a BER se aproxima do resultado de um sistema SISO sujeito a um canal AWGN. Observa-se também que, como esperado, a BER diminui com o aumento do número de estágios empregados no detector MLAS. Além disso, o emprego do resultado da detecção por um filtro MMSE como vetor candidato inicial do primeiro estágio (MMSE-MLAS) gera melhores resultados do que quando emprega-se o resultado da detecção por filtro casado (MF-MLAS).

Em relação ao número médio de flops por bit transmitido, a complexidade do detector MLAS aumenta com o número de estágios, conforme esperado. Ademais, como pode ser observado na Figura 3.15, o detector MMSE-MLAS possui maior complexidade computacional devido ao custo inicial de obtenção 


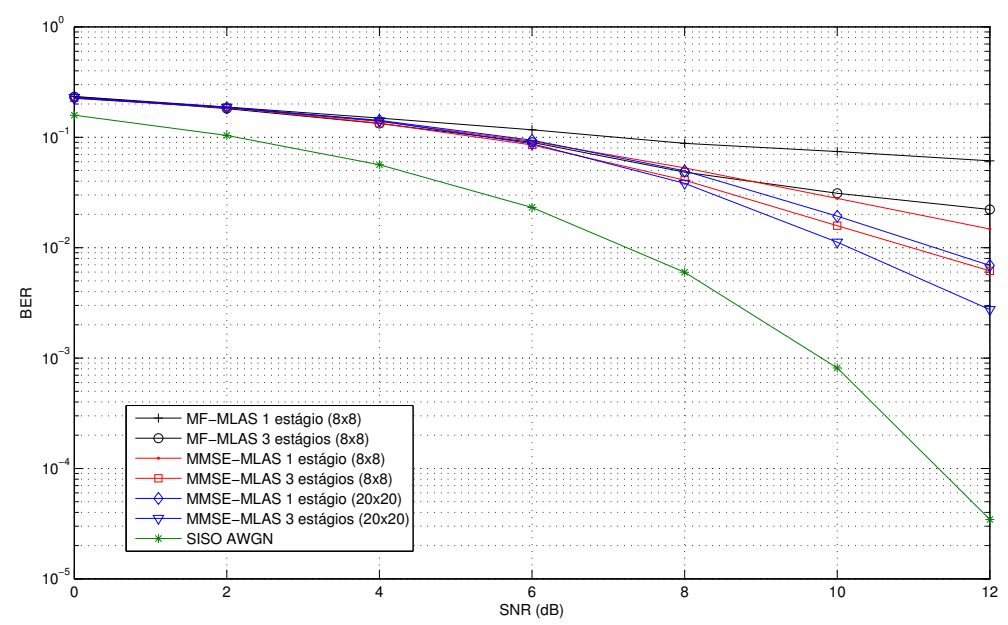

Figura 3.14: Curvas de BER pela SNR de detectores MLAS com modulação 4-QAM.

do vetor de símbolos candidatos inicial.

\subsection{2}

\section{Algoritmos LAS com Seleção de Saídas Múltiplas}

Em [22] duas estratégias para melhorar o desempenho em termos de BER do algoritmo SLAS foram propostas. Ambas objetivam evitar máximos locais por meio da geração de diferentes buscas LAS, das quais é selecionado o resultado da busca com maior métrica de verossimilhança. Por meio desse procedimento, espera-se aumentar a probabilidade de que o resultado final do detector seja o vetor com máxima métrica de verossimilhança globalmente, i.e., o resultado de uma detecção ML. Esses detectores fazem parte da classe de detectores baseados na busca LAS chamada de LAS com seleção de saídas múltiplas (Multiple Output Selection LAS - MOS-LAS) e são descritos a seguir.

\subsubsection{1}

\section{Algoritmo LAS com Múltiplos Vetores de Entrada (MIV-LAS)}

As operações efetuadas pelo detector MIV-LAS são enumeradas a seguir:

1) Produção de $K$ vetores de símbolos candidatos iniciais $\mathbf{d}_{1}(0), \mathbf{d}_{2}(0) . \cdots, \mathbf{d}_{K}(0)$;

2) Obtenção de $K$ resultados do algoritmo SLAS, cada um empregando um dos vetores de símbolos candidatos iniciais obtidos anteriormente no passo $1)$;

3) Seleção do vetor de símbolos resultado das buscas efetuadas no passo 2) com maior valor da métrica de verossimilhança da equação (3-1) como 


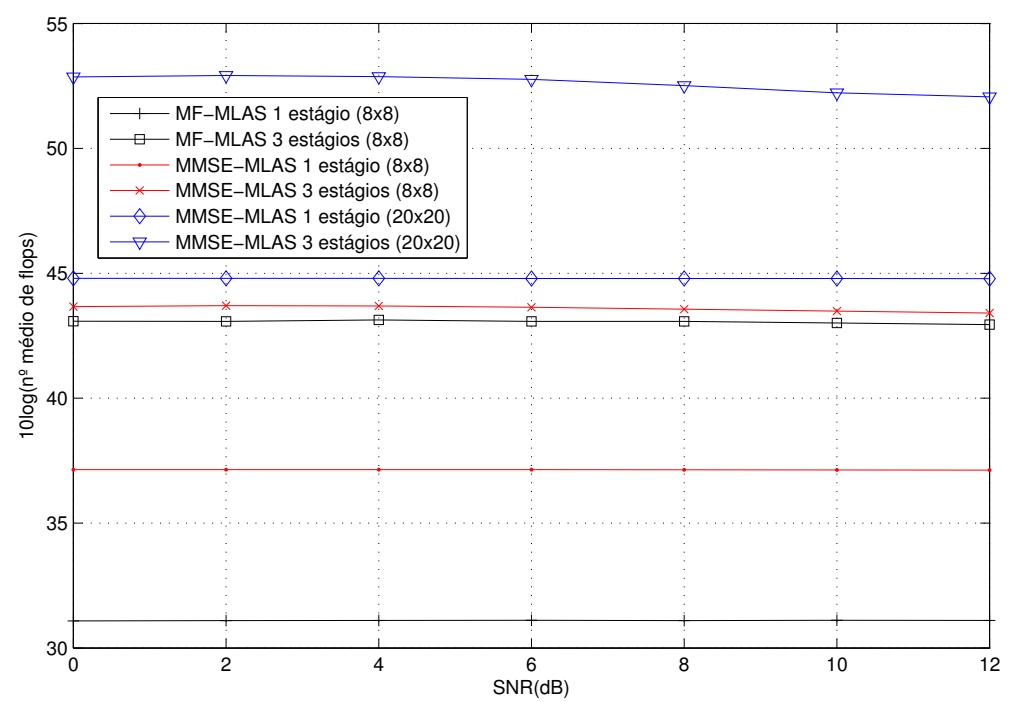

Figura 3.15: Curvas do número médio de flops por bit transmitido pela SNR de detectores MLAS com modulação 4-QAM.

resultado final da detecção.

Cabe observar que os vetores iniciais do passo 1) não são necessariamente oriundos de detectores conhecidos, podendo ser inclusive vetores de símbolos escolhidos aleatoriamente. Apesar disso, os resultados das detecções MF, ZF e MMSE podem ser empregados como vetores candidatos iniciais originando o chamado MF/ZF/MMSE-MIV-LAS. Quando empregam-se $K$ vetores de símbolos candidatos iniciais escolhidos aleatoriamente, o detector resultante é denominado de $K$ R-MIV-LAS.

\subsubsection{2}

Algoritmo LAS com Múltiplos Conjuntos de Candidatos de Busca (MSCSLAS)

A outra abordagem proposta em [22] emprega diversas buscas LAS cada uma com sua sequência de SCS distinta, porém todas com o mesmo vetor de símbolos candidatos inicial. Em [22], os autores sugerem o emprego do resultado da detecção MMSE como vetor de símbolos candidatos inicial, visto que, em geral, o uso deste vetor produz os melhores resultados em termos de BER quando se tem apenas um vetor de símbolos candidatos inicial disponível.

As operações efetuadas pelo detector $K$-MSCS-LAS são enumeradas a seguir:

1) Obtenção de $K$ sequências de SCS circulares distintas, $L_{1}(n), L_{2}(n), \cdots, L_{K}(n)$. Estas sequências, por serem circulares, podem ser definidas pela sequência de índices a serem testados durante um período e são 
obtidas por permutações aleatórias da sequência $\left[\{1\},\{2\}, \cdots,\left\{N_{t}\right\}\right]$;

2) Obtenção de $K$ resultados de buscas MMSE-SLAS, em que cada busca emprega uma das sequência de SCS obtidas no passo anterior;

3) Seleção do vetor de símbolos resultado das buscas efetuadas no passo 2) com maior valor da métrica de verossimilhança da equação (3-1) como resultado final da detecção.

É interessante mencionar que, tanto no algoritmo MIV-LAS quanto no MSCS-LAS, não é garantido que todos os $K$ resultados das buscas SLAS sejam distintos.

De forma a obter-se curvas de BER e número médio de flops por SNR, simulações de Monte Carlo foram realizadas, cujos resultados são apresentados nas Figuras 3.16 e 3.17, respectivamente. Estes resultados são constituídos pelas médias de 1000 ensaios independentes da transmissão de um quadro de 10 vetores de símbolos 4-QAM em um canal de acordo com o cenário A, detalhado no Capítulo 2.
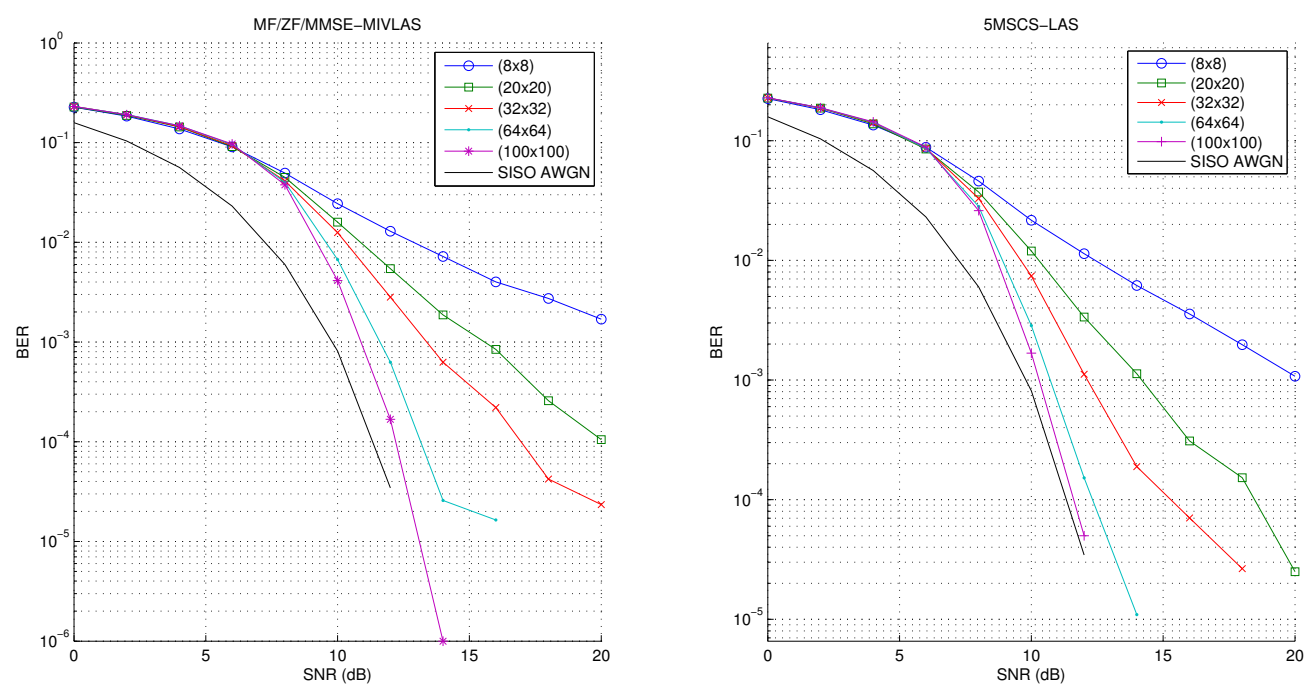

Figura 3.16: Curvas de BER pela SNR de detectores MOS-LAS com modulação 4-QAM.

A Figura 3.16 apresenta os resultados de BER para os detectores MF/ZF/MMSE-MIV-LAS e 5-MSCS-LAS. Novamente, da mesma forma que nos detectores SLAS, conforme o número de antenas aumenta, as curvas de BER se aproximam do resultado de BER de um sistema SISO AWGN. Porém esta melhoria com o número de antenas é bem mais acentuada, como pode ser observado ao se comparar as curvas desta figura com as da Figura 3.4. Além disso, verifica-se, para o cenário considerado, que o detector 5-MSCSLAS obteve melhores resultados do que o detector MF/ZF/MMSE-MIV-LAS. 

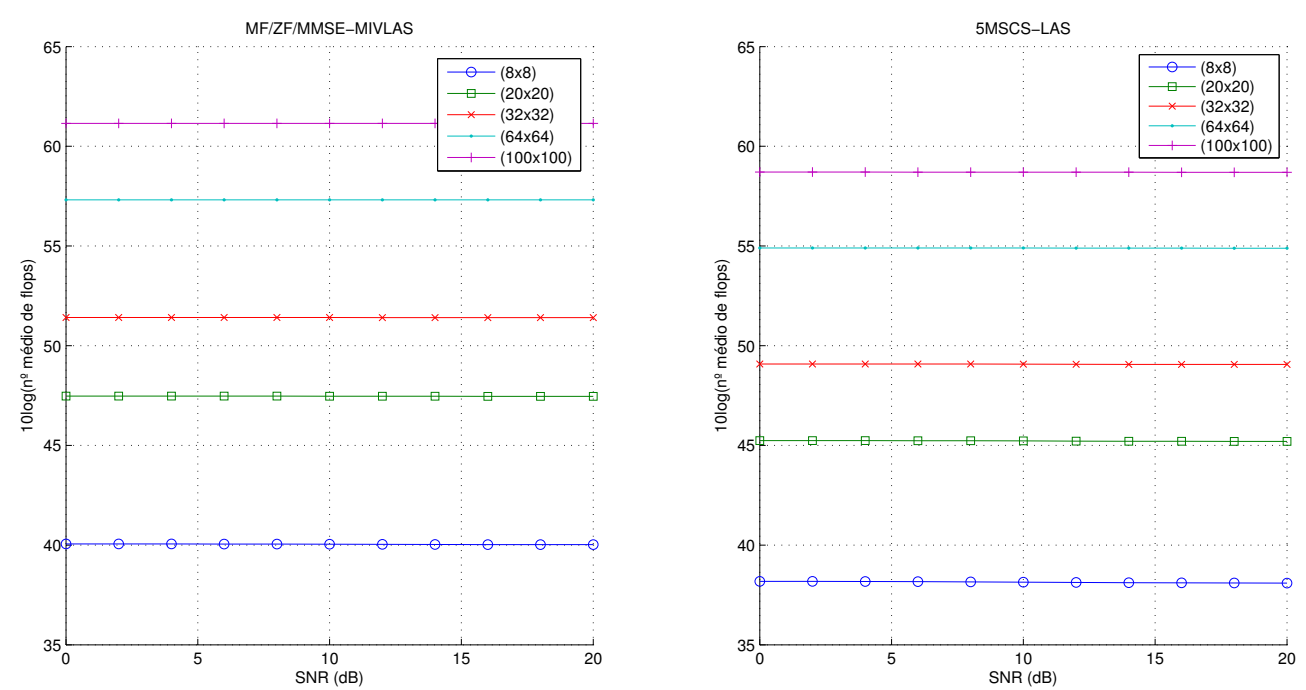

Figura 3.17: Curvas do número médio de flops por bit transmitido pela SNR de detectores MOS-LAS com modulação 4-QAM.

Na Seção 3.4, estes resultados serão comparados aos de outros detectores para os cenários A e B descritos no Capítulo 2.

Curvas de complexidade computacional em termos do número médio de flops por bit transmitido pela SNR são apresentadas na Figura 3.17. Observa-se que, similarmente ao detector SLAS, a complexidade computacional é invariante com a SNR. Estas curvas mostram que o detector MF/ZF/MMSE-MIVLAS possui maior complexidade computacional do que o 5-MSCS-LAS. Este fato justifica-se devido a maior complexidade em se obter os vetores de símbolos candidatos iniciais do MF/ZF/MMSE-MIV-LAS. Apesar de efetuar apenas 3 buscas LAS, enquanto que o 5-MSCS-LAS efetua 5, o MF/ZF/MMSE-MIVLAS necessita inverter duas matrizes de dimensões $\left(N_{t} \times N_{t}\right)$ na obtenção dos vetores candidatos inciais, ao passo em que o 5-MSCS-LAS apenas efetua a inversão de uma matriz de dimensões $\left(N_{t} \times N_{t}\right)$.

\subsection{3}

\section{Detector Random-List Based LAS}

Em [30], em decorrência dos trabalhos desta tese, outro algoritmo baseado na busca LAS foi proposto. De forma similar ao realizado nos detectores MOS-LAS, a ideia central do algoritmo RLB-LAS proposto também é a de se evitar os máximos locais por meio da condução de diversas buscas LAS e da escolha do melhor resultado destas buscas. Uma das principais diferenças entre o RLB-LAS e os detectores MOS-LAS é que o número de buscas efetuadas não é pré-definido, como no caso dos algoritmos MOS-LAS, mas sim controlado 
por um critério de parada, que depende do maior valor da métrica de verossimilhança dos vetores resultados das buscas realizadas até o momento. Essas buscas são efetuadas iterativamente, cada uma empregando um vetor de símbolos candidatos inicial distinto derivado do vetor inicial utilizado na primeira iteração (busca). Ao final de cada iteração, caso o critério de parada seja atingido, o algoritmo encerra e elege o vetor de símbolos detectados como sendo o vetor de símbolos resultado das buscas anteriores que obteve o maior valor da métrica de verossimilhança. Além disso, o detector RLB-LAS não efetua uma busca SLAS a cada iteração, mas sim uma busca MLAS com apenas 1 estágio, ou seja, não são empregados SCS predefinidos, sendo a posição a ser trocada do vetor de símbolos candidatos em cada passo das buscas aquela que produzirá o maior aumento na métrica de verossimilhança do vetor de símbolos candidatos.

De forma a manter a complexidade do algoritmo em níveis baixos, propõe-se o emprego do vetor resultado da detecção MF como vetor de símbolos candidatos inicial na primeira iteração. Neste caso, denota-se o detector resultante por MF-RLB-LAS. Analogamente, pode-se empregar o resultado da detecção MMSE como vetor de símbolos candidatos inicial, chegando-se, neste caso, ao detector MMSE-RLB-LAS. Resultados de simulações, que serão discutidas a seguir, mostram que os detectores MF-RLB-LAS e MMSE-RLBLAS apresentam BER similares.

Assumindo o emprego do vetor $\mathbf{d}^{(0)}$ como o vetor de símbolos candidatos inicial da primeira iteração, a saída da busca MLAS com apenas 1 estágio da primeira iteração é eleita como a decisão corrente do algoritmo, d. Para cada uma das iterações seguintes, os passos 1 a 7 são realizados:

1) Define-se $\mathbf{d}_{m}^{(0)}=\mathbf{d}^{(0)}$, em que $m$ denota a iteração atual;

2) Sorteia-se o valor $C$ de uma variável aleatória uniformemente distribuída sobre o conjunto de números inteiros $\left[1, \cdots, N_{t}\right]$ a fim de se escolher o número de símbolos a serem trocados do vetor $\mathbf{d}_{m}^{(0)}$;

3) Sorteia-se $C$ valores com mesma probabilidade e sem reposição do conjunto de inteiros $\left[1, \cdots, N_{t}\right]$ para formar o conjunto de índices, $\mathbf{i}=$ $\left[i_{1}, \cdots, i_{C}\right]$, de símbolos do vetor $\mathbf{d}_{m}^{(0)}$ a serem de trocados;

4) Para $l=1,2, \cdots, C$, seleciona-se $\mathbf{d}_{m}^{(0)}\left(i_{l}\right)$ da constelação de símbolos $\mathbb{B}$ aleatoriamente com mesma probabilidade. Os passos 1 a 4 definem o novo vetor de símbolos candidatos inicial a ser empregado na $m$-ésima iteração;

5) Efetua-se a busca MLAS com um estágio empregando $\mathbf{d}_{m}^{(0)}$ como vetor de símbolos candidatos inicial;

6) Caso a métrica de verossimilhança do resultado da busca da iteração atual seja maior que a métrica de verossimilhança da solução corrente, atualiza- 
se a solução corrente como o resultado da busca da iteração atual;

7) Verifica-se o critério de parada. Se este não tiver sido atingido, passase para a próxima iteração. Caso contrário elege-se o vetor detectado como sendo o vetor da solução corrente.

O detector proposto é nomeado de RLB-LAS visto que os vetores de símbolos candidatos iniciais empregados em cada iteração são obtidos por meio de mudanças aleatórias do vetor de símbolos candidatos empregados na primeira iteração. De forma a completar o algoritmo, um critério de parada deve ser definido. Uma estratégia simples seria estabelecer um número fixo de iterações, $N_{p}$, o que pode não ser apropriado, causando perda de desempenho em termos de BER ou aumento desnecessário de complexidade, especialmente em situações de elevada SNR. De forma a contornar este problema, o número de iterações deve depender da qualidade da métrica de verossimilhança da solução corrente, d. Se esta qualidade for baixa, então um grande número de iterações necessita ser realizado de forma a evitar-se mínimos locais. Por outro lado, se a qualidade for alta, então um número menor de iterações é preferível. Neste trabalho utiliza-se a métrica de qualidade empregada em [52]. Ela é determinada em termos da proximidade do custo ML de um determinado vetor a um valor obtido empregando-se as estatísticas do custo ML de uma solução livre de erros.

Considerando os modelos apresentados anteriormente, o custo ML de um vetor de símbolos pode ser definido com base na métrica de verossimilhança da equação (3-1), por:

$$
\mathcal{C}(\mathbf{d})=\|\mathbf{y}-\mathbf{H} \mathbf{d}\|^{2} .
$$

Considerando o modelo do sinal recebido da equação (2-9), observa-se que o custo ML de uma detecção livre de erros corresponde a $\|\mathbf{n}\|^{2}$, que é uma variável aleatória com distribuição Chi-quadrada com $2 N_{r}$ graus de liberdade, que possui média $N_{r} \sigma_{n}^{2}$ e variância $N_{r} \sigma_{n}^{4}$. Dessa forma, a métrica de qualidade é definida como a diferença entre o custo ML do vetor em questão e a média de $\|\mathbf{n}\|^{2}$, dividida pelo seu desvio padrão, ou seja, a métrica de qualidade da solução corrente, $\phi(\mathbf{d})$, é dada por:

$$
\phi(\mathbf{d})=\frac{\|\mathbf{y}-\mathbf{H} \mathbf{d}\|^{2}-N_{r} \sigma_{n}^{2}}{\sqrt{N_{r}} \sigma_{n}^{2}} .
$$

Esta métrica é denominada de custo ML padronizado (standardized $M L$ cost) de $\mathbf{d}$ e quanto maior o seu valor, pior é a qualidade da solução corrente d. Sendo assim, é desejável que $N_{p}$ seja definido como uma função crescente de $\phi(\mathbf{d})$. Nesta tese, escolheu-se uma função linear. Além disso, um valor mínimo para $N_{p}$ foi estabelecido, i.e.: 


$$
N_{p}=\left\lceil\max \left(c_{1} \phi(\mathbf{d}), N_{p_{\min }}\right)\right\rceil
$$

em que $c_{1}$ é um parâmetro ajustável e $\lceil a\rceil$ representa o menor inteiro maior que $a$.

Como última observação em relação ao número de iterações a serem realizadas, destaca-se que a cada atualização da solução corrente o valor de $N_{p}$ também é atualizado conforme a equação (3-25). Esta atualização é necessária, uma vez que, especialmente no caso do MF-RLB-LAS, as soluções correntes nas primeiras iterações do algoritmo possuem métrica de verossimilhança menores que as soluções correntes de iterações posteriores, uma vez que esta solução só é atualizada se o resultado da busca da iteração atual possuir melhor métrica que a da solução corrente. Sendo assim, caso $N_{p}$ fosse avaliado na primeira iteração e não fosse atualizado, o número de iterações necessárias seria desnecessariamente elevado, aumentando dessa forma a complexidade do algoritmo. Ao final de cada iteração, caso o número de iterações já efetuadas seja maior que $N_{p}$, o algoritmo encerra e elege a solução corrente como o resultado final da detecção, visto que a solução corrente é o vetor de símbolos resultado cujo valor da métrica de verossimilhança é o maior dentre os resultados de todas as buscas LAS realizadas até o momento.

As curvas de BER e número médio de flops por bit transmitido por SNR para o detector MF-RLB-LAS, obtidas por meio de simulações de Monte Carlo, são apresentadas nas Figuras 3.18 e 3.19. Essas curvas são médias de 1000 ensaios independentes da transmissão de um quadro de 10 vetores de símbolos 4-QAM em um canal de acordo com o cenário A, detalhado no Capítulo 2. Em todas as simulações, o parâmetro $c_{1}$, necessário ao cálculo do número de iterações efetuadas pelo detector, foi escolhido igual a 5 e o número mínimo de iterações a serem realizadas considerado foi 2.

A Figura 3.18 apresenta os resultados de BER pela SNR do detector MF-RLB-LAS para diversos valores de $N_{t}=N_{r}=N$. Novamente, conforme o número de antenas aumenta, a BER se aproxima do resultado de um sistema SISO sujeito ao canal AWGN. Será mostrado na próxima seção que esse efeito ocorre com maior intensidade no detector MF-RLB-LAS do que nos demais detectores analisados, i.e., o número de antenas necessário para que as curvas de BER pela SNR do detector MF-RLB-LAS se aproxime dos resultados de sistemas SISO AWGN é menor do que o número de antenas necessário quando se empregam outros detectores baseados na busca LAS.

A Figura 3.19 ilustra o número médio de flops por bit transmitido pela SNR para diversos valores de $N_{t}=N_{r}$. Diferentemente dos detectores apresentados anteriormente, neste caso o número médio de flops aumenta com a SNR até um valor máximo para valores elevados da SNR. Esta característica explica- 


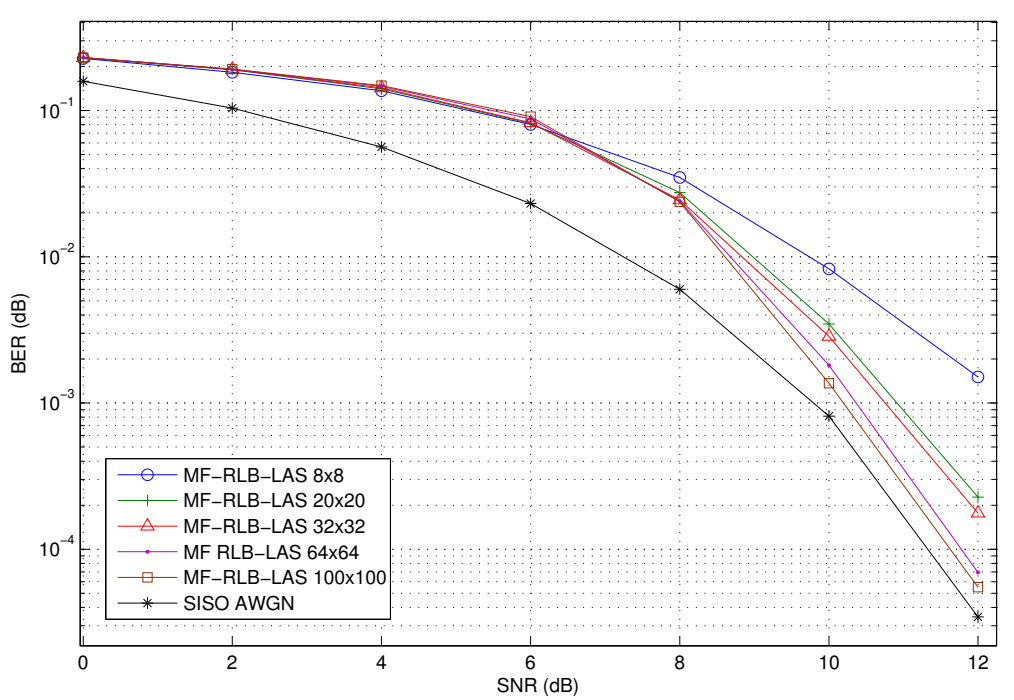

Figura 3.18: Curvas de BER pela SNR do detector MF-RLB-LAS com modulação 4-QAM.

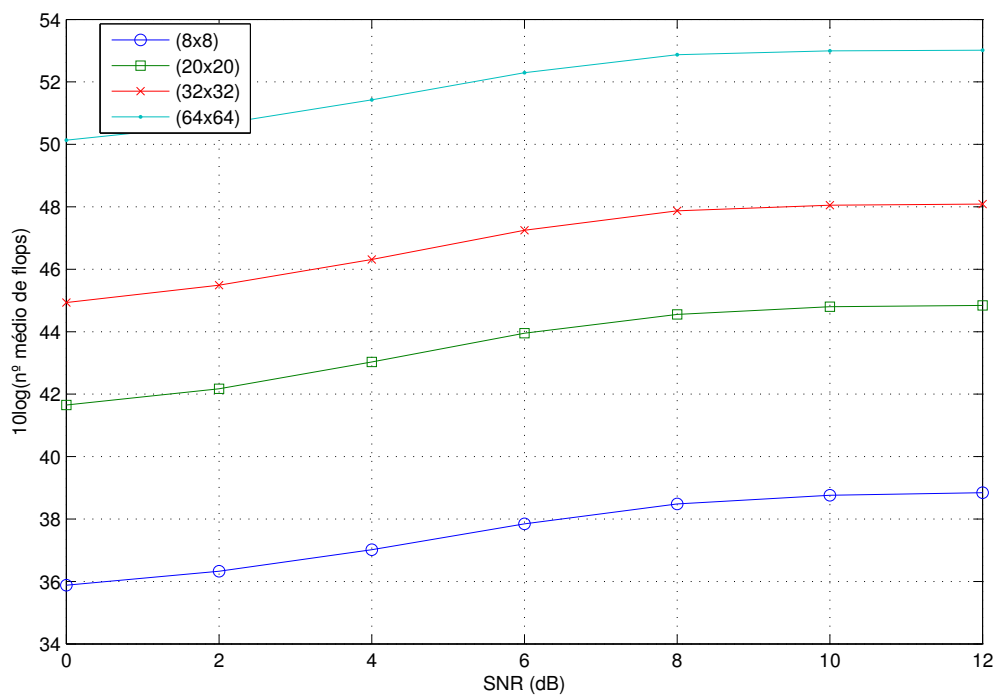

Figura 3.19: Curvas do número médio de flops pela SNR de detectores MFRLB-LAS com modulação 4-QAM. 
se por dois motivos: primeiramente, considera-se a incapacidade do detector MF, empregado para gerar o vetor de símbolos candidatos iniciais, em tratar a interferência espacial entre os símbolos transmitidos, principalmente para valores elevados da SNR, o que gera a necessidade de se efetuar mais iterações para valores de SNR elevados. Além disso, aumentando a SNR, aumenta-se a métrica de qualidade empregada no cálculo do número de iterações necessárias do algoritmo RLB-LAS, conforme equação (3-24). Ressalta-se, entretanto, que, se o número de iterações não fosse atualizado juntamente com a atualização da solução corrente de acordo com a equação (3-25), o número médio de flops não seria limitado a um valor máximo, conforme observado na Figura 3.19.

A Figura 3.20 a seguir apresenta, conforme realizado anteriormente, curvas em escala log-log do número médio de flops por $N_{t}=N_{r}=N$ do detector MF-RLB-LAS necessário para se alcançar uma BER alvo de $10^{-2}$, bem como curvas lineares e quadráticas que servem de limitantes para a curva de complexidade do detector MF-RLB-LAS. Como pode ser observado pela inclinação desta curva, comparando-as com as curvas limitantes, pode-se afirmar que a complexidade computacional do detector MF-RLB-LAS não é maior do que $\mathcal{O}\left(N^{2}\right)$.

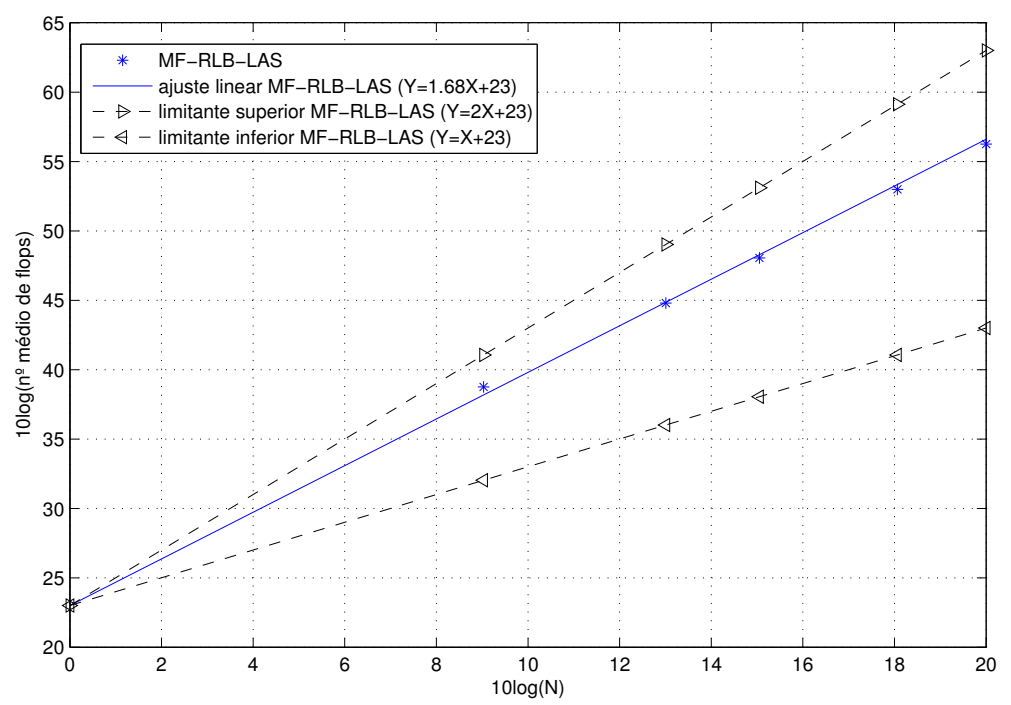

Figura 3.20: Curvas do número médio de flops por $N_{t}=N_{r}=N$ em escala log-log do detector MF-RLB-LAS com modulação 4-QAM.

\section{4}

\section{Comparação de Desempenho dos Detectores LAS}

Nesta seção, os desempenhos dos algoritmos de detecção baseados na busca LAS em termos de BER e complexidade computacional são discutidos e 
comparados. Para tanto, diversas simulações de Monte Carlo foram realizadas nas quais os cenários A e B, detalhados no capítulo 2 , foram considerados. O cenário A consiste em sistemas sujeitos a canais que apresentam desvanecimento plano e lento em que os efeitos da correlação entre as antenas de transmissão e entre as antenas de recepção, bem como os efeitos de sombreamento e perda de percurso, não são considerados. Já no cenário B, estes efeitos são incluídos no modelo do canal adotado. Os efeitos da correlação entre as antenas de transmissão e entre as antenas de recepção são incorporados ao modelo de canal por meio das matrizes de correlação da equação (2-23), definidas pelos índices de correlação $\rho_{t}$ e $\rho_{r}$, respectivamente, e os efeitos do sombreamento log-normal são incluídos por meio da variável aleatória $\beta_{k}$ conforme equação (2-27).

Os resultados aqui apresentados foram obtidos por meio da média de 1000 ensaios independentes da transmissão de um quadro de 10 vetores de símbolos de uma modulação 4-QAM. Para o cenário B, os índices de correlação empregados foram $\rho_{k}=\rho_{r}=0.2$ e considerou-se o espalhamento de sombreamento $\sigma_{k}=6 d B$. Os parâmetros do detector RLB-LAS empregados foram $c_{1}=5$ and $N_{p_{\min }}=2$. A SNR (em dB) foi definida, para ambos cenários, como $S N R(d B)=10 \log \left(\frac{N_{t}}{\sigma_{n}^{2}}\right)$. Além disso, considerou-se conhecidas as matrizes de coeficientes dos canais de todos os usuários pelo receptor.

Na Figura 3.21, as curvas de BER pela SNR dos detectores MF-RLBLAS, MMSE-RLB-LAS, MMSE-MLAS com 1 e 3 estágios, MF/ZF/MMSEMIV-LAS e 5-MSCS-LAS são apresentadas. Na Figura 3.22, além da curva de BER pela SNR do algoritmo MF-RLB-LAS, são apresentadas curvas de BER para dois outros detectores que empregam as técnicas de cancelamento de interferência serial (SIC) e cancelamento de interferência serial com múltiplos ramos (Multi-Branch - SIC-MB) $[47,53,54]$. Todos os resultados de simulação apresentados nestas figuras consideram o cenário A descrito anteriormente com $N_{t}=N_{r}=20$. Como pode ser observado em ambas as figuras, os detectores RLB-LAS alcançam melhores resultados em comparação com os demais detectores analisados. Considerando que ao passo em que o número de antenas do sistema aumenta os resultados de BER de todos detectores baseados na busca LAS se aproximam do resultado de BER de um sistema SISO sob canal AWGN, com base nos resultados apresentados nestas figuras, pode-se dizer que o algoritmo RLB-LAS necessita de um menor número de antenas para chegar ao resultado do sistema SISO AWGN. Além disso, observa-se na Figura 3.21 que as curvas de BER dos detectores MF-RLB-LAS e MMSE-RLBLAS são muito próximas. Dessa forma, não é necessário o emprego do resultado da detecção MMSE como vetor de símbolos candidatos iniciais, evitando assim a operação de inversão de matrizes correspondente. 


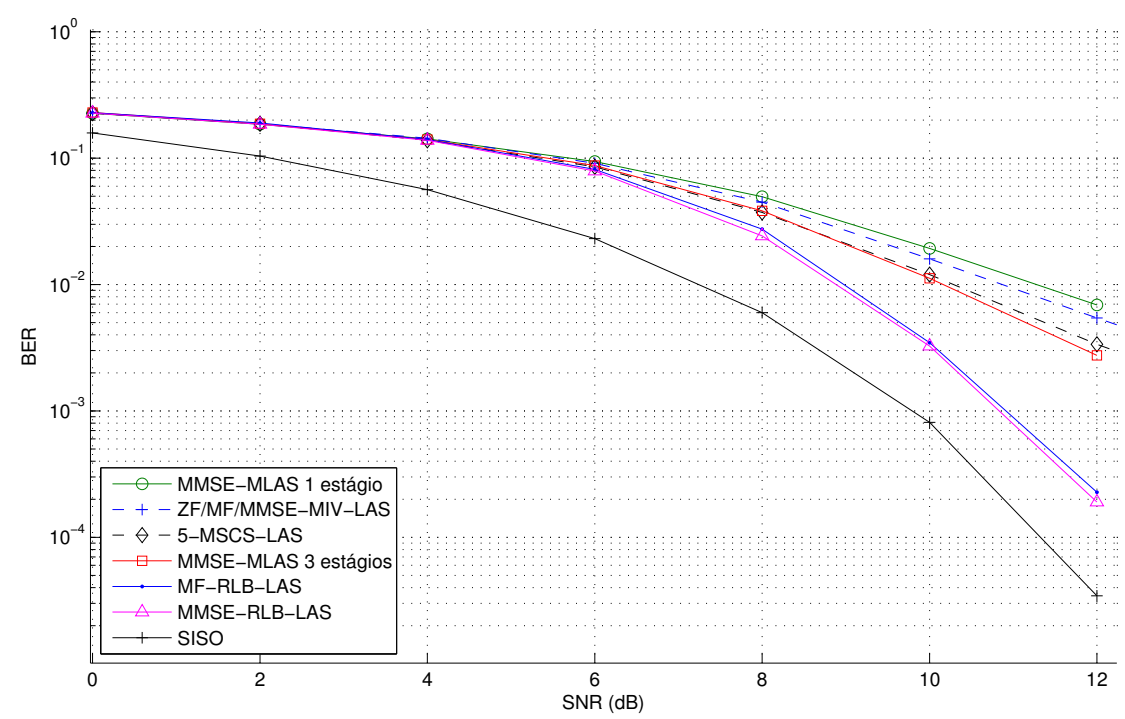

Figura 3.21: Curvas de BER pela SNR dos detectores MF-RLB-LAS, MMSERLB-LAS, MMSE-MLAS, MF/ZF/MMSE-MIV-LAS e 5-MSCS-LAS com modulação 4-QAM no cenário A e $N_{t}=N_{r}=20$.

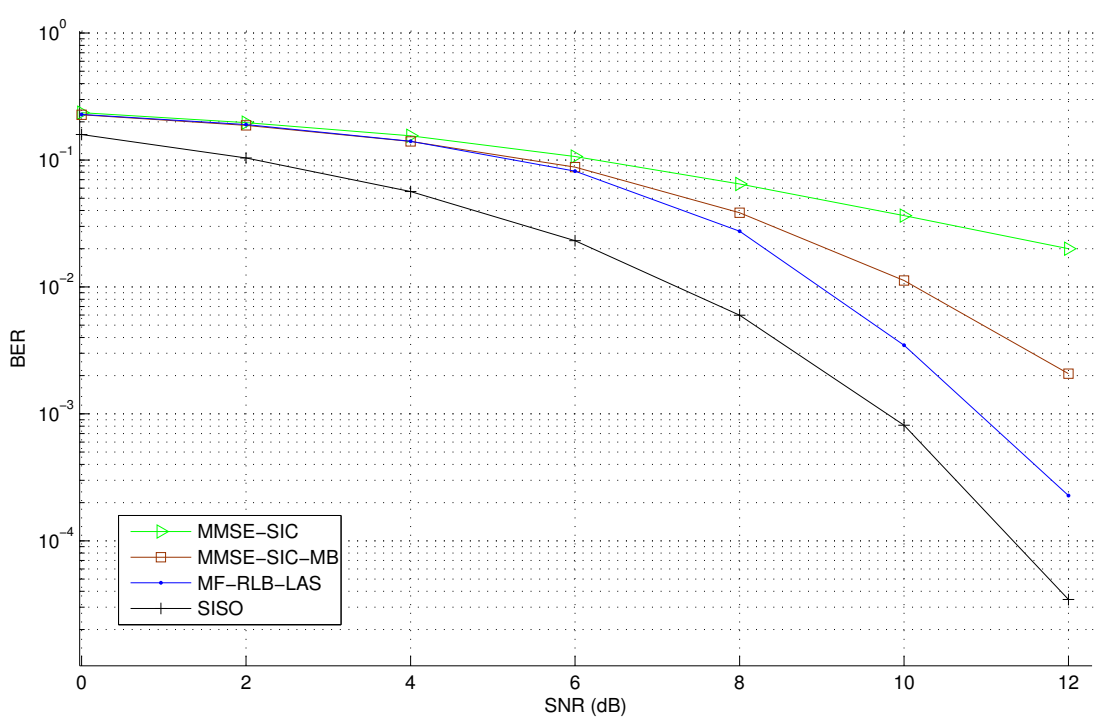

Figura 3.22: Curvas de BER pela SNR dos detectores MF-RLB-LAS, MMSESIC e MMSE-SIC-MB com modulação 4-QAM no cenário A e $N_{t}=N_{r}=20$. 
A Figura 3.23 ilustra os resultados de número médio de flops por bit transmitido pela SNR para os detectores MF-RLB-LAS, MMSE-RLBLAS, MMSE-SIC, MMSE-SIC-MB, ZF/MF/MMSE-MIV-LAS, 5-MSCS-LAS e MMSE-MLAS com 3 estágios considerando o cenário A para um sistema MIMO com $N_{t}=N_{r}=20$. Como pode ser observado nesta figura, apesar dos algoritmos MMSE-RLB-LAS e MF-RLB-LAS atingirem curvas de BER similares, o detector MF-RLB-LAS possui menor complexidade computacional.

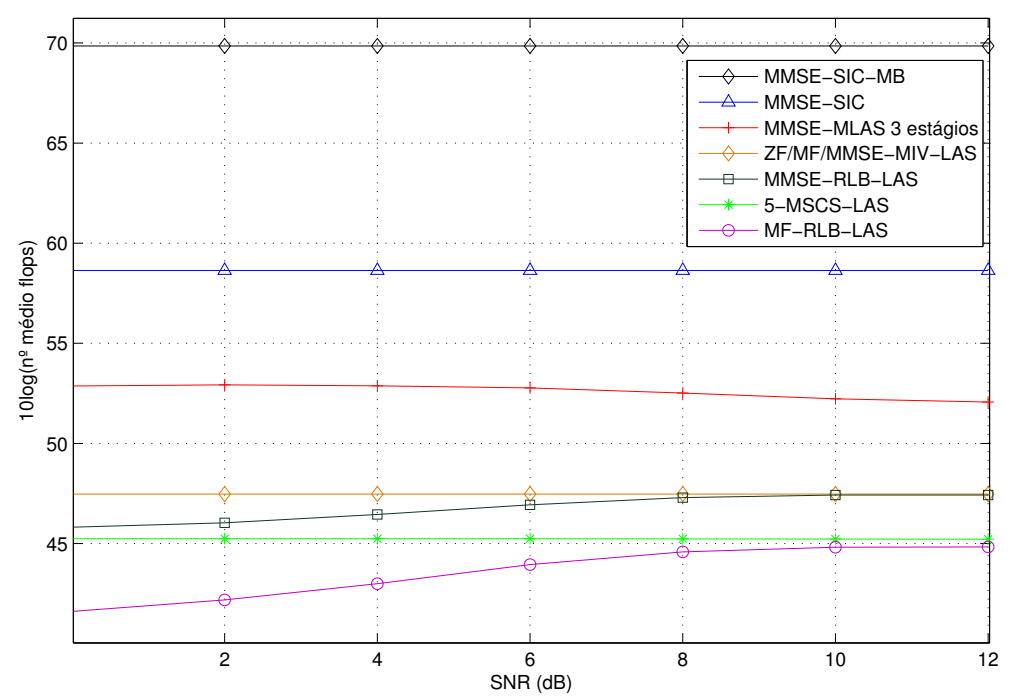

Figura 3.23: Curvas do número médio de flops por bit transmitido pela $S N R$ de diversos detectores MIMO com modulação 4-QAM considerando o cenário A e $N_{t}=N_{r}=20$.

Resultados de BER pela SNR para os detectores MF-RLB-LAS, $\mathrm{MF} / \mathrm{ZF} / \mathrm{MMSE}-\mathrm{MIV}$-LAS e 5-MSCS-LAS para sistemas MIMO com $N_{t}=$ $N_{r}=8$ e $N_{t}=N_{r}=64$, considerando o cenário B, são apresentados na Figura 3.24. O número de antenas por usuário foi fixado em 2 e as matrizes de coeficientes de canal foram consideradas conhecidas no receptor. Neste caso, a melhoria na BER com o aumento do número de antenas para o detector MF-RLB-LAS apenas pode ser observada para valores elevados da SNR. Entretanto, o detector MF-RLB-LAS é capaz de ultrapassar o desempenho em termos de BER dos demais algoritmos baseados na busca LAS, até mesmo ao comparar-se os resultados do sistema que emprega o MF-RLB-LAS com apenas 8 antenas de transmissão e recepção com os os dos demais detectores em sistemas com maior número de antenas. Nota-se ainda a ocorrência de um limitante inferior dependente do número de antenas do sistema para a curva 
de BER do algoritmo 5-MSCS-LAS, devido ao qual o aumento da SNR não promove a redução da BER.

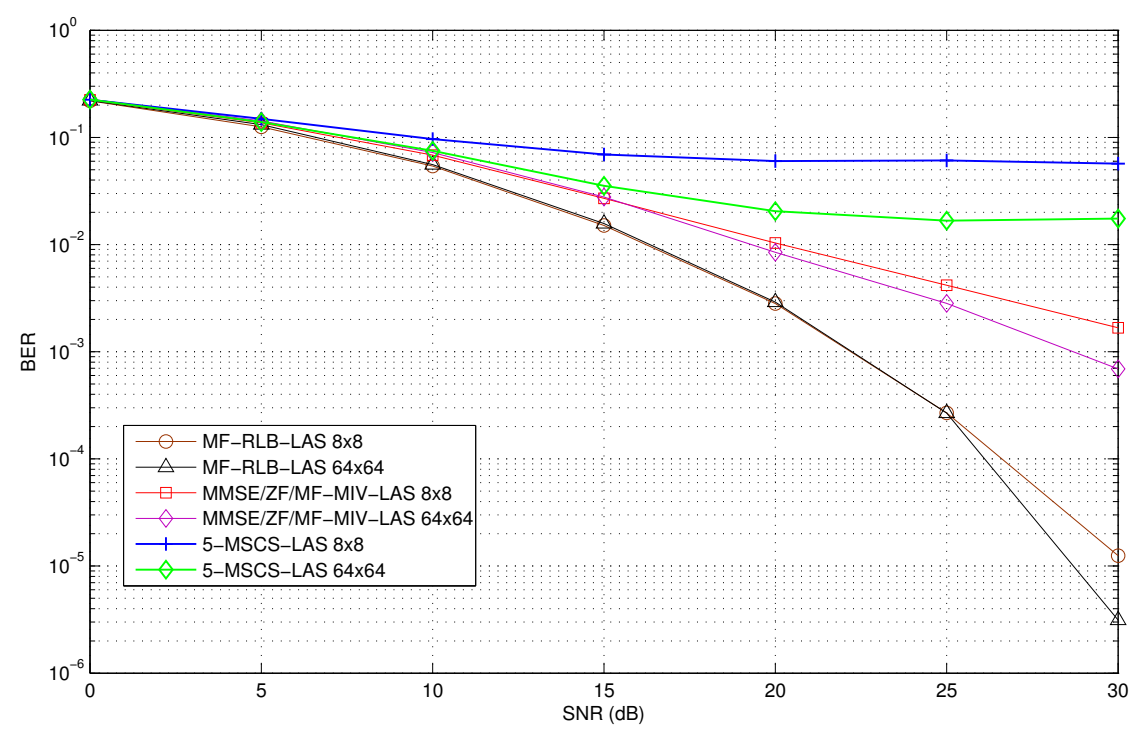

Figura 3.24: Curvas de BER pela SNR dos detectores MF-RLB-LAS, MMSE/ZF/MF-MIV-LAS e 5-MSCS-LAS com modulação 4-QAM no cenário $\mathrm{B}\left(\rho=0.2, \sigma_{k}=6 d B\right)$.

Os resultados de complexidade em termos do número médio de flops por bit transmitido pela SNR para os detectores MF-RLB-LAS, 5-MSCS-LAS e MF/ZF/MMSE-MIV-LAS são ilustrados na Figura 3.25 para sistemas MIMO com $N_{t}=N_{r}=20$ sob as condições do cenário A e B, em que cada usuário possui 2 antenas de transmissão. Nota-se que a complexidade dos detectores 5 MSCS-LAS e MF/ZF/MMSE-MIV-LAS não depende do cenário empregado, fato este esperado uma vez que o número de operações deste detector não depende das condições de transmissão do sistema. Já a complexidade do detector MF-RLB-LAS depende das condições do canal empregado, como pode ser observado pelas suas curvas de complexidade apresentadas. Apesar dessa variação, o limitante superior da complexidade deste detector mantemse inalterado ao se mudar o cenário analisado, sendo que no cenário A este patamar é atingido com valores menores da SNR. Verifica-se ainda que o algoritmo MF-RLB-LAS apresenta a menor complexidade computacional dentre os detectores analisados em ambos os cenários.

Finalizando as comparações entre os detectores baseados na busca LAS, a Figura 3.26 apresenta curvas do número médio de flops por bit transmitido por $N_{t}=N_{r}$ em escala log-log para os detectores MF-RLB-LAS, 5-MSCS-LAS e MMSE/ZF/MF-MIV-LAS no cenário B. No caso do detector MF-RLB-LAS, considerou-se o número médio de flops para uma SNR que alcance a BER 


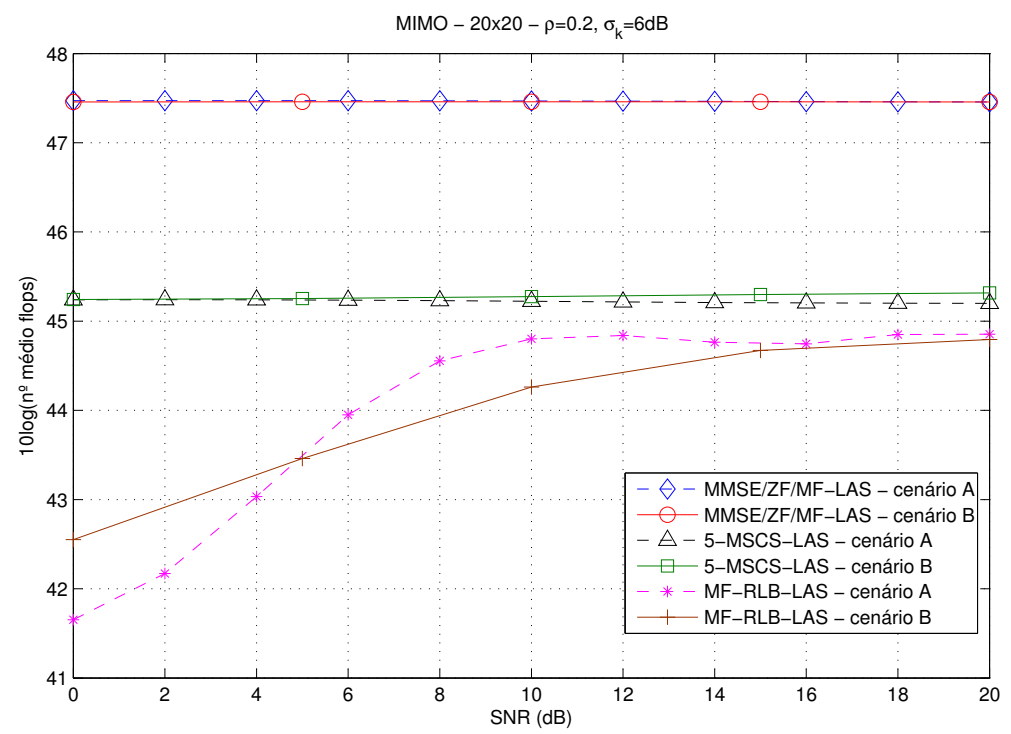

Figura 3.25: Curvas do número médio de flops por bit transmitido pela $S N R$ para os detectores MF-RLB-LAS, MMSE/ZF/MF-LAS e 5-MSCS-LAS com modulação 4-QAM e $N_{t}=N_{r}=20$ considerando os cenários A e B $(\rho=0.2$, $\left.\sigma_{k}=6 d B\right)$.

alvo de $10^{-2}$. Apesar do 5-MSCS-LAS não atingir esta BER alvo especificada, devido à saturação observada na Figura 3.24, sua curva de complexidade foi incluída a título de comparação. Além das curvas de complexidade, também são apresentadas curvas lineares e quadráticas, em escala log-log, de forma a servir como curvas de referência, por meio das quais pode-se verificar que a complexidade dos detectores analisados é polinomial com $N_{t}=N_{r}$ de ordem não superior a 2 , uma vez que as curvas de complexidade em escala log-log destes detectores são retas com inclinações menores que a da reta oriunda da curva de referência quadrática. Apesar de não constarem na Figura 3.26, os limites superiores dos intervalos de confiança de $95 \%$ dos ajustes presentes nesta figura corroboram a afirmação anterior, visto que suas inclinações foram de $k_{M F-R L B-L A S}^{\text {sup }}=1.661, k_{5-M S C S-L A S}^{\text {sup }}=1.956$ e $k_{M I V-L A S}^{\text {sup }}=1.974$. Além disso, ao comparar-se as inclinações das curvas de complexidade de cada algoritmo analisado, verifica-se que o detector MF-RLB-LAS possui menor ordem de complexidade do que a dos demais. 


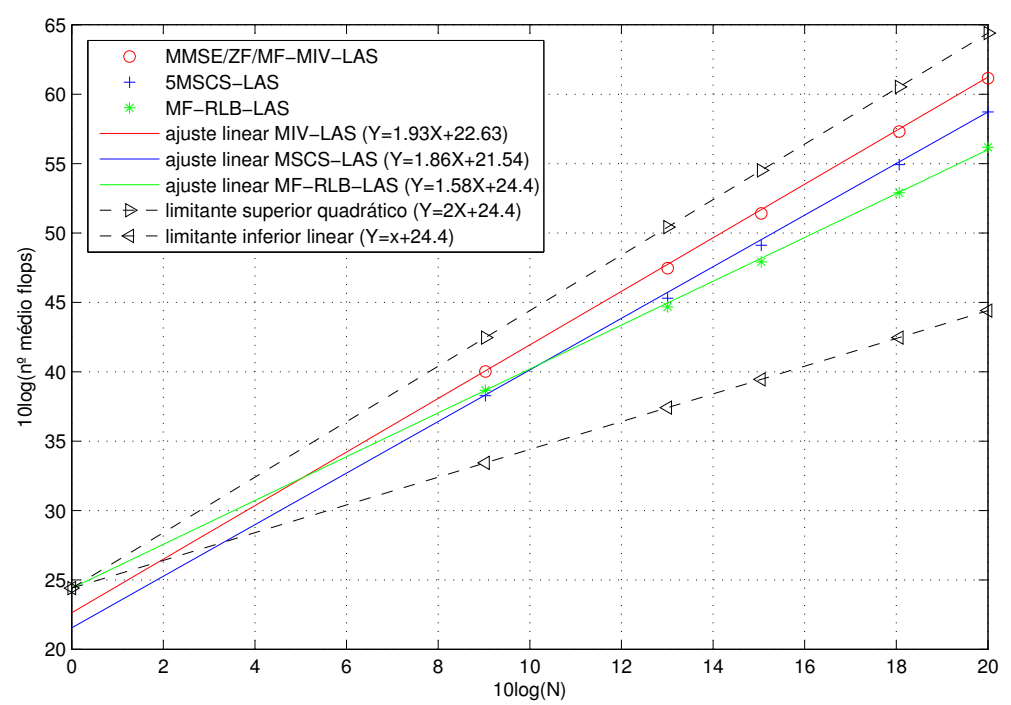

Figura 3.26: Curvas do número médio de flops por bit transmitido por $N_{t}=$ $N_{r}=N$ em escala log-log dos detectores MF-RLB-LAS, MMSE/ZF/MF-LAS e 5-MSCS-LAS com modulação 4-QAM considerando o cenário B $(\rho=0.2$, $\left.\sigma_{k}=6 d B\right)$.

\section{5}

\section{Conclusões}

Neste capítulo o algoritmo de busca por verossimilhança ascendente foi detalhado com a proposição alternativa do algoritmo LAS já conhecido de forma a estender sua aplicação a sistemas que empregam qualquer tipo de modulação cuja constelação seja composta por símbolos complexos. Em seguida, os seguintes detectores baseados nesta estratégia de busca foram apresentados: detector LAS com conjuntos de candidatos de busca unitários (SLAS); LAS multiestágio (MLAS); LAS com múltiplos vetores de entrada (MIV-LAS); LAS com múltiplos conjuntos de candidatos de busca (MSCSLAS); e random-list based LAS (RLB-LAS), sendo este último proposto em decorrência dos estudos efetuados no presente trabalho.

Resultados de diversas simulações de Monte Carlo foram apresentados, por meio dos quais pôde-se verificar o desempenho dos algoritmos analisados em termos de BER e complexidade computacional avaliada pelo número de operações de ponto-flutuante (flops) por bit transmitido nos cenários A e B descritos no capítulo anterior. Observou-se que a BER de todos os algoritmos baseados na busca LAS considerados se aproxima da BER de um sistema SISO sujeito a um canal AWGN a medida em que o número de antenas de transmissão e recepção do sistema aumenta, fato este que ilustra a capacidade destes detectores em remover os efeitos do desvanecimento e a interferência espacial 
ao passo em que o número de antenas componentes do sistema aumenta. Em relação à complexidade computacional, foi observado que os detectores MIVLAS que emprega os resultados das detecções por filtros MMSE, ZF e MF como vetores de símbolos candidatos iniciais (MMSE/ZF/MF-MIV-LAS), o detector 5-MSCS-LAS e o detector RLB-LAS que emprega o resultado da detecção por filtro casado como vetor de símbolos candidatos iniciais da primeira iteração (MF-RLB-LAS) apresentam complexidade computacional polinomial com o número de antenas nos casos em que $N=N_{t}=N_{r}$ de ordem não superior a $\mathcal{O}\left(N^{2}\right)$, sendo, em todos os casos analisados, o algoritmo MF-RLB-LAS o que apresentou menor complexidade, com melhores curvas de BER.

No próximo capítulo, técnicas de codificação em sistemas MIMO serão abordadas. Em especial, o emprego de técnicas de detecção e decodificação iterativas (Iterative Detection and Decoding - IDD) em sistemas MIMO, baseadas no princípio dos códigos Turbo, será detalhado. Uma proposta de detector IDD de baixa complexidade para sistemas MIMO de larga escala é realizada e resultados de simulação são apresentados e discutidos. 


\section{4 \\ Detecção e Decodificação Iterativas em Sistemas MIMO}

\section{1 \\ Introdução}

Apesar das grandes vantagens do emprego dos sistemas MIMO de larga escala em atingir altas taxas de dados, de forma a projetar receptores que se aproximem da capacidade de informação dos sistemas sem fio, códigos corretores de erros são usualmente empregados a fim de prover mecanismos de redundância e proteção contra os erros causados pelo desvanecimento, interferências e ruídos aditivos [32]. Dessa forma, neste capítulo, serão investigados esquemas de codificação e decodificação em sistemas MIMO, tendo em foco a sua complexidade computacional, visando o seu emprego em sistemas de larga escala.

Neste contexto, as estratégias de detecção e decodificação iterativas (Iteractive Detection and Decoding - IDD) em sistemas MIMO, baseadas no princípio dos códigos turbo [33] têm se mostrado promissoras. Em tais sistemas, o detector ótimo a ser empregado é um detector MAP de entradas e saídas suaves, que são constituídas por razões de log-verossimilhança (Log-Likelihood Ratios - LLRs). Este detector possui complexidade computacional que cresce de forma exponencial com o número de antenas. De forma a evitar esta complexidade proibitiva, diversos sistemas de recepção IDD, que empregam outros detectores, foram propostos na literatura. Em [32], detectores MIMO de saídas suaves baseados no detector sphere decoder (SD) [55-57] foram empregados a fim de aproximar as probabilidades a posteriori necessárias ao esquema IDD. Posteriormente, [34] aprimorou o trabalho em [32] empregando um código turbo como o codificador componente do esquema IDD e propondo diferentes perfis de iteração para este esquema. Em [35], mantém-se o detector de saídas suaves MAP, porém a complexidade computacional é reduzida por meio do emprego da saída de um segundo detector, o MB-LR-SIC [47], como entrada ao detector MAP, no lugar do vetor de símbolos recebidos. Outra estratégia de redução de complexidade foi proposta em [36]. Nesse caso, são utilizadas técnicas de redução de dimensionalidade [58] de forma a se alcançar melhores relações custo-benefício entre complexidade e desempenho. 
Apesar dos bons resultados apresentados nos trabalhos acima mencionados, a complexidade computacional global dos sistemas ainda é proibitiva ao se considerar um elevado número de elementos de transmissão e recepção. Nesta tese, é proposta uma estratégia para reduzir ainda mais a complexidade do detetor MAP empregado no esquema IDD. Esta estratégia baseia-se no emprego de detectores de baixa complexidade para sistemas MIMO, como os apresentados no Capítulo 3, seguida de cancelamentos de interferência paralelos (Parallel Interference Cancellation - PIC) e filtragem de forma a produzir as entradas do detector MAP do esquema IDD.

Na próxima seção, a estratégia IDD é detalhada e o detector MIMO de entrada e saídas suaves proposto é apresentado. Em seguida, resultados de simulação de sistemas que empregam a estratégia IDD implementada com o detector de entradas e saídas suaves proposto neste trabalho, bem como os resultados de sistemas que utilizam a estratégia tradicional de detecção dos símbolos transmitidos seguida da decodificação da sequência de bits codificados e resultados de sistemas não codificados são apresentados e discutidos na Seção 4.3. Por fim, as conclusões são apresentadas na Seção 4.4.

\section{2}

\section{Estratégia de Detecção e Decodificação Iterativa (Turbo)}

Nesta seção, o esquema de detecção e decodificação iterativa, baseado na estratégia turbo, é apresentado. O receptor destes sistemas é composto de dois estágios principais: o primeiro integrado por um detector MIMO multiusuário de entradas e saídas suaves; e o segundo por $N_{t}$ decodificadores em paralelo, também de entradas e saídas suaves, responsáveis pela realização da decodificação de cada uma das $N_{t}$ sequências de bits transmitidas. Os códigos corretores de erros empregados no presente trabalho foram os códigos convolucionais sistemáticos recursivos (Recursive Systematic Codes - RSC).

A Figura 4.1 ilustra este sistema, baseado no trabalho apresentado em [59], em que foi proposto uma estratégia de detecção iterativa para sistemas CDMA. No sistema de transmissão ilustrado na figura, o canal MIMO é visto como um segundo codificador convolucional e, de forma a evitar-se erros em rajadas oriundos de desvanecimentos profundos, as saídas dos codificadores de canal em cada transmissor são entrelaçadas antes da transmissão. Consequentemente, no receptor, os dois estágios do esquema IDD são separados por desentrelaçadores $\left(\pi^{-1}\right)$ e entrelaçadores $(\pi)$.

O diagrama de blocos dos transmissores está representado na porção superior da Figura 4.1. Verifica-se a partir dele que a sequência de bits referente a cada antena de transmissão, $\mathbf{m}_{i}$, é codificada resultando na sequência de bits 


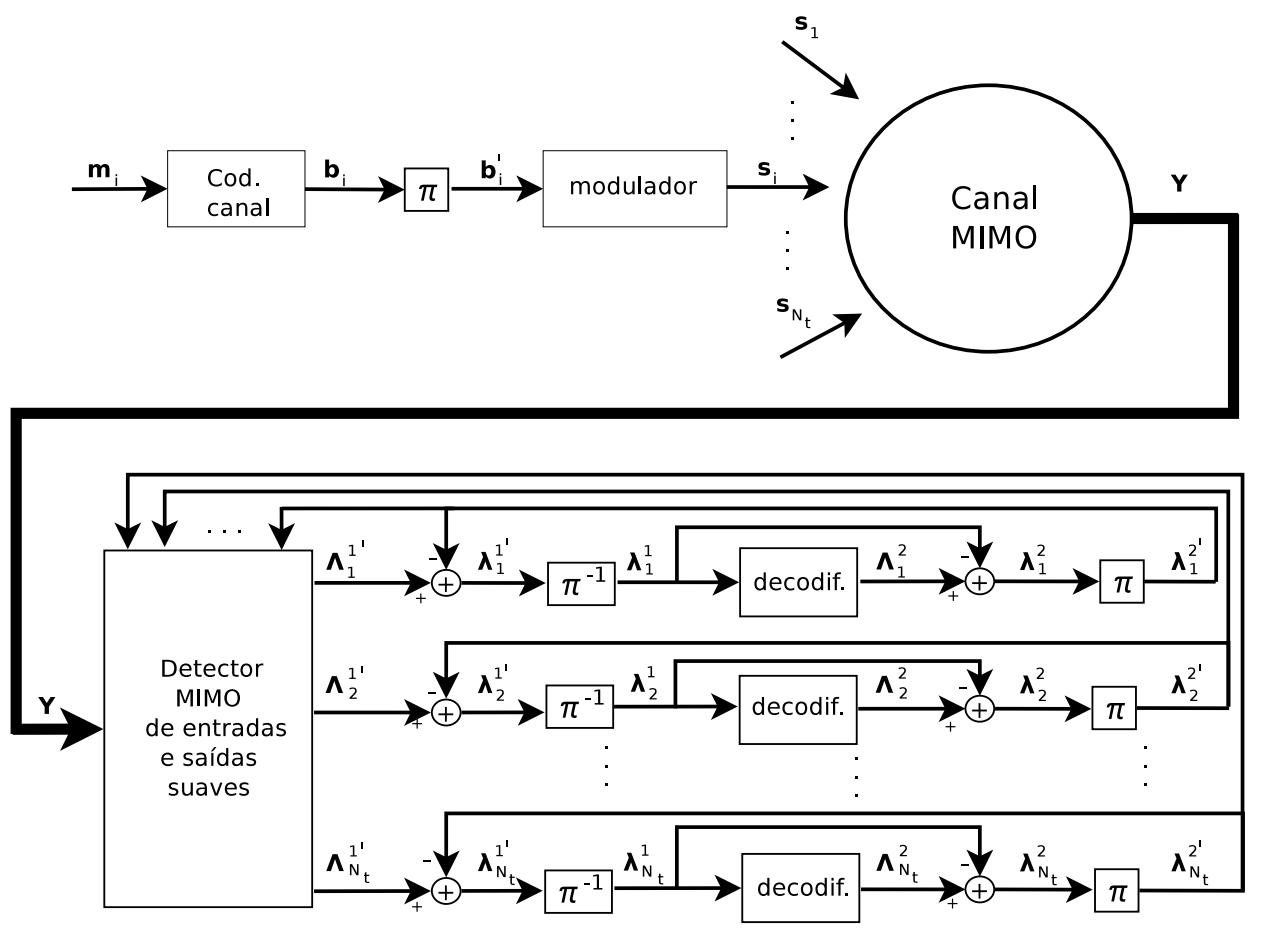

Figura 4.1: Esquema de detecção e decodificação iterativo para sistemas MUMIMO.

codificada, $\mathbf{b}_{i}$. Como já mencionado, esta sequência de bits $\mathbf{b}_{i}$ é entrelaçada e mapeada na sequência de símbolos da modulação empregada na transmissão, $\mathbf{s}_{i}=\left[s_{i 1}, s_{i 2}, \cdots, s_{i \tau}\right]$, que será transmitida pelo canal, em que $\tau$ representa o número de símbolos transmitidos por antena por quadro. Neste ponto, os valores dos bits " 1 " e " 0 " serão representados pelos níveis de sinal "+1" e "-1", respectivamente.

No lado do receptor, o detector MIMO de entradas e saídas suaves emprega a sequência de vetores de sinais recebidos, $\mathbf{Y}=\left[\mathbf{y}_{1}, \mathbf{y}_{2}, \cdots, \mathbf{y}_{\tau}\right] \in$ $\mathbb{C}^{N_{r} \times \tau}$, em conjunto com a sua informação a priori, constituída pelas LLRs $\boldsymbol{\lambda}_{i}^{2^{\prime}}=\left[\boldsymbol{\lambda}_{i 1}^{2^{\prime}}, \boldsymbol{\lambda}_{i 2}^{2^{\prime}}, \cdots, \boldsymbol{\lambda}_{i \tau}^{2^{\prime}}\right] \in \mathbb{R}^{B \times \tau}, i=1,2, \cdots, N_{t}$, em que $B=\log _{2}(M)$ é o número de bits por símbolo da constelação utilizada, para calcular as LLRs a posteriori dos bits de código "+1" e "-1" para todos os bits de todos os símbolos transmitidos de cada usuário, $\boldsymbol{\Lambda}_{i}^{1^{\prime}}, i=1,2, \cdots, N_{t}$ da seguinte forma:

$$
\boldsymbol{\Lambda}_{i}^{1^{\prime}}(m, t) \triangleq \log \frac{P\left[b_{i}(m, t)=+1 \mid \mathbf{y}_{t}\right]}{P\left[b_{i}(m, t)=-1 \mid \mathbf{y}_{t}\right]}
$$

para $m=1 \cdots, B$ e $t=1, \cdots, \tau$. Na equação acima, $b_{i}(m, t)$ corresponde ao $m$-ésimo bit referente ao símbolo $s_{i t}$. Empregando a regra de Bayes, (4-1) 
pode ser reescrita como

$$
\boldsymbol{\Lambda}_{i}^{\mathbf{1}^{\prime}}(m, t)=\underbrace{\log \frac{p\left[\mathbf{y}_{t} \mid b_{i}(m, t)=+1\right]}{p\left[\mathbf{y}_{t} \mid b_{i}(m, t)=-1\right]}}_{\boldsymbol{\lambda}_{i}^{1^{\prime}}(m, t)}+\underbrace{\log \frac{P\left[b_{i}(m, t)=+1\right]}{P\left[b_{i}(m, t)=-1\right]}}_{{\boldsymbol{\lambda _ { i } ^ { \prime }}}^{2^{\prime}(m, t)}},
$$

em que $p\left[\mathbf{y}_{t} \mid b_{i}(m, t)= \pm 1\right]$ denota o valor da função densidade de probabilidade do vetor de sinal recebido dado $b_{i}(m, t)= \pm 1$ avaliada no vetor $\mathbf{y}_{t}$ e o segundo termo da equação acima, $\boldsymbol{\lambda}_{i}^{2^{\prime}}(m, t)$, é a LLR a priori do bit transmitido $b_{i}(m, t)$ calculada pelo $i$-ésimo decodificador de canal na iteração anterior, entrelaçada e realimentada ao detetor MIMO do primeiro estágio. Na primeira iteração, assumindo-se que todos os bits são transmitidos com mesma probabilidade, tem-se que $\boldsymbol{\lambda}_{i}^{2^{\prime}}(m, t)=0$, para $m=1, \cdots, B, t=1, \cdots, \tau$ e $i=$ $1,2, \cdots, N_{t}$.

O primeiro termo em (4-2), $\boldsymbol{\lambda}_{i}^{1^{\prime}}(m, t)$, é a informação extrínseca passada pelo detector do primeiro estágio para os decodificadores do segundo estágio. Essa informação é desentrelaçada e passada ao $i$-ésimo decodificador de canal que a emprega como sua informação a priori na iteração atual.

No segundo estágio da estratégia IDD, todos os decodificadores calculam as LLRs a posteriori dos bits transmitidos com base nas suas informações a priori passadas pelo detector e nas restrições impostas pela estrutura do código empregado da seguinte forma:

$$
\boldsymbol{\Lambda}_{i}^{2}(m, t) \triangleq \log \frac{P\left[b_{i}(m, t)=+1 \mid \boldsymbol{\lambda}_{i}^{1}(m, r)_{r=1}^{\tau} ; \text { estrutura do código }\right]}{P\left[b_{i}(m, t)=-1 \mid \boldsymbol{\lambda}_{i}^{1}(m, r)_{r=1}^{\tau} ; \text { estrutura do código }\right]}
$$

para $i=1, \cdots, N_{t}, m=1, \cdots, B$ e $t=1, \cdots, \tau$. Como será evidenciado a seguir, $\Lambda_{i}^{2}(m, t)$ é constituído pela soma da informação prévia acerca dos bits transmitidos, $\boldsymbol{\lambda}_{i}^{1}(m, t)$, com a informação extraída das informações prévias acerca dos demais bits em todos os outros instantes, $\left\{\boldsymbol{\lambda}_{i}^{1}(m, r)\right\}_{r \neq t}$, e das restrições do código. As informações geradas em cada decodificador, $\boldsymbol{\lambda}_{i}^{2}$, $i=1, \cdots, N_{t}$, são então entrelaçadas e passadas ao detector do primeiro estágio, que as empregará como informações a priori sobre os bits transmitidos na detecção efetuada na próxima iteração.

Adicionalmente, os decodificadores calculam as LLRs a posteriori dos bits de informação de modo a efetuar a decisão final sobre os bits da mensagem transmitida na última iteração. Cabe ressaltar que, no início do processo, as informações extrínsecas $\boldsymbol{\lambda}^{1}$ e $\boldsymbol{\lambda}^{2}$ são estatisticamente independentes, porém, ao passo que as iterações ocorrem, elas tornam-se mais correlatadas e, consequentemente, o ganho no desempenho do sistema a cada iteração diminui.

Na próxima subseção, o algoritmo de decodificação empregado nos siste- 
mas IDD será detalhado. Em seguida, na subseção 4.2.2, é apresentada uma proposta de estratégia de detecção com entradas e saídas suaves de baixa complexidade computacional a fim de substituir o detector MAP empregado classicamente nos esquemas IDD.

\subsection{1}

\section{Decodificador de Canal de Entradas e Saídas Suaves}

O decodificador de entradas e saídas suaves, componente da estratégia IDD considerado nesta tese, consiste em uma versão modificada do algoritmo MAP BCJR [60] para códigos convolucionais como proposta em [59]. Este decodificador recebe como entrada as LLRs dos bits transmitidos (codificados) pela $i$-ésima antena e produz como saída uma atualização destas mesmas LLRs com base na estrutura em treliça desses códigos. Além disso, de forma a decidir sobre os bits de mensagem (não codificados), o algoritmo também calcula as LLRs referentes a esses bits.

Neste trabalho, foram considerados códigos convolucionais com taxa $R=\frac{1}{n_{0}}$ e comprimento de restrição $\nu$. Considerou-se neste trabalho as seguintes definições de variáveis:

- $m_{i}^{t}$ : entrada do codificador referente à $i$-ésima antena de transmissão no instante de tempo $t$;

- $\mathbf{b}_{i}^{t}=\left(b_{i 1}^{t}, \cdots, b_{i n_{0}}^{t}\right)$ : saída do codificador referente à entrada $m_{i}^{t}$;

- $\mathbf{w}_{i}^{t}=\left(w_{i 1}^{t}, \cdots, w_{i(\nu-1)}^{t}\right)$ : vetor ordenado de $(\nu-1)$ posições que define o estado da treliça do respectivo código no instante de tempo $t$. Seus elementos $w_{i j}^{t}$ podem assumir os valores binários " 0 " ou " 1 ";

- $m_{i}\left(\mathbf{w}^{\prime}, \mathbf{w}\right)$ : bit de mensagem que provoca a mudança do estado $\mathbf{w}_{i}^{(t-1)}=$ $\mathbf{w}^{\prime}$ para o estado $\mathbf{w}_{i}^{t}=\mathbf{w}$;

- $\mathbf{b}_{i}\left(\mathbf{w}^{\prime}, \mathbf{w}\right)$ : saída do codificador correspondente à entrada $m_{i}\left(\mathbf{w}^{\prime}, \mathbf{w}\right)$.

Denota-se ainda a probabilidade da saída $\mathbf{b}_{i}^{t}$, do $i$-ésimo codificador no instante $t$, assumir o valor $\mathbf{b}_{i}\left(\mathbf{w}^{\prime}, \mathbf{w}\right)$ por:

$$
P\left[\mathbf{b}_{i}^{t}\left(\mathbf{w}^{\prime}, \mathbf{w}\right)\right] \triangleq P\left[\mathbf{b}_{i}^{t}=\mathbf{b}_{i}\left(\mathbf{w}^{\prime}, \mathbf{w}\right)\right]
$$

Como o algoritmo de decodificação opera analogamente para todos os $N_{t}$ decodificadores referentes à sequência de bits transmitidos em cada antena, por razões de simplicidade, o índice $i$ das variáveis acima definidos será desconsiderado.

Sem perda de generalidade, considerou-se ainda que todos os codificadores iniciam no estado $\mathbf{w}^{0}=\mathbf{0}$ e que eles são terminados, ou seja, após 
receberem a sequência de bits de mensagem $\left\{m^{t}\right\}_{t=1}^{T}$, estes codificadores recebem um bloco de $\nu$ bits de forma que o estado final de suas treliças sejam o estado $\mathbf{w}^{\tau}=\mathbf{0}$, com $\tau=T+\nu$. Nestas considerações, o vetor $\mathbf{0}$ é o vetor de $(\nu-1)$ posições cujos elementos são iguais a 0.

A seguir, o algoritmo de decodificação presente em [59] será descrito na sua forma logarítmica:

Sejam $\alpha^{t}(\mathbf{w})$ e $\beta^{t}(\mathbf{w})$ os logaritmos das recursões avante e reversa, respectivamente, definidas em [60] como:

$$
\begin{gathered}
\alpha^{t}(\mathbf{w})=\log \left(\sum_{\mathbf{w}^{\prime}} \exp \left\{\alpha^{t-1}\left(\mathbf{w}^{\prime}\right)+\log \left(P\left[\mathbf{b}^{t}\left(\mathbf{w}^{\prime}, \mathbf{w}\right)\right]\right)\right\}\right), t=1,2, \cdots, \tau, \\
\beta^{t}(\mathbf{w})=\log \left(\sum_{\mathbf{w}^{\prime \prime}} \exp \left\{\beta^{t+1}\left(\mathbf{w}^{\prime \prime}\right)+\log \left(P\left[\mathbf{b}^{t+1}\left(\mathbf{w}, \mathbf{w}^{\prime \prime}\right)\right]\right)\right\}\right), t=\tau-1, \tau-2, \cdots, 0 .
\end{gathered}
$$

De acordo com as considerações anteriormente assumidas, as condições de contorno para $\alpha^{t}(\mathbf{w})$ e $\beta^{t}(\mathbf{w})$ são:

1. $\alpha^{0}(\mathbf{0})=0$ e $\alpha^{0}(\mathbf{w} \neq \mathbf{0})=-\infty$; e

2. $\beta^{\tau}(\mathbf{0})=0$ e $\beta^{\tau}(\mathbf{w} \neq \mathbf{0})=-\infty$.

Com o objetivo de evitar-se instabilidades numéricas, as recursões avante e reversa são escaladas como se segue: Seja $\tilde{\alpha}^{t}$ a versão escalada de $\alpha^{t}$. Inicialmente, faz-se $\tilde{\alpha}^{1}(\mathbf{w})=c_{1}+\hat{\alpha}^{1}(\mathbf{w})$, com $\hat{\alpha}^{1}(\mathbf{w})=\alpha^{1}(\mathbf{w})$ de $(4-5) \mathrm{e}$ $c_{1} \triangleq-\log \left(\sum_{\mathbf{w}} \exp \left\{\hat{\alpha}^{1}(\mathbf{w})\right\}\right)$. Em seguida, para cada $t \geq 2, \tilde{\alpha}^{t}(\mathbf{w})$ é dado por:

$$
\tilde{\alpha}^{t}(\mathbf{w})=c_{t}+\hat{\alpha}^{t}(\mathbf{w})
$$

em que

$$
\hat{\alpha}^{t}(\mathbf{w})=\log \left(\sum_{\mathbf{w}^{\prime}} \exp \left\{\tilde{\alpha}^{t-1}\left(\mathbf{w}^{\prime}\right)+\log \left(P\left[\mathbf{b}^{t}\left(\mathbf{w}^{\prime}, \mathbf{w}\right)\right]\right)\right\}\right)
$$

com

$$
c_{t}=-\log \left(\sum_{\mathbf{w}} \exp \left\{\hat{\alpha}^{t}(\mathbf{w})\right\}\right) .
$$

Por meio de indução matemática a partir das equações (4-7) e (4-8), pode-se chegar ao seguinte resultado:

$$
\tilde{\alpha}^{t-1}(\mathbf{w})=\sum_{i=1}^{t-1} c_{i}+\alpha^{t-1}(\mathbf{w}) \triangleq C^{t-1}+\alpha^{t-1}(\mathbf{w}) .
$$

Aplicando (4-10) em (4-7) e (4-8), chega-se a:

$$
\tilde{\alpha}^{t}(\mathbf{w})=\log \left(\frac{\exp \left\{\alpha^{t}(w)\right\}}{\sum_{w} \exp \left\{\alpha^{t}(w)\right\}}\right) .
$$


Considerando que as variáveis $\tilde{\alpha}^{t}(\mathbf{w})$ e $\alpha^{t}(\mathbf{w})$ referem-se aos logaritmos da recursão avante escalada e da recursão avante, respectivamente, observa-se a partir de (4-11) que o escalamento proposto é nada mais do que a divisão da recursão avante pela soma desta recursão em todos os seus possíveis estados.

De forma análoga, seja $\tilde{\beta}^{t}(\mathbf{w})$ a versão escalada da recursão reversa. Para $t=\tau-1, \tilde{\beta}^{\tau-1}(\mathbf{w})=c_{\tau-1}+\hat{\beta}^{\tau-1}(\mathbf{w}), \operatorname{com} \hat{\beta}^{\tau-1}(\mathbf{w})=\beta^{\tau-1}(\mathbf{w})$ de $(4-6)$. Partindo-se desse ponto, para cada $t \leq \tau-2$, tem-se:

$$
\tilde{\beta}^{t}(\mathbf{w})=c_{t}+\hat{\beta}^{t}(\mathbf{w})
$$

em que

$$
\hat{\beta}^{t}(\mathbf{w})=\log \left(\sum_{\mathbf{w}^{\prime \prime}} \exp \left\{\tilde{\beta}^{t+1}\left(\mathbf{w}^{\prime \prime}\right)+\log \left(P\left[\mathbf{b}^{t+1}\left(\mathbf{w}, \mathbf{w}^{\prime \prime}\right)\right]\right)\right\}\right) .
$$

Como feito anteriormente, por indução, temos que:

$$
\tilde{\beta}^{t}(\mathbf{w})=\sum_{i=t}^{\tau-1} c_{i}+\beta^{t}(\mathbf{w}) \triangleq D^{t}+\beta^{t}(\mathbf{w})
$$

As demonstrações por indução das equações (4-10) e (4-14), bem como a prova da equação (4-11) estão detalhadas no Apêndice A da presente tese.

Definindo-se os conjuntos $\mathcal{W}_{m}^{+}$e $\mathcal{W}_{m}^{-}$como os conjuntos de pares de estados $\left(\mathbf{w}^{\prime}, \mathbf{w}\right)$ tais que o $m$-ésimo bit de $\mathbf{b}\left(\mathbf{w}^{\prime}, \mathbf{w}\right)$ seja "+1" e "- 1 ", respectivamente, o algoritmo BCJR calcula as LLRs a posteriori como se segue:

$$
\begin{aligned}
& \mathbf{\Lambda}^{2}(m, t) \triangleq \log \frac{P[b(m, t)=+1 \mid \text { estrutura do código }]}{P[b(m, t)=-1 \mid \text { estrutura do código }]} \\
& =\log \frac{\sum_{\mathcal{W}_{m}^{+}} \exp \left\{\alpha^{t-1}\left(\mathbf{w}^{\prime}\right)+\beta^{t}(\mathbf{w})+\log \left(P\left[\mathbf{b}^{t}\left(\mathbf{w}^{\prime}, \mathbf{w}\right)\right]\right)\right\}}{\sum_{\mathcal{W}_{m}^{-}} \exp \left\{\alpha^{t-1}\left(\mathbf{w}^{\prime}\right)+\beta^{t}(\mathbf{w})+\log \left(P\left[\mathbf{b}^{t}\left(\mathbf{w}^{\prime}, \mathbf{w}\right)\right]\right)\right\}} \\
& =\log \frac{\sum_{\mathcal{W}_{m}^{+}} \exp \left\{\alpha^{t-1}\left(\mathbf{w}^{\prime}\right)+\beta^{t}(\mathbf{w})+\log \left(\prod_{j=1}^{n_{0}} P\left[b_{j}^{t}\left(\mathbf{w}^{\prime}, \mathbf{w}\right)\right]\right)\right\}}{\sum_{\mathcal{W}_{m}^{-}} \exp \left\{\alpha^{t-1}\left(\mathbf{w}^{\prime}\right)+\beta^{t}(\mathbf{w})+\log \left(\prod_{j=1}^{n_{0}} P\left[b_{j}^{t}\left(\mathbf{w}^{\prime}, \mathbf{w}\right)\right]\right)\right\}} \\
& =\log \frac{\sum_{\mathcal{W}_{m}^{+}} \exp \left\{\alpha^{t-1}\left(\mathbf{w}^{\prime}\right)+\beta^{t}(\mathbf{w})+\log \left(P\left[b_{m}^{t}=+1\right]\right)+\sum_{j \neq m} \log \left(P\left[b_{j}^{t}\left(\mathbf{w}^{\prime}, \mathbf{w}\right)\right]\right)\right\}}{\sum_{\mathcal{W}_{m}^{-}} \exp \left\{\alpha^{t-1}\left(\mathbf{w}^{\prime}\right)+\beta^{t}(\mathbf{w})+\log \left(P\left[b_{m}^{t}=-1\right]\right)+\sum_{j \neq m} \log \left(P\left[b_{j}^{t}\left(\mathbf{w}^{\prime}, \mathbf{w}\right)\right]\right)\right\}} \\
& =\log \frac{\sum_{\mathcal{W}_{m}^{+}} \exp \left\{\alpha^{t-1}\left(\mathbf{w}^{\prime}\right)+\beta^{t}(\mathbf{w})+\sum_{j \neq m} \log \left(P\left[b_{j}^{t}\left(\mathbf{w}^{\prime}, \mathbf{w}\right)\right]\right)\right\}}{\sum_{\mathcal{W}_{m}^{-}} \exp \left\{\alpha^{t-1}\left(\mathbf{w}^{\prime}\right)+\beta^{t}(\mathbf{w})+\sum_{j \neq m} \log \left(P\left[b_{j}^{t}\left(\mathbf{w}^{\prime}, \mathbf{w}\right)\right]\right)\right\}}+\log \frac{P\left[b_{m}^{t}=+1\right]}{P\left[b_{m}^{t}=-1\right]} \\
& = \\
& \log \frac{\sum_{\mathcal{W}_{m}^{+}} \exp \left\{\tilde{\alpha}^{t-1}\left(\mathbf{w}^{\prime}\right)+\tilde{\beta}^{t}(\mathbf{w})+\sum_{j \neq m} \log \left(P\left[b_{j}^{t}\left(\mathbf{w}^{\prime}, \mathbf{w}\right)\right]\right)\right\}}{\sum_{\mathcal{W}_{m}^{-}} \exp \left\{\tilde{\alpha}^{t-1}\left(\mathbf{w}^{\prime}\right)+\tilde{\beta}^{t}(\mathbf{w})+\sum_{j \neq m} \log \left(P\left[b_{j}^{t}\left(\mathbf{w}^{\prime}, \mathbf{w}\right)\right]\right)\right\}}+ \\
& \quad \underbrace{\log \frac{P[b(m, t)=+1]}{P[b(m, t)=-1]}}_{\lambda^{1}(m, t)}
\end{aligned}
$$


em que a última igualdade justifica-se uma vez que $C_{t-1}+D_{t}=\sum_{i=1}^{t-1} c_{i}+$ $\sum_{i=t}^{\tau-1} c_{i}=\sum_{i=1}^{\tau-1} c_{i}$ é uma constante independente de $t, \mathbf{w}$ e $\mathbf{w}^{\prime}$. Como pode ser observado em (4-15), a saída de cada decodificador referente ao bit $b(m, t)$ é constituída pela soma da informação prévia oriunda do detector MIMO, $\lambda^{1}(m, t)$, com a informação extrínseca obtida pela informação a priori acerca dos outros bits da sequência de bits transmitida e pela estrutura do código, caracterizada pelas recursões avante e reversa.

O logaritmo da probabilidade do $j$-ésimo bit de $\mathbf{b}^{\mathbf{t}}\left(\mathbf{w}^{\prime}, \mathbf{w}\right)$, $\log \left(P\left[b_{j}^{t}\left(\mathbf{w}^{\prime}, \mathbf{w}\right)\right]\right)$, é calculado com base nas LLRs a priori dos bits codificados, $\boldsymbol{\lambda}^{1}(m, t)$, da seguinte forma:

$\log \left(P\left[b_{j}^{t}\left(\mathbf{w}^{\prime}, \mathbf{w}\right)\right]\right)=\frac{-\boldsymbol{\lambda}^{1}(j, t)}{2}-\log \left(1+\exp \left\{-\boldsymbol{\lambda}^{1}(j, t)\right\}\right)+\frac{b_{j}^{t}\left(\mathbf{w}^{\prime}, \mathbf{w}\right) \boldsymbol{\lambda}^{1}(j, t)}{2}$.

De forma a calcular as LLRs dos bits de mensagem, $\Lambda^{3}\left(m^{t}\right)$, efetuada na última iteração do procedimento IDD, considera-se os conjuntos $\mathcal{U}_{m}^{+}$and $\mathcal{U}_{m}^{-}$formado pelos pares de estados $\left(\mathbf{w}^{\prime}, \mathbf{w}\right)$ tais que $m^{t}$ seja "+1" e "- 1 ", respectivamente. Sendo assim,

$$
\Lambda^{3}\left(m^{t}\right)=\log \frac{\sum_{\mathcal{U}_{m}^{+}} \exp \left\{\tilde{\alpha}^{t-1}\left(\mathbf{w}^{\prime}\right)+\tilde{\beta}^{t}(\mathbf{w})+\sum_{j=1}^{n_{0}} \log \left(P\left[b_{j}^{t}\left(\mathbf{w}^{\prime}, \mathbf{w}\right)\right]\right)\right\}}{\sum_{\mathcal{U}_{m}^{-}} \exp \left\{\tilde{\alpha}^{t-1}\left(\mathbf{w}^{\prime}\right)+\tilde{\beta}^{t}(\mathbf{w})+\sum_{j=1}^{n_{0}} \log \left(P\left[b_{j}^{t}\left(\mathbf{w}^{\prime}, \mathbf{w}\right)\right]\right)\right\}} .
$$

Após a obtenção das LLRs dos bits de mensagem na última iteração, o bit de informação $m_{i}^{t}$ é decodificado de acordo com

$$
m_{i}^{t}=\operatorname{sign}\left(\Lambda^{3}\left(m_{i}^{t}\right)\right)
$$

\subsection{2}

\section{Detector de entradas e saídas suaves PIC MF MIMO}

Nesta subseção, um detector de entradas e saídas suaves alternativo ao detector MAP para a obtenção de $\boldsymbol{\lambda}_{i}^{1^{\prime}}(m, t)$ é apresentado. Considerando a constelação de sinais estendida $\mathcal{B}^{N_{t}}$, as densidades de probabilidade da equação (4-2) podem ser desenvolvidas como:

$$
\begin{aligned}
& p\left[\mathbf{y}_{t} \mid b_{i}(m, t)= \pm 1\right]= \\
& =\frac{\sum_{\mathbf{a} \in \mathcal{B}^{N_{t}}}\left\{p\left[\mathbf{y}_{t} \mid b_{i}(m, t)= \pm 1, \mathbf{s}_{t}=\mathbf{a}\right] \cdot P\left[\mathbf{s}_{t}=\mathbf{a}, b_{i}(m, t)= \pm 1\right]\right\}}{P\left[b_{i}(m, t)= \pm 1\right]} \\
& =\frac{\sum_{\mathbf{a} \in \mathcal{A}_{i m}^{t \pm}} p\left[\mathbf{y}_{t} \mid \mathbf{s}_{t}=\mathbf{a}\right] P\left[\mathbf{s}_{t}=\mathbf{a}\right]}{P\left[b_{i}(m, t)= \pm 1\right]}
\end{aligned}
$$




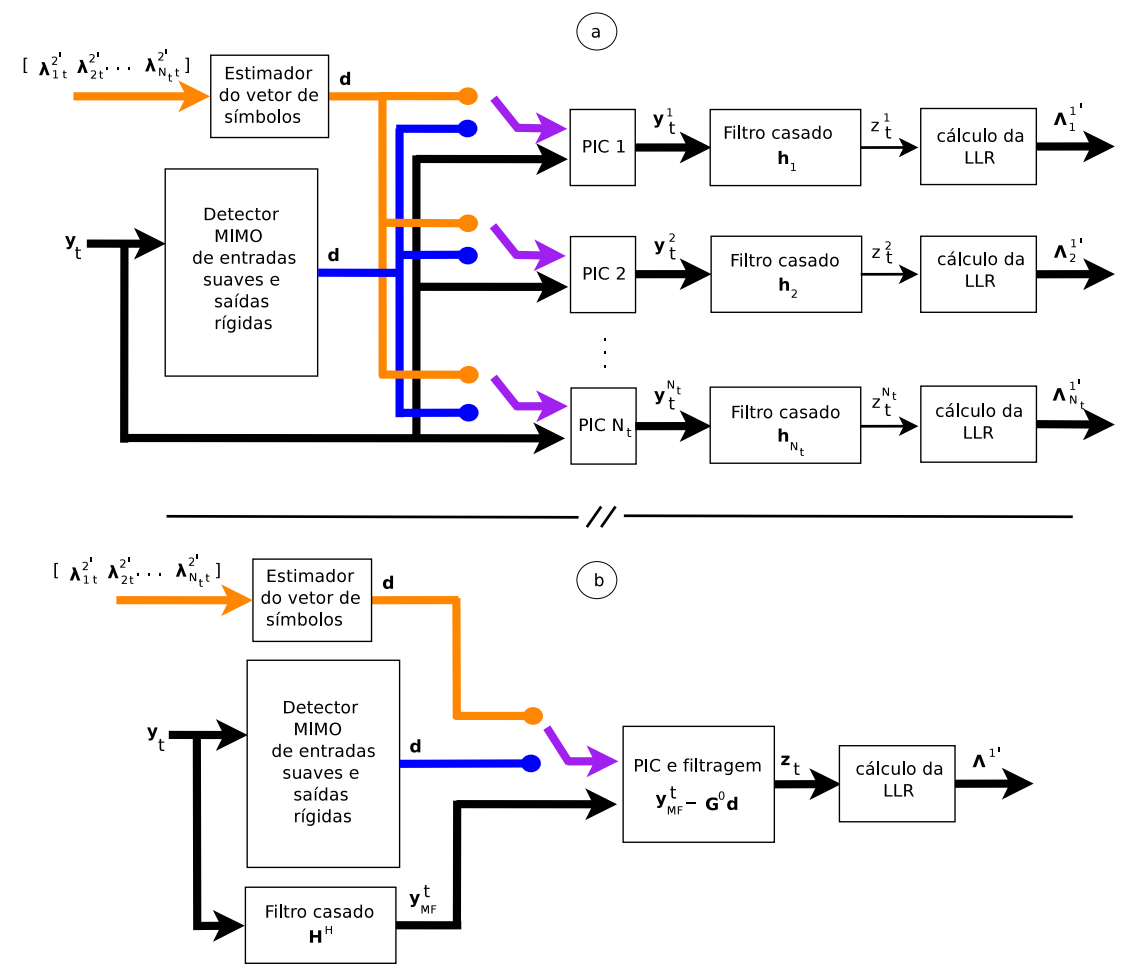

Figura 4.2: Detector MIMO de entradas e saídas suaves com cancelamento de interferência paralelo. a) estrutura analítica, b) estrutura sintética.

em que $\mathbf{s}_{t}=\left[s_{1 t}, s_{2 t}, \cdots, s_{N_{t} t}\right]$ é o vetor composto por todos os símbolos transmitidos no instante $t$, e $\mathcal{A}_{i m}^{t \pm}$ é o subconjunto de $\mathcal{B}^{N_{t}}$ tal que o $m$-ésimo bit referente a $s_{i t}$ é \pm 1 . Observa-se que o cálculo de $p\left[\mathbf{y}_{t} \mid b_{i}(m, t)=\right.$ \pm 1 ] como expresso em (4-19) possui complexidade computacional exponencial com $N_{t}$ de ordem $\mathcal{O}\left(2^{B N_{t}-1}\right)$.

De forma a evitar esta complexidade proibitiva, em decorrência dos estudos da presente tese, propôs-se a estratégia de detecção suave ilustrada na Figura 4.2 a). Ela consiste no cálculo das LLRs em duas etapas, sendo a primeira constituída de $N_{t}$ ramos distintos de cancelamentos paralelos de interferência (Parallel Interference Cancellation - PIC), referentes aos $N_{t}$ símbolos transmitidos em cada antena de transmissão, de forma a eliminar os efeitos da transmissão dos outros símbolos que não sejam o símbolo referente ao ramo respectivo. Na segunda etapa, as LLRs são calculadas a partir do resultado de uma filtragem casada do vetor recebido, já livre de interferências, $\mathbf{y}_{t}^{i}$, ao vetor de coeficientes de canal referente ao respectivo ramo, $\mathbf{h}_{\mathbf{i}}$. Sendo assim, o esquema de detecção e decodificação iterativo que emprega o detector MIMO suave descrito na Figura 4.2 será referido neste texto como esquema IDD PIC MF.

$\mathrm{Na}$ primeira etapa da primeira iteração do processo IDD, um detector MIMO de saídas rígidas (hard output) deve ser empregado nos cancelamentos 
de interferência. Este detector pode ser um dos detectores analisados no Capítulo 3 da presente tese. A partir da segunda iteração, as LLRs a priori $\lambda_{i t}^{2^{\prime}}, i=1, \cdots, N_{t}$, passadas pelos decodificadores na iteração anterior são utilizadas a fim de gerar estimativas dos símbolos transmitidos a serem empregadas no cancelamento de interferências. $\mathrm{O}$ vetor de sinal recebido no $i$-ésimo ramo, após o PIC, $\mathbf{y}_{t}^{i}$, é dado por:

$$
\mathbf{y}_{t}^{i}=\mathbf{y}_{t}-\mathbf{H}^{i-} \mathbf{d}
$$

em que $\mathbf{H}^{i-}$ é obtido da matriz de coeficientes de canal $\mathbf{H}$ com os elementos da sua $i$-ésima coluna modificados para 0. Assumindo o perfeito cancelamento das interferências, $\mathbf{y}_{t}^{i}$ é dado por:

$$
\mathbf{y}_{t}^{i}=\mathbf{h}_{i} s_{i t}+\mathbf{n} .
$$

Seja $z_{t}^{i}$ o resultado da pré-multiplicação de $\mathbf{y}_{t}^{i}$ por $\mathbf{h}_{i}^{H}$ :

$$
z_{t}^{i}=\mathbf{h}_{i}^{H} \mathbf{h}_{i} s_{i t}+\mathbf{h}_{i}^{H} \mathbf{n}=s_{i t}^{\prime}+n^{\prime}
$$

Sendo assim, dado $s_{i t}$, $z_{t}^{i}$ é uma variável aleatória gaussiana complexa com média $s_{i t}^{\prime}=\mathbf{h}_{i}^{H} \mathbf{h}_{i} s_{i t}$ e variância igual a $\sigma_{n^{\prime}}^{2}=\sigma_{n}^{2} \mathbf{h}_{i}^{H} \mathbf{h}_{i}$. Dessa forma, $\boldsymbol{\lambda}_{i}^{1^{\prime}}(m, t)$ em (4-2) pode ser aproximado por:

$$
\boldsymbol{\lambda}_{i}^{1^{\prime}}(m, t) \approx \log \frac{p\left[z_{t}^{i} \mid b_{i}(m, t)=+1\right]}{p\left[z_{t}^{i} \mid b_{i}(m, t)=-1\right]} .
$$

Considerando $\mathcal{C}_{i m}^{t \pm}$, o subconjunto de $\mathcal{B}$ tal que $\mathcal{C}_{i m}^{t \pm}=\left\{s_{i t} \mid\right.$ o $m$-ésimo respectivo bit de $s_{i t}$ é \pm $1\}$, as densidades de probabilidade em (4-23) podem ser calculadas por:

$$
p\left[z_{t}^{i} \mid b_{i}(m, t)= \pm 1\right]=\frac{\sum_{s_{i t} \in \mathcal{C}_{i m}^{t \pm}} p\left[z^{i} \mid s_{i t}\right] P\left[s_{i t}\right]}{P\left[b_{i}(m, t)= \pm 1\right]}
$$

em que $p\left[z_{t}^{i} \mid s_{i t}\right]$ é dado por

$$
p\left[z_{t}^{i} \mid s_{i t}\right]=\frac{1}{\pi \sigma_{n^{\prime}}^{2}} \exp \left\{\frac{-\left|z_{t}^{i}-\mathbf{h}_{i}^{H} \mathbf{h}_{i} s_{i t}\right|^{2}}{\sigma_{n^{\prime}}^{2}}\right\} .
$$

Da equação acima, verifica-se que a complexidade para o cálculo de $\boldsymbol{\lambda}_{i}^{1^{\prime}}(m, t)$ segundo (4-23) é da ordem de $\mathcal{O}\left(2^{B}\right)$, ou seja, independente do número de antenas de transmissão.

Este detector alternativo de entradas e saídas suaves pode ser mais convenientemente implementado por meio da junção das operações de PIC e filtragem como ilustrado na Figura 4.2 b). Neste caso, $\mathbf{z}_{t}=\left[z_{t}^{1}, z_{t}^{2}, \cdots, z_{t}^{N_{t}}\right]$ é dado por:

$$
\mathbf{z}_{t}=\mathbf{y}_{M F}^{t}-\mathbf{G}^{0} \mathbf{d},
$$

em que $\mathbf{G}^{0}$ é obtido da matriz $\mathbf{G}=\mathbf{H}^{H} \mathbf{H}$ com seus elementos da diagonal 
principal mudados para 0 , e $\mathbf{y}_{M F}^{t}=\mathbf{H}^{H} \mathbf{y}_{t}$.

Destaca-se que a aproximação em (4-23) depende do correto cancelamento de interferência realizado em (4-20). Inicialmente, a eficiência deste cancelamento de interferência depende do resultado da detecção do detector interno empregado na primeira etapa da primeira iteração, porém, conforme as iterações progridem, devido à melhoria da detecção dos símbolos transmitidos, o resultado do PIC também melhora. Sendo assim, a perda de desempenho em termos de BER causada pelo uso de detectores internos mais simples é mitigada pelo aumento no número de iterações no processo IDD, conforme será evidenciado nos resultados de simulações apresentados na Seção 4.3. Apesar disso, é importante ter em mente que, como o detector MIMO de entradas e saídas suaves e os decodificadores empregados no processo IDD empregam indiretamente o mesmo conjunto de informações, esta melhoria resultante do aumento do número de iterações irá diminuir gradualmente.

\section{3}

\section{Resultados de simulação}

Nesta seção, resultados de simulações de Monte Carlo são apresentados com o objetivo de ilustrar o desempenho das estratégias iterativas IDD PIC MF em termos de complexidade computacional avaliada pelo número médio de flops por bit de mensagem (não codificado). As simulações foram realizadas considerando os cenários A e $\mathrm{B}$ descritos no Capítulo 2. Para o cenário B, o índice de correlação entre antenas adjacentes empregado foi $\rho=0.2$ e o espalhamento de sombreamento (shadowing spread) foi considerado o mesmo para todos os usuários e igual a $\sigma_{k}=6 d B, k=1,2, \cdots, K$. Os resultados são uma média de 10000 ensaios, cada um composto pela transmissão de 126 bits de mensagem por usuário por antena de transmissão em que a modulação 4-QAM foi empregada. Todos os usuários do sistema possuem $N_{t_{k}}=2$ antenas de transmissão e foram utilizados entrelaçadores aleatórios [61] no caso do esquema IDD PIC MF. As matrizes de coeficientes de canal foram consideradas invariantes durante a transmissão de um quadro e o código corretor de erros empregado em todos os casos foi o código convolucional sistemático recursivo de taxa $R=0.5, \operatorname{RSC}(7,5)$, cujos polinômios geradores avante e reverso são $G_{f}(D)=1+D+D^{2}$ e $G_{r}(D)=1+D^{2}$, respectivamente [61].

Foram efetuadas simulações considerando as matrizes de coeficientes de canal conhecidas no receptor e também simulações em que essas matrizes foram estimadas empregando-se a transmissão de sequências de sinais pilotos ortogonais de 32 bits de comprimento conforme disposto na Seção 2.4 do Capítulo 2. Em todos os resultados apresentados, a SNR na etapa de estimação 
foi considerada igual à SNR empregada na transmissão de dados. Para a estratégia IDD PIC MF, os parâmetros dos detectores internos empregados foram: $N_{p_{\text {min }}}=2$ e $c_{1}=5$ para o detector MF-RLB-LAS e o número de iterações empregadas no detector MSCS-LAS foi $N_{l}=5$. O número de flops foi calculado com o auxílio da biblioteca de funções do Matlab Lightspeed Matlab toolbox [50].

A fim de se comparar o desempenho de sistemas codificados e não codificados, os resultados apresentados a seguir são avaliados em função da razão sinal-ruído de informação $\left(S N R_{B}\right)$, referente aos bits de mensagem antes da codificação, definida por $S N R_{B}=\frac{N_{t}}{R \sigma_{n}^{2}}$, uma vez que a energia por bit antes da codificação é maior do que a energia por bit depois da codificação na proporção inversa à taxa do código empregado, consideradas inalteradas a taxa de bits de informação e a potência de transmissão. Sendo assim, a razão sinal-ruído antes da codificação é maior do que a razão sinal-ruído depois da codificação, ou seja:

$$
S N R_{B}=\frac{S N R}{R}=\frac{N_{t}}{R \sigma_{n}^{2}} .
$$

As Figuras 4.3 a 4.8 apresentam curvas de BER versus $S N R_{B}$ para um sistema com $N_{t}=N_{r}=20$ que emprega o esquema IDD PIC MF para diversas iterações do processo IDD. Nessas figuras, são ilustrados resultados tanto para os casos nos quais os coeficientes de canal são considerados conhecidos, quanto para quando estes coeficientes são estimados no receptor com o auxílio de sinais pilotos.

A Figura 4.3 ilustra os resultados de BER quando o detector MF-1LAS é empregado como detector interno do esquema IDD PIC MF, considerando o cenário A. Os resultados apresentados mostram que para valores de $S N R_{B}$ suficientemente elevados, a BER melhora a cada iteração e, como mencionado anteriormente, essa melhoria diminui ao passo em que o número de iterações cresce, até o ponto em que não há mais ganho considerável. Observa-se ainda, que o erro de estimação do canal degrada significativamente a BER do esquema IDD PIC MF que emprega o detector interno MF-1LAS. Além disso, o erro de estimação aumenta o valor de $S N R_{B}$ a partir do qual a BER melhora com novas iterações, diminuindo o intervalo de valores de $S N R_{B}$ em que é vantajosa a execução de mais de uma iteração.

Por sua vez, ao ser considerado o cenário B, verifica-se a partir da Figura 4.4 que, apesar de ocorrer uma degradação geral da BER, visto que se trata de um ambiente mais desafiador, novas iterações não degradam a BER, como no cenário ideal para valores pequenos de $S N R_{B}$, independentemente dos valores da $S N R_{B}$ considerados. Além disso, a degradação de desempenho decorrente dos erros de estimação de canal, apesar de existentes, são menos significativas 

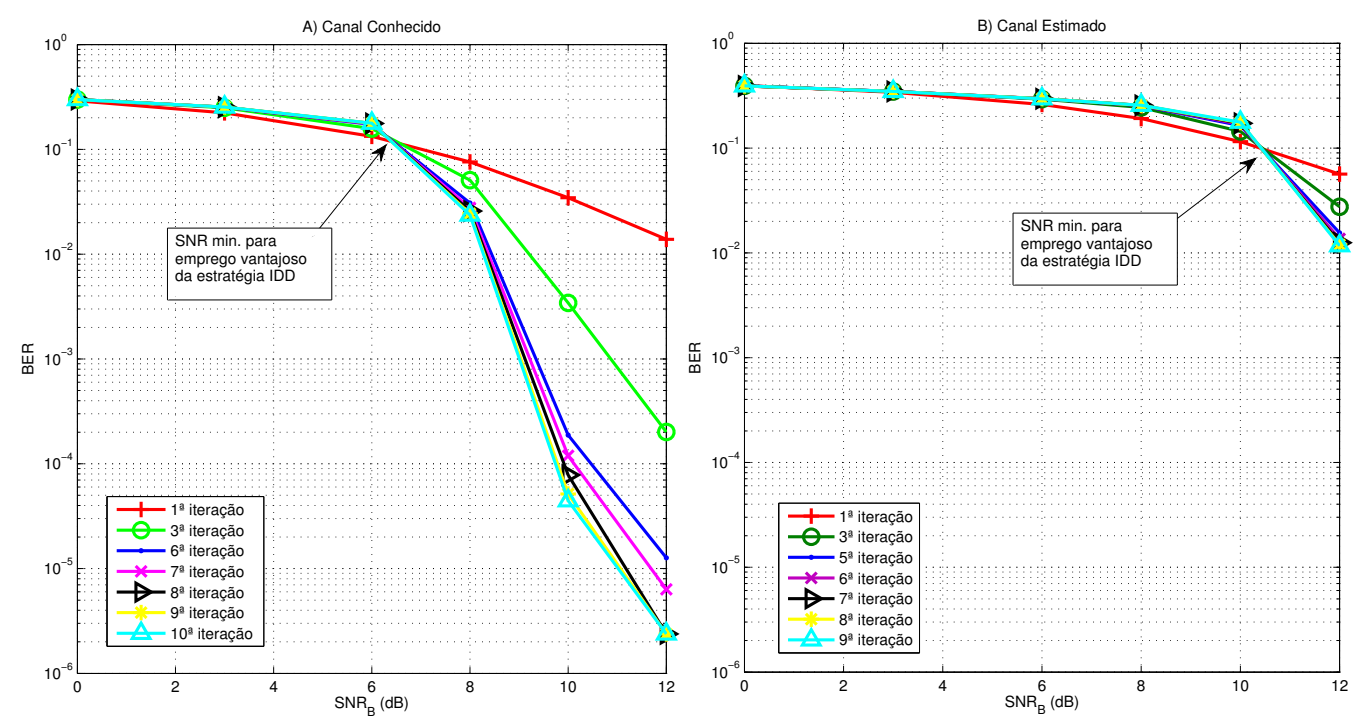

Figura 4.3: BER versus $S N R_{B}$ de diversas iterações da detecção IDD turbo com o detector interno MF-1LAS para sistemas MIMO com $N_{r}=N_{t}=20$ para canal conhecido e estimado no cenário A.

do que no caso do cenário ideal. Este fato indica que os erros de estimação tornam-se de menor expressão em face das distorções impostas pelo canal. Verifica-se ainda que o número de iterações até se chegar à saturação também é reduzido no cenário B: enquanto que no cenário A a estratégia IDD PIC MF com o detector MF-1LAS levou 8 iterações para o caso de canal conhecido e 5 iterações para o canal estimado, no cenário B, ambos os casos atingiram a saturação da BER com apenas 3 iterações.

Os mesmos resultados para o caso em que foram empregados os detectores internos MSCS-LAS e MF-RLB-LAS são apresentados nas Figuras 4.5 e 4.7, para o detector MSCS-LAS, e nas Figuras 4.6 e 4.8 para o detector MF-RLBLAS. Considerando o cenário A, observa-se das Figuras 4.5 e 4.6 que o valor limite da $S N R_{B}$, após o qual a execução de novas iterações passa a melhorar o desempenho do esquema IDD PIC MF mantém-se inalterado mesmo ao se empregar detectores internos mais sofisticados (e complexos). Apesar disso, verifica-se que a degradação oriunda dos erros de estimação é reduzida com o uso destes detectores internos e que o número de iterações necessárias para se atingir a saturação de desempenho é reduzido de 8 (1-MLAS) para 5 (MSCSLAS/MF-RLB-LAS) no caso em que os coeficientes de canal são conhecidos.

Ao se considerar o cenário B, verifica-se dos resultados apresentados nas Figuras 4.7 e 4.8 que a saturação é alcançada já na segunda iteração para ambos detectores internos.

A Figura 4.9 apresenta as curvas de BER mínima alcançada pelos 

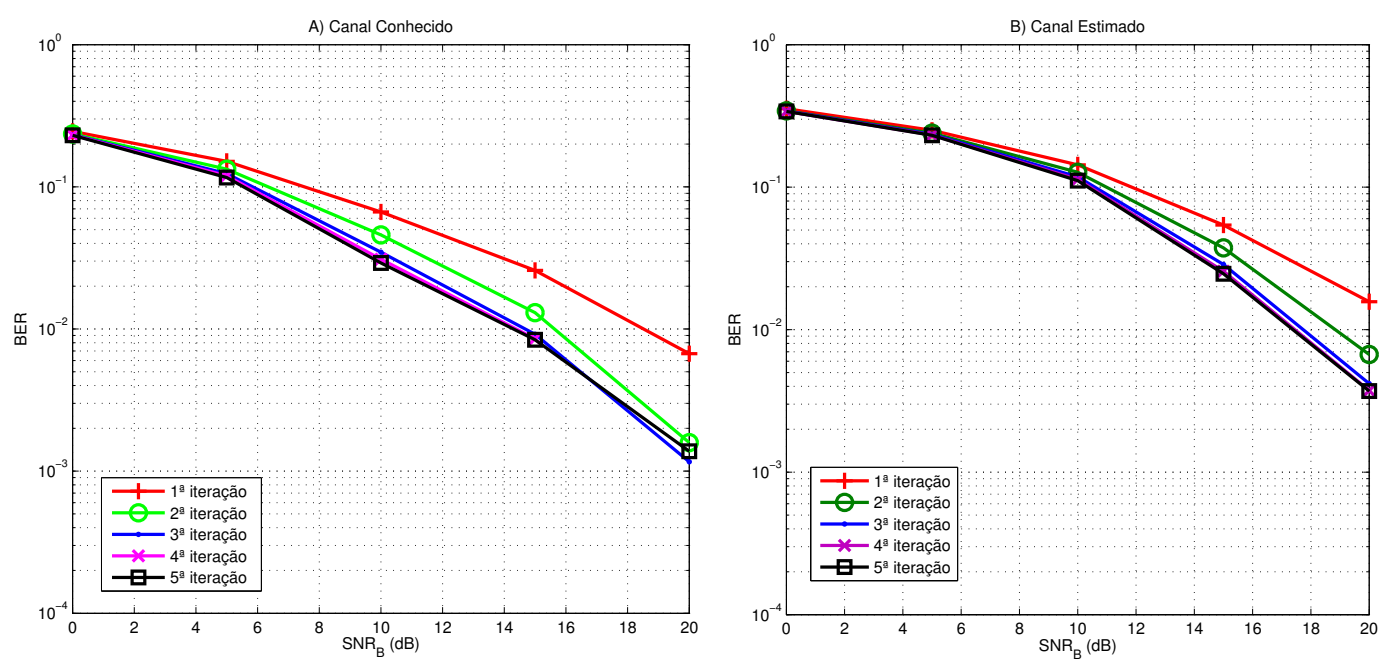

Figura 4.4: BER versus $S N R_{B}$ de diversas iterações da detecção IDD turbo com o detector interno MF-1LAS para sistemas MIMO com $N_{r}=N_{t}=20$ para canal conhecido e estimado no cenário B com $\rho=0.2$ and $\sigma_{k}=6 d B$.

esquemas IDD PIC MF com os detectores internos MF-1LAS, MSCS-LAS e RLB-LAS, além das curvas de BER de esquemas tradicionais de detecção seguido de decodificação que empregam o decodificador de Viterbi [61] e os detectores MSCS-LAS e MF-RLB-LAS, bem como curvas de BER dos sistemas não codificados que empregam os detectores MSCS-LAS e MF-RLB-LAS. Todos os resultados foram obtidos considerando-se o cenário A com as matrizes de coeficientes de canais estimadas com o auxílio de sinais pilotos. Apesar do número de iterações necessárias para alcançar a BER mínima no esquema IDD PIC MF depender do detector interno empregado, o esquema IDD PIC MF com o detector MF-RLB-LAS obteve o melhor resultado de BER, seguido de perto pelo esquema IDD PIC MF com o detector MSCS-LAS. Ao se compararem os resultados das diferentes estratégias presentes na figura, verifica-se que, com exceção dos esquemas IDD PIC MF com MF-RLB-LAS e MSCS-LAS, todos os esquemas de transmissão considerados obtiveram desempenho em termos de BER pior do que a transmissão não codificada com o detector MF-RLB-LAS para a faixa de $S N R_{B}$ considerada. O esquema IDD PIC MF ultrapassou o desempenho do sistema não codificado MF-RLB-LAS para valores de $S N R_{B}$ maiores do que $11 \mathrm{~dB}$.

Os resultados de BER dos sistemas IDD PIC MF que utilizam os detectores MF-RLB-LAS e MF-1MLAS, bem como o resultado do esquema tradicional de detecção MF-RLB-LAS seguido de decodificação de Viterbi e os resultados dos detectores MF-RLB-LAS e MSCS-LAS em sistemas não codificados para o cenário B são apresentados na Figura 4.10, em que os 

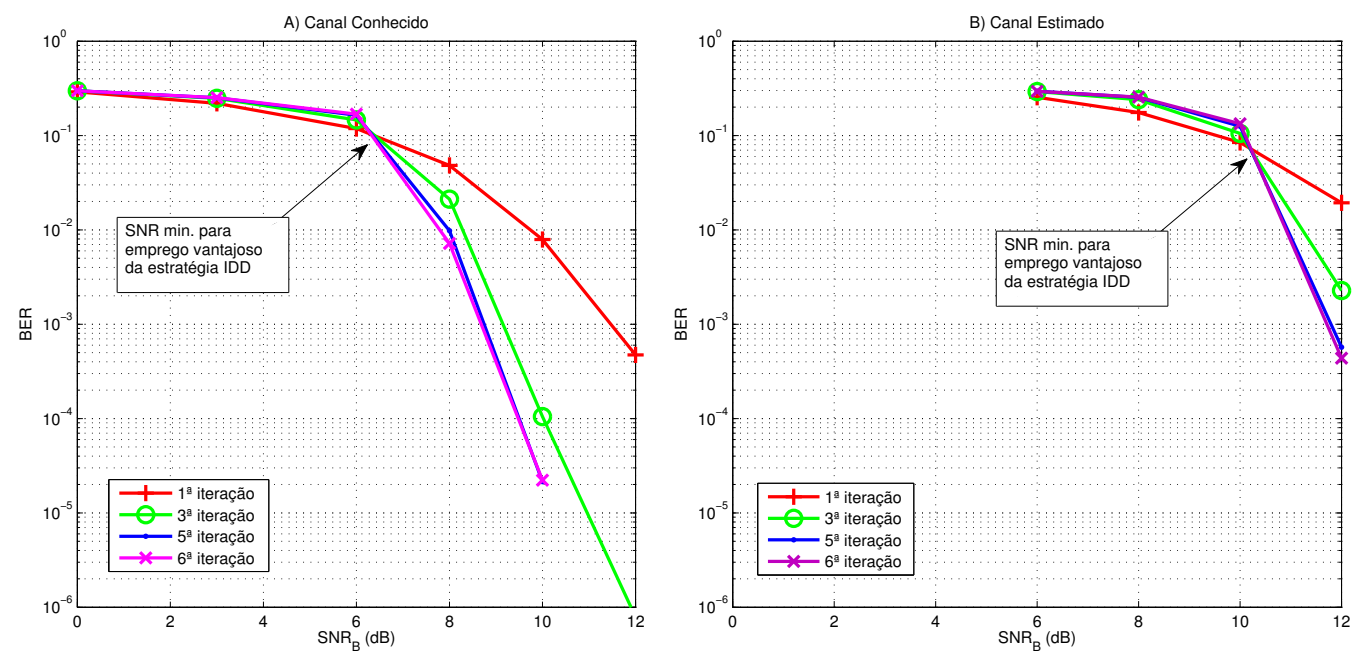

Figura 4.5: BER versus $S N R_{B}$ de diversas iterações da detecção IDD turbo com o detector interno 5-MSCS-LAS para sistemas MIMO com $N_{r}=N_{t}=20$ para canal conhecido e estimado no cenário A.
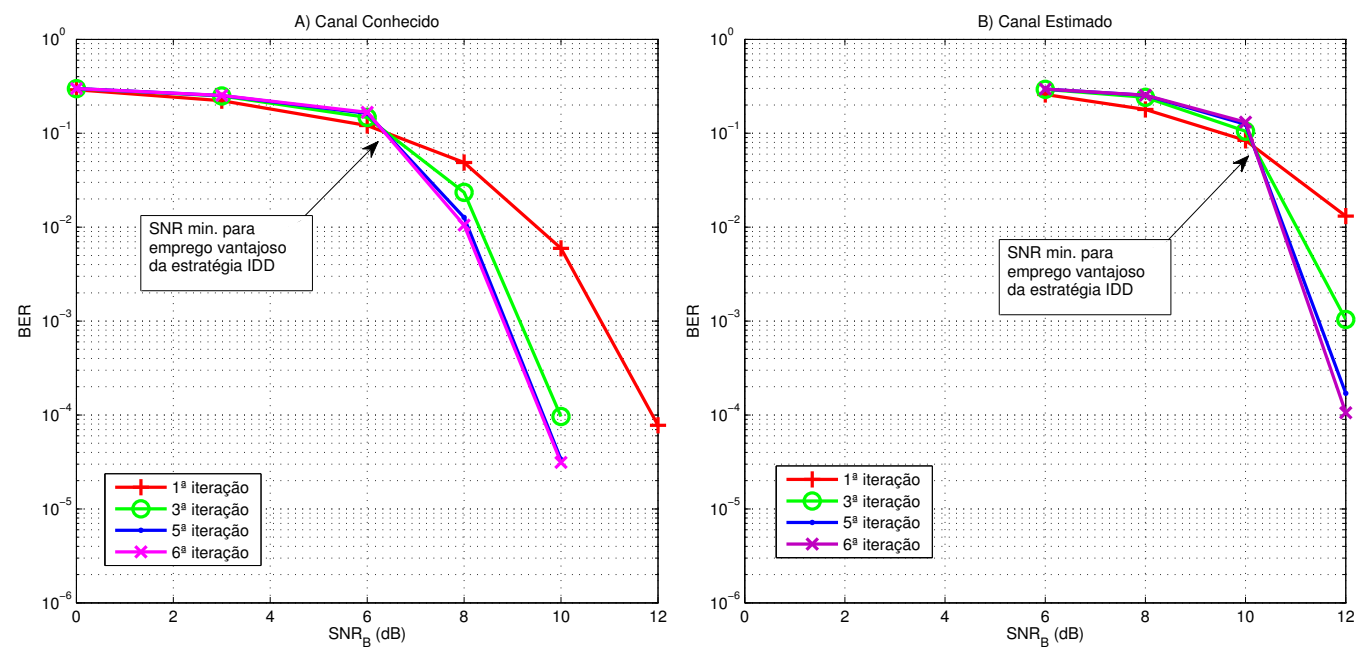

Figura 4.6: BER versus $S N R_{B}$ de diversas iterações da detecção IDD turbo com o detector interno MF-RLB-LAS para sistemas MIMO com $N_{r}=N_{t}=20$ para canal conhecido e estimado no cenário A. 

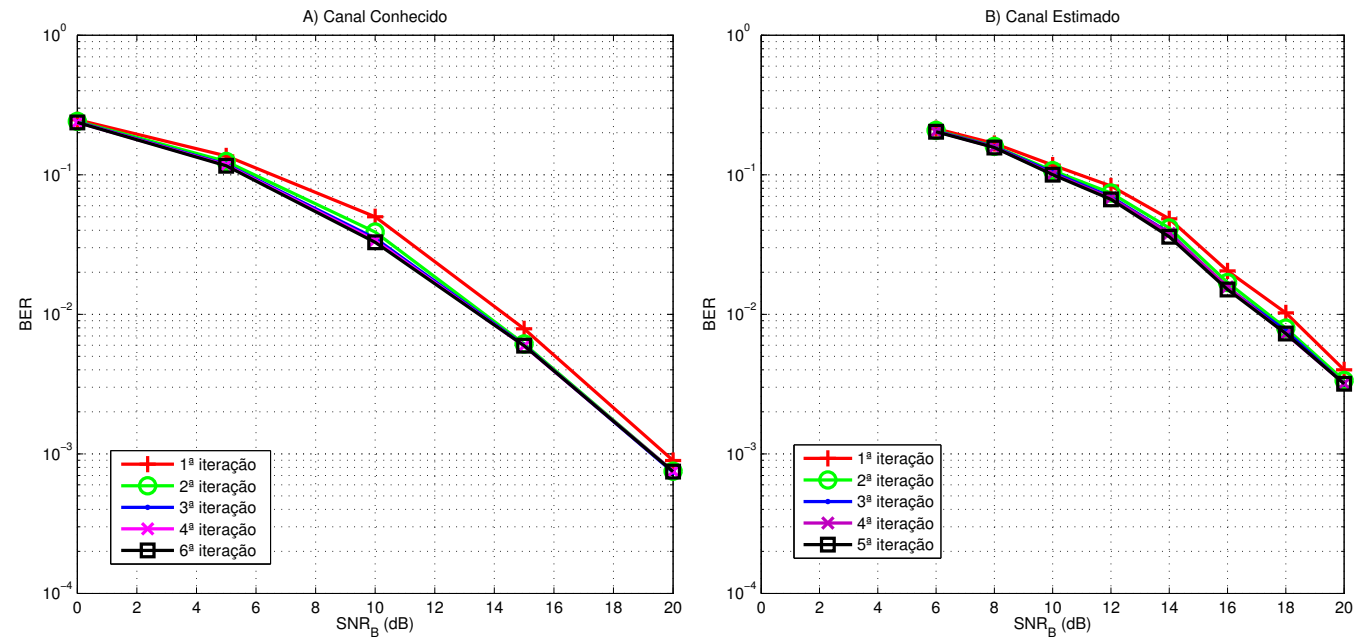

Figura 4.7: BER versus $S N R_{B}$ de diversas iterações da detecção IDD turbo com o detector interno 5-MSCS-LAS para sistemas MIMO com $N_{r}=N_{t}=20$ para canal conhecido e estimado no cenário B com $\rho=0.2$ and $\sigma_{k}=6 d B$.
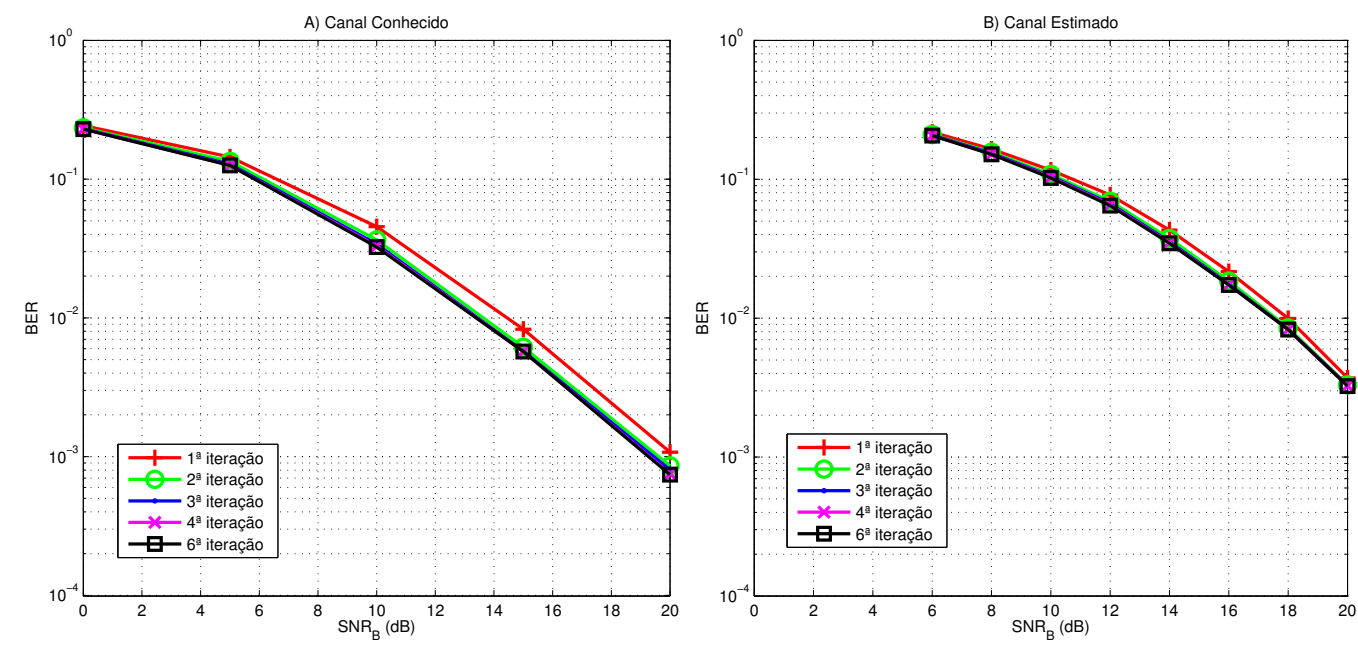

Figura 4.8: BER versus $S N R_{B}$ de diversas iterações da detecção IDD turbo com o detector interno MF-RLB-LAS para sistemas MIMO com $N_{r}=N_{t}=20$ para canal conhecido e estimado no cenário B $\operatorname{com} \rho=0.2$ and $\sigma_{k}=6 d B$. 


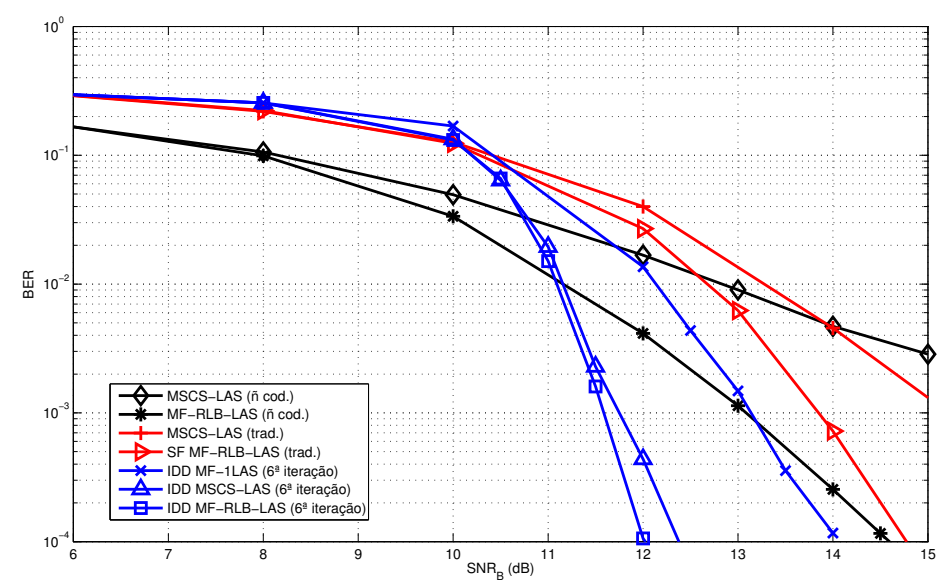

Figura 4.9: BER versus $S N R_{B}$ de diversos esquemas de detecção e decodificação para sistemas MIMO com $N_{r}=N_{t}=20$ sujeito às condições do cenário A para canal estimado.

coeficientes de canal foram estimados. As curvas de BER obtidas para a estratégia de detecção e decodificação IDD PIC MF com MSCS-LAS e para a detecção MSCS-LAS seguida da decodificação de Viterbi não são apresentadas nesta figura por motivo de manter-se a sua clareza, uma vez que as curvas obtidas para as mencionadas estratégias foram muito próximas às curvas dos esquemas IDD PIC MF com MF-RLB-LAS e da estratégia tradicional de detecção MF-RLB-LAS seguida da decodificação de Viterbi, respectivamente. Observa-se a partir das curvas apresentadas nesta figura que, para canais mais desafiadores, todas as estratégias de detecção e decodificação alcançam resultados similares. Mesmo assim, as estratégias tradicionais de detecção seguida de decodificação obtiveram resultados ligeiramente piores que os dos sistemas não codificados. Além disso, para valores de $S N R_{B}$ maiores que $25 \mathrm{~dB}$, o esquema IDD PIC MF com MF-RLB-LAS (bem como com MSCS-LAS) obteve melhor desempenho do que o dos sistemas não codificados.

A Figura 4.11 apresenta a complexidade computacional em termos do número médio de flops versus $S N R_{B}$ das estratégias IDD PIC MF com os detectores internos MF-1LAS, MSCS-LAS and MF-RLB-LAS, bem como curvas de complexidade para as estratégias tradicionais de detecção MF-RLBLAS e MSCS-LAS seguidas de decodifivação de Viterbi, além da complexidade de detectores MF-RLB-LAS e MSCS-LAS em sistemas não codificados. Estes resultados são apresentados para os seguintes casos: a) cenário A com canal conhecido; b) cenário A com canal estimado; c) cenário B com canal conhecido; e d) cenário B com canal estimado. Para os esquemas IDD PIC MF, as curvas de complexidade apresentadas referem-se ao número mínimo de iterações 


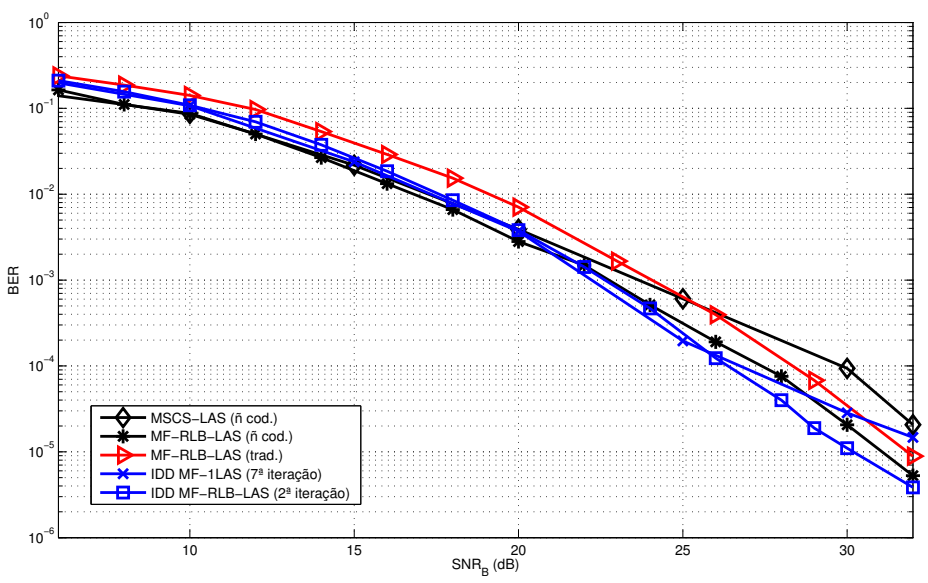

Figura 4.10: BER versus $S N R_{B}$ de diversos esquemas de detecção e decodificação para sistemas MIMO com $N_{r}=N_{t}=20$ sujeito às condições do cenário B $\operatorname{com} \rho=0.2$ e $\sigma_{k}=6 d B$.

necessárias para se alcançar a BER mínima em cada esquema, conforme discutido nos resultados apresentados anteriormente. Observando estas curvas de complexidade, verifica-se que os ganhos na BER quando é empregado o esquema IDD PIC MF são obtidos com aumentos aceitáveis na complexidade computacional, especialmente ao se compararem os resultados da estratégia tradicional com detecção MF-RLB-LAS com os resultados do esquema IDD PIC MF com detector interno MF-RLB-LAS em todos os casos apresentados.

É interessante apontar que, observando a curva de complexidade do esquema IDD PIC MF, que utiliza o MF-1LAS como detector interno, verificase que a complexidade computacional deste esquema é maior no caso mais simples, i.e. cenário A com canal conhecido, do que nos demais casos analisados. Este fato é explicado pelo número de iterações necessárias para alcançar a saturação da BER deste detector nos diversos casos. Como a complexidade do detector MF-1LAS não depende das condições do canal, a complexidade total da estratégia IDD PIC MF com este detector dependerá apenas do número de iterações realizadas. Tendo em vista que no caso do cenário A com canal conhecido o detector IDD PIC MF com MF-1MLAS efetua mais iterações até alcançar a saturação na BER do que nos demais casos, a sua complexidade computacional acaba sendo maior neste caso do que nos demais. O mesmo ocorre no caso da estratégia IDD PIC MF com o detector MSCS-LAS, ao se comparar os seus resultados nos cenários A e B, tanto com canais conhecidos quanto com canais estimados. No cenário A, este esquema emprega 5 iterações para chegar na curva de BER mínima, enquanto que no cenário B, apenas são necessárias 2 iterações. Já para o caso IDD PIC MF com o detector MF-RLB- 

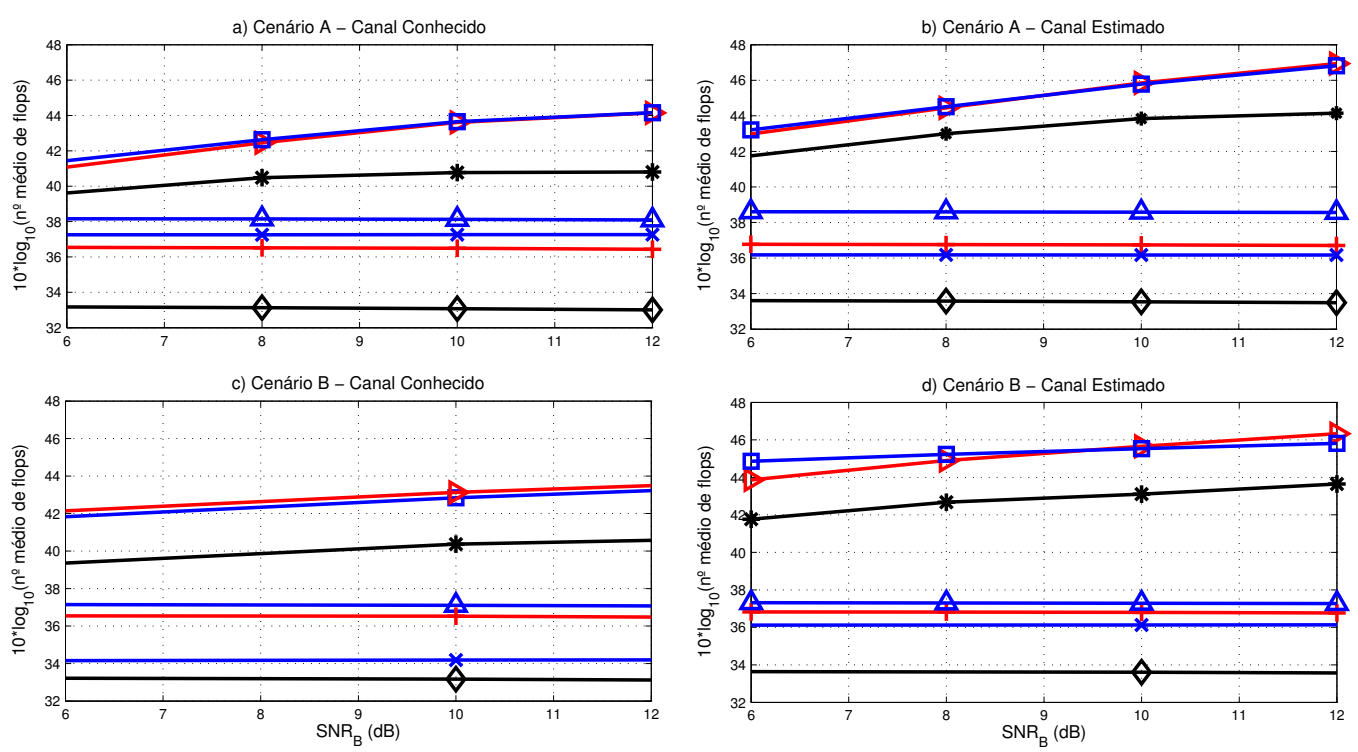

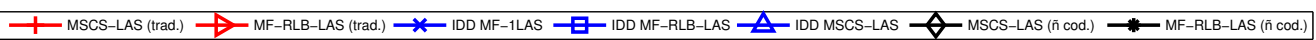

Figura 4.11: Complexidade computacional total de diversos esquemas de detecção e decodificação para um sistema MIMO com $N_{r}=N_{t}=20$.

LAS, não é possível afirmar o mesmo, uma vez que a complexidade do detector MF-RLB-LAS depende das condições dos canais de comunicações. Neste caso, ocorrem duas situações conflitantes: ao passo em que o número de iterações do esquema IDD requeridas para se alcançar a saturação diminui para canais mais desafiadores, o número de buscas 1-MLAS efetuadas na detecção MF-RLBLAS aumenta. Por essa razão observa-se nas curvas apresentadas para esse esquema de detecção e decodificação que, para valores de $S N R_{B}$ pequenos, a complexidade aumenta ligeiramente do cenário A para o cenário $\mathrm{B}$, ao passo em que, para valores mais elevados da $S N R_{B}$, essa mesma complexidade diminui.

Observando os resultados de complexidade e BER apresentados para o cenário A, verifica-se que é vantajoso empregar o esquema IDD PIC MF com o detector interno MSCS-LAS, uma vez que essa estratégia obtém melhores resultados em termos de BER com complexidade computacional menor do que a estratégia não codificada com detecção MF-RLB-LAS. Para o cenário $\mathrm{B}$, observou-se que, para valores pequenos da $S N R_{B}$ todas as estratégias apresentaram resultados de desempenho em termos de BER similares. Sendo assim, para a faixa de $S N R_{B} \leq 20 \mathrm{~dB}$, dentre as estratégias consideradas, recomenda-se o uso da menos complexa, ou seja, o emprego de sistemas não codificados com detecção MSCS-LAS. Já para valores elevados da $S N R_{B}$, a estratégia IDD PIC MF com o detector MSCS-LAS é recomendada, visto que ela obteve os melhores resultados em termos de BER com complexidade computacional não superior a 2.32 vezes a complexidade do esquema menos 
complexo (MSCS-LAS não codificado).

\section{4}

\section{Conclusão}

Apesar dos sistemas MIMO de larga escala possuírem a capacidade de melhorar significativamente as taxas de transmissão alcançáveis em sistemas de comunicações sem fio, o aumento do número de elementos de transmissão e recepção impõe uma elevada complexidade computacional aos receptores desses sistemas, especialmente quando esquemas de codificação são empregados. Neste capítulo, foi apresentada a estratégia de detecção e decodificação conjunta iterativa (IDD) aplicada aos sistemas MIMO que propicia bons resultados em termos da diminuição da taxa de erros de bits desses sistemas.

Com o intuito de diminuir a complexidade computacional dos esquemas IDD, foi proposto um detector MIMO de entradas e saídas suaves baseado em técnicas de cancelamento paralelo de interferências e filtragem como alternativa ao detector MAP empregado em tais esquemas. Na primeira iteração do processo IDD, o detector proposto faz uso do resultado da detecção de um detector de entradas suaves e saídas rígidas, como os detectores apresentados no capítulo anterior, para efetuar o referido cancelamento de interferências que visa a redução do espaço de busca da detecção MAP.

Foram apresentados resultados de simulações a fim de comparar a estratégia IDD PIC MF proposta com sistemas não codificados e sistemas que empregam a estratégia tradicional de efetuar a detecção da sequência de bits codificada e, em seguida, a sua decodificação. Ambos os cenários A e B, descritos no capítulo 2, foram analisados e considerou-se situações em que os coeficientes da matriz de canal eram conhecidos pelo receptor e situações em que esses coeficientes foram estimados por meio do envio de sinais pilotos.

As simulações efetuadas mostraram que a estratégia IDD PIC MF é vantajosa em todos os cenários analisados apresentando melhores resultados em termos de BER e complexidade computacional, avaliada em termos do número médio de flops por bit de mensagem transmitido, do que as estratégias tradicionais de detecção seguida de decodificação e a alternativa de não empregar codificação.

No próximo capítulo os efeitos das interferências oriundas de outras células componentes dos sistemas MIMO multicelulares serão abordados. Em especial, será tratado o problema da contaminação por sinais pilotos, um dos principais limitantes às vantagens oriundas do aumento do número de elementos de transmissão nos sistemas de múltiplas antenas. 


\section{5}

\section{Contaminação por Pilotos e Estimação e Detecção Conjuntas}

\section{1 \\ Introdução}

Neste capítulo será abordado o problema da contaminação por pilotos no processo de estimação das matrizes de coeficientes de canal em sistemas MIMO multicelulares, que é oriunda das interferências causadas pelo emprego de sequências pilotos não ortogonais nas diferentes células do sistema de comunicações.

Em [6], é defendido que no limite, quando o número de antenas das EB de sistemas MIMO multicelulares tende a infinito, considerando um número finito de usuários munidos de um número finito de antenas, o único efeito degradante do sistema que não pode ser eliminado é a contaminação por pilotos. De fato, ganhos expressivos na capacidade de transmissão e na eficiência energética desses sistemas foram demonstrados e explorados em $[14,15]$ sob as condições de que as suas células são isoladas umas das outras e suas estações base possuem completo conhecimento dos estados dos canais envolvidos.

Em $[6,62]$ foram derivadas expressões para a SINR de sistemas MIMO multicelulares considerando os efeitos das interferências oriundas do emprego de sinais pilotos não ortogonais em células distintas. Verifica-se nesses estudos que, mesmo no caso limite em que o número de antenas das EB cresce ilimitadamente, a SINR atinge um valor assintótico. Dessa forma, o desempenho desses sistemas estaria limitado pelas interferências intercelulares, oriundas do emprego de sequências pilotos não ortogonais nas diferentes células. Nesses sistemas, as EB de cada célula operam independentemente das demais, constituindo assim um sistema não cooperativo.

Tendo como foco o problema da contaminação por pilotos, trabalhos com o objetivo de minimizar os efeitos dessas interferências foram realizados [63-67]: em [64], um esquema de estimação e detecção iterativo foi proposto em que a cada iteração os símbolos detectados nas iterações anteriores são empregados, juntamente com os sinais pilotos, para se obter estimativas dos canais menos degradadas pela contaminação por pilotos, que são empregadas na detecção do bloco de símbolos da iteração atual; em [65], propôs-se diferentes padrões de 
distribuição dos sinais pilotos dentro do quadro de símbolos transmitidos; em [66], o uso de padrões como os empregados em [65] são aliados a esquemas de controle de potência para a diminuição das interferências entre sinais pilotos; e em [67], a alocação de sinais pilotos é determinada pelo nível de interferência entre as células adjacentes.

Apesar disso, em [68] verificou-se que, caso seja permitida a cooperação entre as EB das diversas células, sob determinadas condições, é possível eliminar os efeitos da contaminação por pilotos. Além disso, em [69], foi proposto um esquema cooperativo de pré-codificação no enlace direto e filtragem no enlace reverso, destinado a combater os efeitos da contaminação por pilotos. Ainda em [69], expressões para a SINR de sistemas MIMO que empregam esse esquema foram derivadas para o caso em que o número de antenas nas EB tenda a infinito e verifica-se, a partir dessas expressões, que a contaminação por pilotos pode ser efetivamente eliminada.

Ressalta-se que as estratégias mencionadas anteriormente baseiam-se no seguinte modo de operação: inicialmente emprega-se estimadores dos coeficientes de canal entre as diversas antenas do sistema e, com base nessas estimativas, efetua-se a devida detecção do sinal transmitido. Alternativamente, a estimação do canal e a detecção do sinal transmitido podem ser realizadas conjuntamente, i.e., as sequências de treinamento e de dados são transmitidas sucessivamente e, no lado do receptor, todo o sinal recebido é processado de forma conjunta para realizar a detecção da sequência de dados. Esta estratégia baseia-se no fato de que o processamento conjunto das sequências de treinamento conhecidas e do sinal recebido propicia o aproveitamento completo da informação acerca do canal presente no sinal recebido, como feito em [70].

Em [16] o detector teórico de máxima verossimilhança é considerado na detecção e estimação conjunta de sistemas MIMO multicelulares e expressões para a probabilidade de erro símbolo a símbolo (pair-wise) são derivadas. Com base nessas expressões, limitantes superiores e inferiores dessa probabilidade são encontrados e analisados no limite em que a SNR cresce. Verifica-se em [16] que é possível, sob determinadas condições acerca da constelação de símbolos empregada e do tamanho da sequência de dados enviada, levar a probabilidade de erro símbolo a símbolo a zero com o aumento da SNR.

A partir do trabalho de [16] é proposto nesta tese um esquema de detecção e estimação conjuntas com cooperação parcial entre as EB do sistema multicelular. Esta proposta é baseada nas estratégias de detecção LAS, a fim de mitigar os efeitos da contaminação por pilotos presente nos sistemas MIMO multicelulares, uma vez que o detector ML, apesar de ótimo, não apresenta viabilidade de implementação prática devido à sua grande complexidade 
computacional, em especial em sistemas MIMO de larga escala.

O restante deste capítulo está estruturado da seguinte forma: na próxima seção, o modelo do sistema multiusuário multicelular é brevemente descrito e o efeito da contaminação por pilotos no sinal recebido é explicitado matematicamente; na Seção 5.3, são apresentadas as propostas de esquemas de estimação e detecção conjuntas analisadas neste trabalho; na Seção 5.4 os resultados de simulações do desempenho em termos de BER e complexidade computacional dessas estratégias são apresentados e comentados; e, por fim, na Seção 5.5 as conclusões referentes ao presente capítulo são feitas.

\section{2}

Modelo multicelular e efeitos da contaminação por pilotos

\subsection{1}

\section{Modelo multicelular}

Para a análise do cenário multicelular, considera-se o canal reverso de um sistema composto por $L$ células interferentes, cada uma atendida por uma EB. Cada célula atende a $K$ usuários independentes. Visando reduzir a complexidade do modelo, considera-se que cada usuário possui apenas uma antena de transmissão. Ressalta-se entretanto que o cenário descrito neste capítulo pode ser naturalmente estendido para o caso de usuários com múltiplas antenas, conforme modelo apresentado no Capítulo 2. Cada EB é munida de $N_{r}$ antenas de recepção.

O sinal recebido na c-ésima célula é dado por:

$$
\mathbf{y}_{c}=\mathbf{G}_{c, c} \mathbf{x}_{c}+\sum_{l=1}^{L} \mathbf{G}_{c, l} \mathbf{x}_{l}+\mathbf{n}_{c},
$$

em que $\mathbf{x}_{l}$ é o vetor de sinais transmitidos pelos usuários da l-ésima célula e $\mathbf{G}_{i, l}$ é a matriz de coeficientes de canal entre os usuários da $l$-ésima célula e as antenas da EB da $i$-ésima célula. As matrizes $G_{i, l}$ são dadas por:

$$
\mathbf{G}_{i, l}=\mathbf{H}_{i, l} \mathbf{D}_{i, l}^{1 / 2}
$$

sendo que $\mathbf{H}_{i, l}$ representa a matriz de coeficientes de canal do cenário A, conforme descrita no Capítulo 2, e $\mathbf{D}_{i, l}^{1 / 2}$ é uma matriz diagonal cujos elementos não nulos são responsáveis por contabilizar os efeitos das perdas de percurso e do sombreamento. Considerando os modelos descritos nas Seções 2.2 .1 e 2.3.2 (equações (2-3) e (2-27)), os coeficientes não nulos de $\mathbf{D}_{i, l}^{1 / 2}$ são dados por:

$$
\left[\mathbf{D}_{i, l}^{1 / 2}\right]_{n, n}=\sqrt{\theta_{i, n, l}}
$$


em que

$$
\theta_{i, n, l}=\left(\frac{d_{i, n, l}}{d_{0}}\right)^{-\gamma} 10^{\frac{\sigma_{n, l} \mathcal{N}_{n, l}(0,1)}{10}} .
$$

Na equação anterior, $d_{i, n, l}$ é a distância entre o $n$-ésimo usuário da $l$-ésima célula e a EB da $i$-ésima célula, $\sigma_{n, l}$ é o espalhamento de sombreamento do $n$ ésimo usuário da $l$-ésima célula, $\mathcal{N}_{n, l}(0,1)$ representa uma variável aleatória gaussiana de média zero e variância unitária, e $\gamma$ é o expoente de perda de percurso geométrica. Além disso, por simplicidade, a perda de percurso da distância de referência, $\overline{P L}\left(d_{0}\right)$, foi considerada igual a zero.

\section{2 .2}

\section{Efeitos da contaminação por pilotos}

Quando cenários multicelulares são considerados, devido à aquisição das informações sobre os canais de comunicações envolvidos por meio da transmissão de sinais pilotos, surge o problema da contaminação por pilotos [71]. Nestes casos, considerou-se no presente trabalho que a mesma faixa de frequências e o mesmo conjunto de sequências pilotos são empregados nas diversas células do sistema de comunicações. Sendo assim, enquanto a EB estima os coeficientes de canal entre suas antenas e os usuários de sua célula, ela não intencionalmente considera os canais entre suas antenas e os usuários das demais células que empregam sequências pilotos correlacionadas com as de seus usuários, causando a mencionada interferência em toda a comunicação subsequente. Mais especificamente, quando a EB transmite informação para seus terminais, ela acaba interferindo no sinal transmitido pelas outras EB aos usuários das outras células. Da mesma forma, quando a EB combina os sinais de seus usuários no canal reverso, ela acaba combinando os sinais dos usuários das demais células.

De forma a explicitar essas interferências, considera-se a estimação por mínimo erro médio quadrático dos coeficientes do canal reverso por meio da transmissão de sinais pilotos. Assumindo que os usuários transmitem $\tau_{p}$ símbolos pilotos, e que estas sequências de pilotos estão sincronizadas (pior caso), os sinais pilotos de todos os usuários podem ser dispostos em uma matriz de dimensões $\left(K \times \tau_{p}\right)$, denotada por $\sqrt{p_{p}} \boldsymbol{\Phi}$, em que $\boldsymbol{\Phi} \boldsymbol{\Phi}^{H}=\mathbf{I}_{K}, p_{p}=\tau_{p} p_{u}$ e $p_{u}$ é a potência média de transmissão de cada usuário. Sendo assim, de acordo com a equação (5-1), a $i$-ésima EB recebe o sinal oriundo da transmissão dos pilotos dos usuários representado pela matriz $\mathbf{Y}_{p, i}$ de dimensões $\left(N_{r} \times \tau_{p}\right)$ dada por:

$$
\mathbf{Y}_{p, i}=\sqrt{p_{p}} \sum_{l=1}^{L} \mathbf{G}_{i, l} \boldsymbol{\Phi}+\mathbf{N}_{i}
$$

em que $\mathbf{N}_{i}$ representa a matriz de ruído Gaussiano de recepção de dimensões $\left(N_{r} \times \tau_{p}\right)$. A estimativa MMSE de $\mathbf{G}_{l, l}$ é obtida de $\mathbf{Y}_{p, l}$ por meio da equação 
[44]:

$$
\begin{aligned}
\hat{\mathbf{G}}_{l, l} & =\frac{1}{\sqrt{p_{p}}} \mathbf{Y}_{p, l} \boldsymbol{\Phi}^{H} \tilde{\mathbf{D}}_{l, l} \\
& =\left(\sum_{j=1}^{L} \mathbf{G}_{l, j}+\frac{1}{\sqrt{p_{p}}} \mathbf{W}_{l}\right) \tilde{\mathbf{D}}_{l, l}
\end{aligned}
$$

onde

$$
\begin{aligned}
& \tilde{\mathbf{D}}_{l, l}=\mathbf{D}_{l, l}\left(\frac{1}{p_{p}} \mathbf{I}_{K}+\sum_{j=1}^{L} \mathbf{D}_{l, j}\right)^{-1}, \\
& \mathbf{W}_{l}=\mathbf{N}_{l} \boldsymbol{\Phi}^{H}
\end{aligned}
$$

e $\mathbf{D}_{l, l}$ é definida de acordo com (5-3).

A partir da equação (5-6), observa-se que a estimativa da matriz de coeficientes dos canais entre as antenas da EB da l-ésima célula e seus usuários inclui as matrizes de coeficientes de canal entre as antenas dessa EB e os usuários das demais células, o que causa a contaminação por pilotos.

\section{3}

\section{Esquemas de estimação e detecção conjuntos}

Nesta seção, inicialmente a estratégia de estimação e detecção conjunta, como proposta em [16], é apresentada. Essa estratégia é constituída pela detecção ML da matriz $\mathbf{X}$ formada pelos símbolos de informação transmitidos por todos os usuários componentes do sistema. Para essa detecção, a expressão da função densidade de probabilidade da matriz de sinal recebido referente à transmissão dos sinais pilotos e dos símbolos de informação derivada em [16] é reproduzida neste trabalho a título de completude. Com base nesta função densidade de probabilidade, é derivada uma métrica ML que é empregada no detector do trabalho referenciado.

Posteriormente, são apresentados os esquemas de estimação e detecção conjuntos propostos, baseados na estratégia de [16] e nos esquemas de detecção LAS. Esses esquemas empregam a métrica ML do detector de [16] em um processo de busca LAS realizado em todo o espaço vetorial das possíveis matrizes X. Essa busca é efetuada de forma coordenada com cooperação parcial entre as EB componentes do sistema, pela qual o resultado da busca LAS efetuada em uma EB constitui a entrada da busca realizada pela próxima EB. 


\subsection{1}

\section{Estratégia de Estimação e Detecção conjunta}

A seguir, será apresentada a estratégia de estimação e detecção conjunta formulada em [16]. Em [16], a fim de se encontrar expressões analíticas para a probabilidade de erro símbolo a símbolo, considerou-se que cada célula atende a um único usuário apenas $(K=1)$. Neste trabalho, esta estratégia será apresentada considerando o modelo de sistema multicelular apresentado na seção anterior, ou seja, considera-se um sistema formado por $L$ células interferentes, cada uma atendendo a $K$ usuários.

Seja $\mathbf{Y}_{0}^{i}$ a matriz de sinal recebido na EB da $i$-ésima célula referente à transmissão dos sinais pilotos de todos os usuários do sistema, dada por:

$$
\mathbf{Y}_{0}^{i}=\mathbf{G}_{i} \operatorname{diag}(\sqrt{\boldsymbol{\rho}}) \boldsymbol{\Phi}_{0}+\mathbf{W}_{0}
$$

em que $\mathbf{G}_{i}$ é a matriz de coeficientes de canal entre as antenas da EB da $i$-ésima célula e todos os usuários de todas as células do sistema, dada por:

$$
\mathbf{G}_{i}=\left[\begin{array}{llll}
\mathbf{G}_{i, 1} & \mathbf{G}_{i, 2} & \cdots & \mathbf{G}_{i, L}
\end{array}\right]
$$

$\Phi_{0}$ é a matriz de dimensões $\left(K L \times \tau_{p}\right)$ dos sinais pilotos transmitidos por todos os usuários de todas as células. Como neste trabalho é considerado que os sinais pilotos são repetidos em todas as células do sistemas, temos que $\boldsymbol{\Phi}_{0}$ é dada por:

$$
\boldsymbol{\Phi}_{0}=\left[\begin{array}{c}
\boldsymbol{\Phi} \\
\boldsymbol{\Phi} \\
\vdots \\
\boldsymbol{\Phi}
\end{array}\right] \text { "L vezes "]. }
$$

$\mathbf{W}_{0}$ é a matriz de ruído de recepção de dimensões $\left(N_{r} \times \tau_{p}\right)$ cujas entradas são modeladas por variáveis aleatórias gaussianas de média zero e variância unitária. O vetor $\boldsymbol{\rho}=\left[\rho_{1,1}, \rho_{2,1}, \cdots, \rho_{K, 1}, \rho_{1,2}, \cdots, \rho_{k, l}, \cdots, \rho_{K, L}\right]$ é o vetor de coeficientes de controle de potência de cada usuário tal que os sinais transmitidos pelos usuários da célula $i$ cheguem na EB dessa mesma célula com mesma energia média, i.e.

$$
\rho_{k, i} \theta_{i, k, i}=E_{r}, \forall k, \forall i
$$

em que $E_{r}$ é a energia média do símbolo transmitido na recepção. Sendo assim, a SNR média por antena de recepção é dada por:

$$
S N R=K E_{r}=K \rho_{k, i} \theta_{i, k, i}, \quad \forall k, \forall i .
$$

Após a transmissão das sequências pilotos, os usuários do sistema transmitem seus respectivos símbolos de dados. Sendo assim, a matriz de sinal 
recebido na $i$-ésima $\mathrm{EB}$ correspondente aos símbolos de dados dos usuários do sistema é dada por:

$$
\mathbf{Y}_{1}^{i}=\mathbf{G}_{i} \operatorname{diag}(\sqrt{\boldsymbol{\rho}}) \mathbf{X}+\mathbf{W}_{1}
$$

em que $\mathbf{X}$ é a matriz de símbolos transmitidos de dimensões $\left(K L \times T_{m}\right)$ cuja entrada $x_{n l, t}$ representa o símbolo transmitido pelo $n$-ésimo usuário da $l$-ésima célula no instante $t\left(1 \leq t \leq T_{m}\right)$. $\mathbf{W}_{1}$ é a matriz de ruído de recepção durante a transmissão de dados, de dimensões $\left(N_{r} \times T_{m}\right)$. Analogamente a $\mathbf{W}_{0}$, as entradas de $\mathbf{W}_{1}$ são modeladas por variáveis aleatórias Gaussianas de média zero e variância unitária.

A estratégia de estimação e detecção conjunta apresentada em [16] consiste na detecção dos vetores $\mathbf{x}_{n l}$, correspondente à $n l$-ésima linha da matriz $\mathbf{X}$, referente aos símbolos transmitidos pelo $n$-ésimo usuário da $l$-ésima célula componente do sistema, a partir do conhecimento de $\boldsymbol{\Phi}_{0}$ e das matrizes de sinais recebidos $\mathbf{Y}_{0}^{l}$ e $\mathbf{Y}_{1}^{l}$, para $n=1,2, \cdots, K$.

Considerando a matriz $\mathbf{Y}^{l}=\left[\mathbf{Y}_{0}^{l} \mathbf{Y}_{1}^{l}\right]$, a detecção ML de $\mathbf{x}_{k}, k=n l$, é dada por:

$$
\hat{\mathbf{x}}_{k}=\underset{\mathbf{x}_{k} \in \mathcal{B}^{T_{m}}}{\arg \max } f\left(\mathbf{Y}^{l} \mid \mathbf{x}_{k}\right)
$$

em que $\mathcal{B}^{T_{m}}$ é o espaço de vetores $T_{m}$-dimensionais cujas componentes são símbolos da modulação empregada e $f\left(\mathbf{Y}^{l} \mid \mathbf{x}_{k}\right)$ é a função densidade de probabilidade condicional de $\mathbf{Y}^{l}$ dado $\mathbf{x}_{k}$, que pode ser expressa por:

$$
f\left(\mathbf{Y}^{l} \mid \mathbf{x}_{k}\right)=\sum_{\mathbf{x}_{j} \in \mathcal{B}^{T_{m}}, j \neq k}\left\{f\left(\mathbf{Y}^{l} \mid \mathbf{x}_{1}, \mathbf{x}_{2}, \cdots, \mathbf{x}_{K L},\right) \prod^{K L} P\left(\mathbf{x}_{w}\right)\right\}
$$

sendo $P\left(\mathbf{x}_{w}\right)$ a probabilidade de transmitir o vetor $\mathbf{x}_{w}$. Assumindo símbolos equiprováveis e independentes, temos que:

$$
f\left(\mathbf{Y}^{l} \mid \mathbf{x}_{k}\right)=\frac{1}{M^{(K L-1) T_{m}}} \sum_{\mathbf{x}_{j} \in \mathcal{B}^{T_{m}}, j \neq k} f\left(\mathbf{Y}^{l} \mid \mathbf{x}_{1}, \mathbf{x}_{2}, \cdots, \mathbf{x}_{K L}\right)
$$

Por conveniência, em [16] optou-se por trabalhar com o vetor $\operatorname{vec}\left(\mathbf{Y}^{l}\right)$, que é o vetor formado pelo empilhamento das colunas da matriz $\mathbf{Y}$. Como as matrizes $\mathbf{G}_{i}, \mathbf{W}_{0}$ e $\mathbf{W}_{1}$ em (5-9) e (5-14) são matrizes gaussianas com entradas independentes e identicamente distribuídas de média zero, dados $\mathbf{x}_{1}, \mathbf{x}_{2}, \cdots, \mathbf{x}_{K L}, \operatorname{vec}\left(\mathbf{Y}^{l}\right)$ pode ser descrito por um vetor gaussiano $\left(N_{r}\left(T_{m}+\right.\right.$ $\left.\tau_{p}\right)$ )-dimensional com média zero e matriz covariância dada por:

$$
E\left[\operatorname{vec}\left(\mathbf{Y}^{l}\right) \operatorname{vec}\left(\mathbf{Y}^{l}\right)^{H}\right]=\left(\begin{array}{cc}
\sum_{0,0} & \sum_{0,1} \\
\sum_{1,0} & \sum_{1,1}
\end{array}\right)
$$


em que $\sum_{i, j}=E\left[\operatorname{vec}\left(\mathbf{Y}_{i}^{l}\right) \operatorname{vec}\left(\mathbf{Y}_{j}^{l}\right)^{H}\right]$, para $i, j=0,1$. De (5-9) e (5-14) em (5-18), esta matriz covariância pode ser escrita como:

$$
E\left[\operatorname{vec}\left(\mathbf{Y}^{l}\right) \operatorname{vec}\left(\mathbf{Y}^{l}\right)^{H}\right]=\Sigma_{l} \otimes \mathbf{I}_{N_{r}}
$$

sendo $\otimes$ o produto de Kronecker e $\Sigma_{l}$, dada por:

$$
\Sigma_{l}=\left[\begin{array}{cc}
\mathbf{I}_{\tau}+\boldsymbol{\Phi}_{0}^{T} \operatorname{diag}(\sqrt{\boldsymbol{\rho}}) \mathbf{D}_{l} \boldsymbol{\Phi}_{0}^{*} & \boldsymbol{\Phi}_{0}^{T} \operatorname{diag}(\boldsymbol{\rho}) \mathbf{D}_{l} \mathbf{X}^{*} \\
\mathbf{X}^{T} \operatorname{diag}(\boldsymbol{\rho}) \mathbf{D}_{l} \boldsymbol{\Phi}_{0}^{*} & \mathbf{I}_{T_{m}}+\mathbf{X}^{T} \operatorname{diag}(\sqrt{\boldsymbol{\rho}}) \mathbf{D}_{l} \mathbf{X}^{*}
\end{array}\right]
$$

em que

$$
\mathbf{D}_{i}=\left[\begin{array}{cccc}
\mathbf{D}_{i, 1} & \mathbf{0} & \cdots & \mathbf{0} \\
\mathbf{0} & \mathbf{D}_{i, 2} & \cdots & \mathbf{0} \\
\vdots & \vdots & \ddots & \vdots \\
\mathbf{0} & \mathbf{0} & \cdots & \mathbf{D}_{i, L}
\end{array}\right]
$$

e $\mathbf{D}_{i, j}$ é definida em (5-3). Consequentemente, a função densidade de $\operatorname{vec}\left(\mathbf{Y}^{l}\right)$ é expressa por:

$$
\begin{aligned}
& f\left(\operatorname{vec}\left(\mathbf{Y}^{l}\right) \mid \mathbf{x}_{1}, \mathbf{x}_{2}, \cdots, \mathbf{x}_{K L}\right)= \\
& \quad=\frac{1}{\pi N_{r}(T+\tau)} \frac{1}{\operatorname{det}\left(\Sigma_{l} \otimes \mathbf{I}_{N_{r}}\right)} \exp \left(-\operatorname{vec}\left(\mathbf{Y}^{l}\right)^{H}\left(\Sigma_{l} \otimes \mathbf{I}_{N_{r}}\right)^{-1} \operatorname{vec}\left(\mathbf{Y}^{l}\right)\right) .
\end{aligned}
$$

Por fim, de (5-22) e (5-17), a detecção ML de $\mathbf{x}_{k}$ feita pela EB da $l$-ésima célula é dada por:

$$
\hat{\mathbf{x}}_{k}=\underset{\mathbf{x}_{k}}{\arg \max } \sum_{\mathbf{x}_{j} \in \mathcal{B}^{T m}, j \neq k} \frac{1}{\operatorname{det}\left(\Sigma_{l} \otimes \mathbf{I}_{N_{r}}\right)} \exp \left(-\operatorname{vec}\left(\mathbf{Y}^{l}\right)^{H}\left(\Sigma_{l} \otimes \mathbf{I}_{N_{r}}\right)^{-1} \operatorname{vec}\left(\mathbf{Y}^{l}\right)\right) .
$$

A fim de se evitar o somatório da expressão anterior e problemas de instabilidades numéricas, especialmente para valores elevados das componentes de $\boldsymbol{\rho}$, a detecção de todos os vetores linha de $\mathbf{X}$ é realizada conjuntamente com a métrica a ser maximizada dada em sua versão logarítmica, ou seja:

$$
\begin{aligned}
& \left(\hat{\mathbf{x}}_{1}, \hat{\mathbf{x}}_{2}, \cdots, \hat{\mathbf{x}}_{K L}\right)= \\
& \underset{\mathbf{X}}{\arg \max }\left[-N_{r} \log \left(\operatorname{det}\left(\Sigma_{l}\right)\right)-\operatorname{vec}\left(\mathbf{Y}^{l}\right)^{H}\left(\Sigma_{l} \otimes \mathbf{I}_{N_{r}}\right)^{-1} \operatorname{vec}\left(\mathbf{Y}^{l}\right)\right]
\end{aligned}
$$

Como a busca exaustiva acima emprega o sinal recebido na $l$-ésima $\mathrm{EB}$, o detector dessa EB seleciona os vetores resultado da maximização $\left[\hat{\mathbf{x}}_{K(l-1)+1}, \hat{\mathbf{x}}_{K(l-1)+2}, \cdots, \hat{\mathbf{x}}_{K l}\right]$ como vetores de símbolos detectados dos usuários da célula $l$.

Nota-se que a estratégia apresentada é chamada de estratégia de estimação e detecção conjunta em [16] pois, apesar de não encontrar explicitamente 
estimativas para os valores das matrizes de coeficientes de canal, estes coeficientes influenciam o resultado da detecção, uma vez que seus efeitos estão embutidos na matriz de sinal recebido $\mathbf{Y}^{l}$.

\subsection{2}

\section{Esquemas de estimação e detecção propostos}

Tendo em vista a elevada complexidade computacional do detector ML apresentado na subseção anterior, procurou-se empregar a estratégia LAS para a proposição de estimadores/detectores conjuntos que se aproximem do resultado do detector descrito em (5-24). A estratégia LAS foi escolhida uma vez que ela busca se aproximar do resultado da detecção ML com complexidade computacional reduzida. A métrica utilizada durante a busca LAS neste caso é dada pela função objetivo do problema de maximização em (5-24):

$$
f(\mathbf{X})=\left[-N_{r} \log \left(\operatorname{det}\left(\Sigma_{l}\right)\right)-\operatorname{vec}\left(\mathbf{Y}^{l}\right)^{H}\left(\Sigma_{l} \otimes \mathbf{I}_{N_{r}}\right)^{-1} \operatorname{vec}\left(\mathbf{Y}^{l}\right)\right] .
$$

Ressalta-se que a dependência da métrica ML expressa acima com a matriz de sinais transmitidos $\mathbf{X}$ se dá por meio da dependência da matriz $\Sigma_{l} \operatorname{com} \mathbf{X}$.

Antes de descrever os algoritmos propostos, cabe a realização de breves comentários acerca do condicionamento da matriz $\Sigma_{l}$ : a partir de (5-20), considerando as equações (5-13), (5-21) e (5-3), pode-se re-escrever $\Sigma_{l}$ como:

$$
\Sigma_{l}=\mathbf{I}_{T_{m}+\tau_{p}}+\frac{S N R}{K} \underbrace{\left[\boldsymbol{\Phi}_{0} \mathbf{X}\right]^{T} \mathbf{D}_{c}^{l}\left[\mathbf{\Phi}_{0} \mathbf{X}\right]^{*}}_{\mathbf{C}^{\prime}}
$$

em que

$$
\mathbf{D}_{c}^{l}=\operatorname{diag}\left(\left[\frac{\theta_{l, 1,1}}{\theta_{1,1,1}}, \frac{\theta_{l, 2,1}}{\theta_{1,2,1}}, \cdots, \frac{\theta_{l, K, 1}}{\theta_{1, K, 1}}, \cdots, \frac{\theta_{l, K, L}}{\theta_{L, K, L}}\right]\right) .
$$

Como a matriz $\left[\mathbf{\Phi}_{0} \mathbf{X}\right]$ possui dimensões $\left(K L \times\left(T_{m}+\tau_{p}\right)\right)$ e a matriz $\mathbf{D}_{c}^{l}$ é uma matriz diagonal, o posto da matriz $\mathbf{C}^{\prime}$ é dado por:

$$
\operatorname{rank}\left(\mathbf{C}^{\prime}\right)=\min \left(K L, T_{m}+\tau_{p}\right)
$$

Ou seja, caso $K L<T_{m}+\tau_{p}$, $\mathbf{C}^{\prime}$ será uma matriz singular. Dessa forma, nesses casos, para valores elevados da $S N R$, a matriz $\Sigma_{l}$ será mal-condicionada ocasionando problemas numéricos no cálculo da métrica de verossimilhança da equação (5-24) empregada na busca LAS.

A fim de se contornar o problema do mal-condicionamento de $\Sigma_{l}$, pode-se utilizar a técnica de carregamento diagonal (diagonal loading), incluindo uma 
parcela de carregamento na expressão de $\Sigma_{l}$ da seguinte forma:

$$
\begin{aligned}
\Sigma_{l} & =\mathbf{I}_{T_{m}+\tau_{p}}+\frac{S N R}{K} \mathbf{C}^{\prime}+\mathscr{L} \mathbf{I}_{T_{m}+\tau_{p}} \\
& =\frac{S N R}{K}[\underbrace{\left(\frac{K}{S N R}+\frac{K \mathscr{L}}{S N R}\right)}_{\mathscr{P}} \mathbf{I}_{T_{m}+\tau_{p}}+\mathbf{C}^{\prime}] .
\end{aligned}
$$

Forçando $\mathscr{P}=1$ na expressão anterior, temos que o efeito da singularidade de $\mathbf{C}^{\prime}$ é contornado pela adição da matriz identidade. Dessa forma, a fim de mitigar os efeitos do mal-condicionamento da matriz $\boldsymbol{\Sigma}$, empregamos o valor do parâmetro de carregamento $\mathscr{L}$ igual a

$$
\mathscr{L}=\frac{S N R}{K}-1
$$

Cabe destacar que a métrica resultante do emprego da matriz $\Sigma_{l}$ após a inclusão do termo de carregamento $\mathscr{L}$ não é mais uma métrica ML e se afasta da métrica ML com o aumento de $\mathscr{L}$.

A seguir serão descritos os algoritmos baseados na estratégia de estimação e detecção conjunta propostos. Todos esses esquemas são constituídos por uma série de buscas LAS efetuadas em sequência.

\subsubsection{1}

\section{Esquema conjunto não cooperativo}

O primeiro esquema proposto visa empregar a métrica em (5-25) de forma independente em cada célula, com base apenas na matriz de símbolos pilotos enviada pelos usuários da célula desejada, $\mathbf{\Phi}$, e no sinal recebido na EB desta célula.

Este esquema de estimação/detecção é constituído por uma série de buscas LAS efetuadas em cada coluna da matriz de símbolos transmitidos pelos usuários da célula desejada. Parte-se de uma matriz $\mathcal{D}_{0} \in \mathcal{B}^{K \times T_{m}}$ de candidatos iniciais obtida a partir do resultado da detecção por filtro casado à estimativa da matriz de coeficientes de canal, que é obtida apenas para esse fim a partir da transmissão dos símbolos pilotos.

Inicia-se com uma busca LAS sequencial na qual são trocados apenas os símbolos da primeira coluna da matriz de símbolos transmitidos $\mathbf{X}$, sendo

$$
\mathbf{X}=\left[\begin{array}{c}
\mathbf{x}_{1} \\
\mathbf{x}_{2} \\
\vdots \\
\mathbf{x}_{K}
\end{array}\right]
$$


O resultado dessa busca é utilizado como matriz de símbolos candidatos iniciais da próxima busca, que é efetuada trocando-se apenas os símbolos da segunda coluna de $\mathbf{X}$. Esse procedimento repete-se até que a busca LAS seja efetuada sobre os símbolos da última coluna de $\mathbf{X}$, após a qual, todo o processo é repetido um número pré-determinado de vezes, sendo o resultado da busca anterior tomado sempre como entrada da próxima busca.

O algoritmo referente a esse esquema de estimação/detecção conjunta é apresentado abaixo:

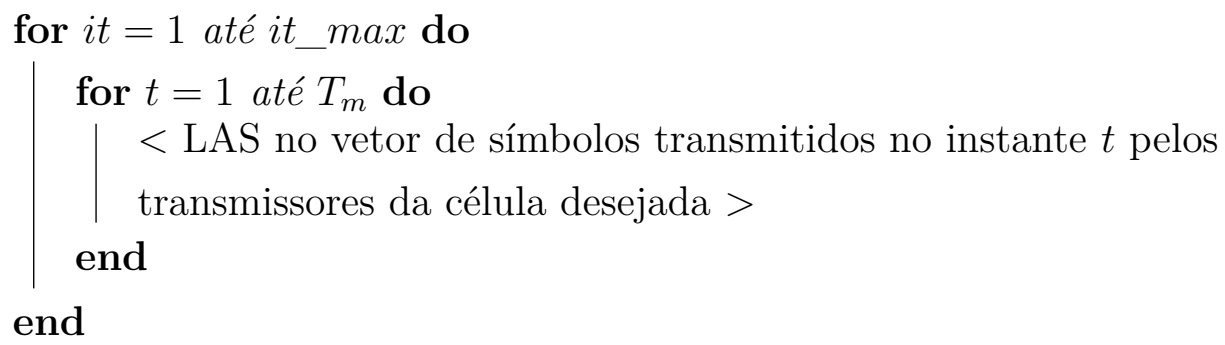

Algoritmo 1: Esquema conjunto não cooperativo

\section{Observações:}

1. A repetição da sequência de buscas LAS it_max vezes é necessária uma vez que a métrica empregada na busca LAS depende de toda a matriz $\mathbf{X}$. Dessa forma, alterações em símbolos transmitidos em instantes de tempo posteriores (ou prévios) podem gerar alterações no resultado da busca referente a algum determinado instante de tempo.

2. Os símbolos transmitidos pelos transmissores das outras células do sistema são desconsiderados nesse esquema de estimação/detecção, i.e., a EB que efetua a detecção considera que não há interferência oriunda das demais células do sistema.

\subsubsection{2}

\section{Esquema conjunto cooperativo}

Com o objetivo de considerar os efeitos causados pela transmissão dos símbolos dos transmissores das demais células, o seguinte esquema de estimação/detecção com cooperação parcial é proposto.

Como no caso anterior, cada EB estima sua matriz de canal entre suas antenas e os usuários da sua célula com base nos pilotos transmitidos a fim de formar uma matriz de símbolos candidatos iniciais, constituída pelos resultados das detecções por filtros casados às matrizes de coeficientes de canal estimadas. O resultado dessa detecção inicial realizada em cada EB é divulgado por todas as EB do sistema para a EB da primeira célula a fim de formar a matriz 
$\mathcal{D}_{0} \in \mathcal{B}^{\left(K L \times T_{m}\right)}$ que será empregada como a matriz de símbolos candidatos inicial para a primeira busca LAS do esquema conjunto. Ressalta-se que, neste caso, esta matriz contém os símbolos candidatos iniciais referentes a todos os símbolos transmitidos por todos os usuários de todas as células do sistema. Da mesma forma que no esquema anterior, o resultado de uma busca LAS é tomado como a entrada da próxima busca

Inicialmente, o algoritmo faz uma busca LAS sequencial alterando apenas os símbolos transmitidos (candidatos) pelos usuários da célula 1 no primeiro instante (período) de símbolo. Essa busca é realizada com base na matriz de símbolos recebidos pela respectiva célula, $\mathbf{Y}^{1}$. Chegando-se a um máximo local, a matriz de símbolos $\mathcal{D}$, resultado da busca que acabou de ser efetuada, é informada para a EB da célula 2, que realiza a mesma busca LAS, empregando como matriz de símbolos candidatos iniciais a matriz $\mathcal{D}$ informada, porém alterando apenas os símbolos transmitidos na célula 2 no instante 1 . Nessa nova busca, emprega-se a matriz de sinal recebido $\mathbf{Y}^{2}$ para o cálculo da métrica ML. Buscas LAS são efetuadas em sequência por cada EB do sistema até que se faça uma busca para cada célula do sistema, sendo que a matriz de símbolos candidatos iniciais da busca atual é o resultado da busca efetuada anteriormente.

Uma vez realizadas as buscas descritas no parágrafo anterior em todos os símbolos de todas as células transmitidos no instante 1 , repete-se esse mesmo processo partindo-se novamente dos símbolos transmitidos na célula 1 até os símbolos transmitidos na célula $L$.

Feitas as buscas em todos os símbolos transmitidos em todas as células 2 vezes para os símbolos transmitidos no instante 1 , repete-se os passos anteriores para os símbolos transmitidos no instante 2 , em seguida, para os símbolos do instante 3 e assim sucessivamente até o instante $T_{m}$ (duração do quadro de símbolos transmitidos por cada usuário).

Por fim, repete-se todo o processo descrito anteriormente até se completar it_max iterações. 
O pseudo-código para o algoritmo acima descrito é apresentado a seguir: for $i t=1$ até it_max do

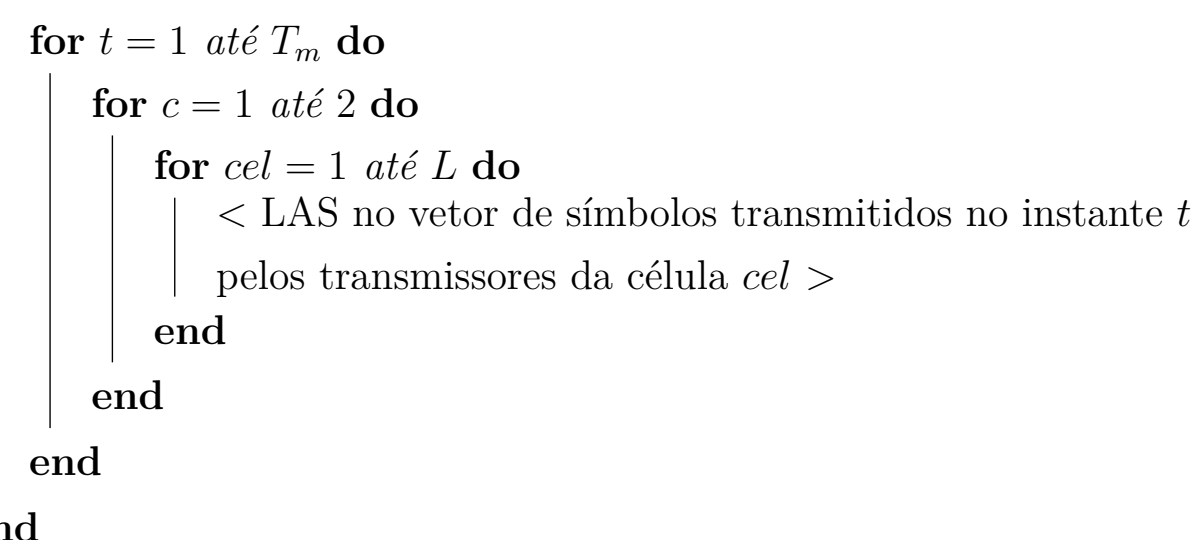

Algoritmo 2: Esquema conjunto cooperativo

Observações:

1. Emprega-se na métrica ML de cada busca, a matriz de símbolos recebida pela EB correspondente aos símbolos que se testa pois, como os transmissores correspondentes estão mais próximos da EB da mesma célula, as trocas desses símbolos impactam de forma mais efetiva a matriz de símbolos recebida em questão.

2. Como no esquema anterior, a necessidade de repetição das buscas LAS após já se ter efetuado buscas anteriormente sobre o mesmo conjunto de símbolos é necessária devido ao fato de alterações de símbolos de outras células (ou outros instantes de tempo) poderem alterar o resultado da busca em um conjunto específico de símbolos, uma vez que a métrica empregada depende de todos os símbolos transmitidos.

3. As repetições de buscas LAS são efetuadas um número pré-determinado de vezes, e não até a sua convergência, pois, a matriz de símbolos recebidos empregada em cada busca depende da célula cujos usuários estão sendo avaliados (testados). Dessa forma, as buscas em células distintas empregam métricas diferentes, o que pode resultar em pontos de máximo distintos para cada busca em cada célula considerada. Sendo assim, o algoritmo descrito acima pode não convergir ao se considerar todas as células do sistema.

4. O algoritmo descrito é considerado um algoritmo com cooperação parcial pois ele pode ser implementado de forma distribuída em cada célula, contanto que haja uma coordenação da sequência de buscas LAS efetuada em cada EB. Nesse caso, a busca LAS com trocas dos símbolos transmitidos pelos usuários da $l$-ésima célula deve ser realizada pela EB 


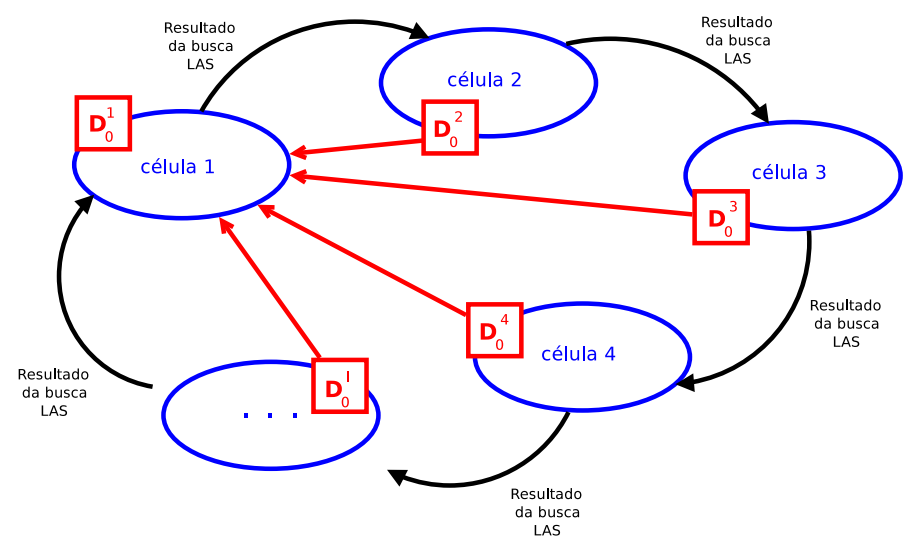

Figura 5.1: Diagrama de cooperação parcial no esquema de estimação/detecção conjunto

desta respectiva célula. A única informação que deve ser transmitida entre as EB das diversas células é o resultado da busca que acabou de ser realizada, conforme esquema ilustrado na Figura 5.1

\subsubsection{3}

\section{Esquema conjunto cooperativo com SCS aleatório}

Este esquema é baseado no algoritmo cooperativo anterior em que se objetiva eliminar a necessidade de se repetir a busca LAS em cada instante de sinalização it_max vezes. Para tanto a busca é realizada em cada célula alterando-se todos os símbolos transmitidos em cada célula em todos os instantes de tempo. Para tanto, a cada busca, são sorteados SCS que definem a ordem do símbolo transmitido (referente a um usuário e a um instante específico) a ser testado para a possível troca durante a busca LAS. Dessa forma, cada busca LAS é efetuada em todos os símbolos transmitidos na célula respectiva (do instante 1 até o instante $T_{m}$ ). Esse SCS é percorrido circularmente até que se chegue a um máximo local em cada busca.

Uma vez atingido o máximo local para os símbolos dos usuários pertencentes à célula 1, passa-se para a busca LAS com os símbolos dos usuários da célula 2 e assim sucessivamente até que se efetue a busca por todas as $L$ células.

Igualmente ao realizado nos algoritmos anteriores, repete-se o procedimento de busca descrito acima partindo-se novamente dos símbolos transmitidos na célula 1 até os símbolos transmitidos na célula $L$. 
O pseudo-código para o algoritmo acima descrito é apresentado a seguir: for $c=1$ até 2 do

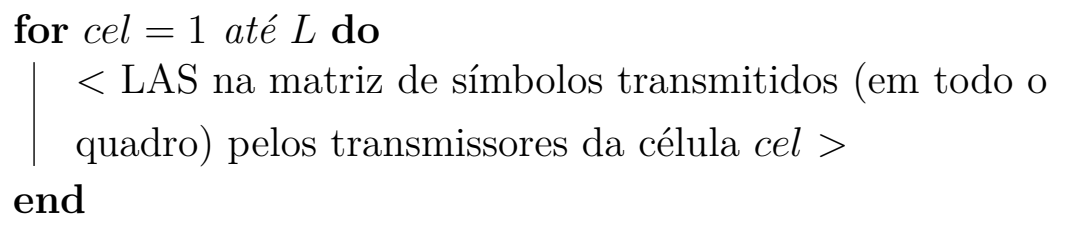

Algoritmo 3: Esquema conjunto cooperativo com SCS aleatório

Observação:

1. A repetição das buscas LAS no loop externo do algoritmo justifica-se pelo mesmo motivo apresentado nos algoritmos anteriores.

\section{4}

\section{Resultados de simulação}

Nesta seção serão apresentados os resultados de simulação de Monte Carlo efetuadas a fim de se avaliar o desempenho em termos de BER e complexidade computacional dos esquemas de estimação/detecção conjuntas.

Nestas simulações, os coeficientes de perda de percurso de larga escala, $\theta_{i, n, l}$, foram calculados de acordo com os modelos apresentados no Capítulo 2 a partir das distâncias entre os diversos usuários do sistema e as suas EB. As distâncias entre os usuários de uma determinada célula desejada e sua respectiva EB foram calculadas com base em uma geometria celular hexagonal e na amostragem uniforme dos vetores posição de cada usuário. A Figura 5.2 ilustra um exemplo de configuração empregada em um dos diversos ensaios realizados. Nessas simulações, considerou-se um raio celular $r_{c}=1600 \mathrm{~m}$ e um raio de exclusão, referente à distância mínima de cada usuário à sua respectiva $\mathrm{EB}, d_{0}=100 \mathrm{~m}$.

O mesmo conjunto de configurações amostradas conforme descrito acima foi empregado em todas as simulações efetuadas, a fim de se manter as simulações dos diversos esquemas analisados nas mesmas condições de avaliação. Os coeficientes $\rho_{n, l}$ são calculados com base na SNR que se deseja avaliar, bem como nos coeficientes $\theta_{i, n, l}$ da respectiva configuração, de acordo com a equação (5-13). Os resultados apresentados são uma média de 1000 ensaios cada um composto da transmissão de um quadro de $\tau_{p}=K$ símbolos pilotos seguidos de $T_{m}=20$ símbolos de dados por cada usuário do sistema. Em cada ensaio foi empregada uma configuração distinta amostrada previamente, conforme descrito no parágrafo anterior. Considerou-se um sistema com $L=4$ células interferentes, $N_{r}=16$ antenas de recepção em cada EB de cada célula 


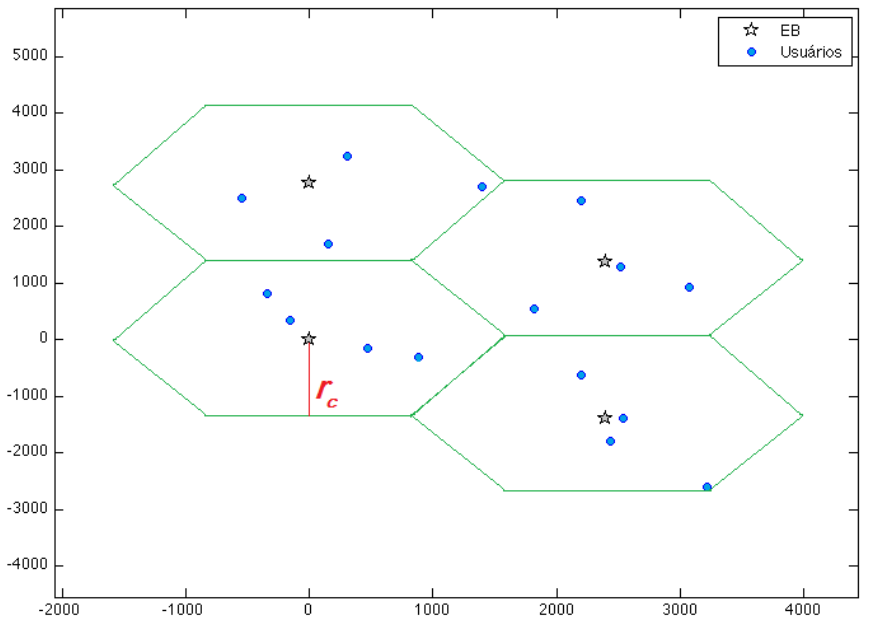

Figura 5.2: Exemplo de configuração de usuários para um sistema MIMO com $L=4$ e $K=4$.

e $K=4$ usuários por célula munidos de uma única antena. Todos os usuários empregaram a modulação 4-QAM para os símbolos de dados e a matriz de pilotos em cada célula foi obtida por meio da matriz de Hadamard de dimensões $(K \times K)$, conforme descrito na seção 2.4. O expoente de perda de percurso geométrico empregado foi $\gamma=3.8$ e não foi considerado o sombreamento lognormal $\left(\sigma_{n, l}=0, \forall n, l\right)$. O número de repetições empregado nos algoritmos conjuntos foi it_max $=5$.

A Figura 5.3 a seguir ilustra os resultados de BER pela SNR dos esquemas de estimação e detecção conjuntos propostos, com o carregamento diagonal (CD) conforme equações (5-29) e (5-30), uma vez que, para o caso simulado, a matriz $\mathbf{C}^{\prime}$ de (5-26) é singular. Além dessas estratégias, são apresentadas nesta figura as curvas de BER versus SNR para a estratégia convencional de realizar a estimação do canal seguida de uma detecção MF-RLB-LAS e do esquema conjunto cooperativo sem o carregamento diagonal.

Pode-se verificar que a estratégia conjunta não cooperativa obteve o pior resultado em termos de BER dentre as estratégias consideradas, atingindo valores de BER maiores até do que a estratégia convencional de realizar a estimação da matriz do canal seguida da detecção MF-RLB-LAS. Este fato pode ser explicado pela ausência da única vantagem que a estratégia conjunta provê ao esquema de detecção quando são desconsiderados os sinais transmitidos nas demais células do sistema: a diminuição dos efeitos da contaminação por pilotos. Além disso, o emprego do detector LAS sequencial na estratégia conjunta, que é um detector que alcança resultados de BER piores do que o detector MF-RLB-LAS, empregado na estratégia convencional, 


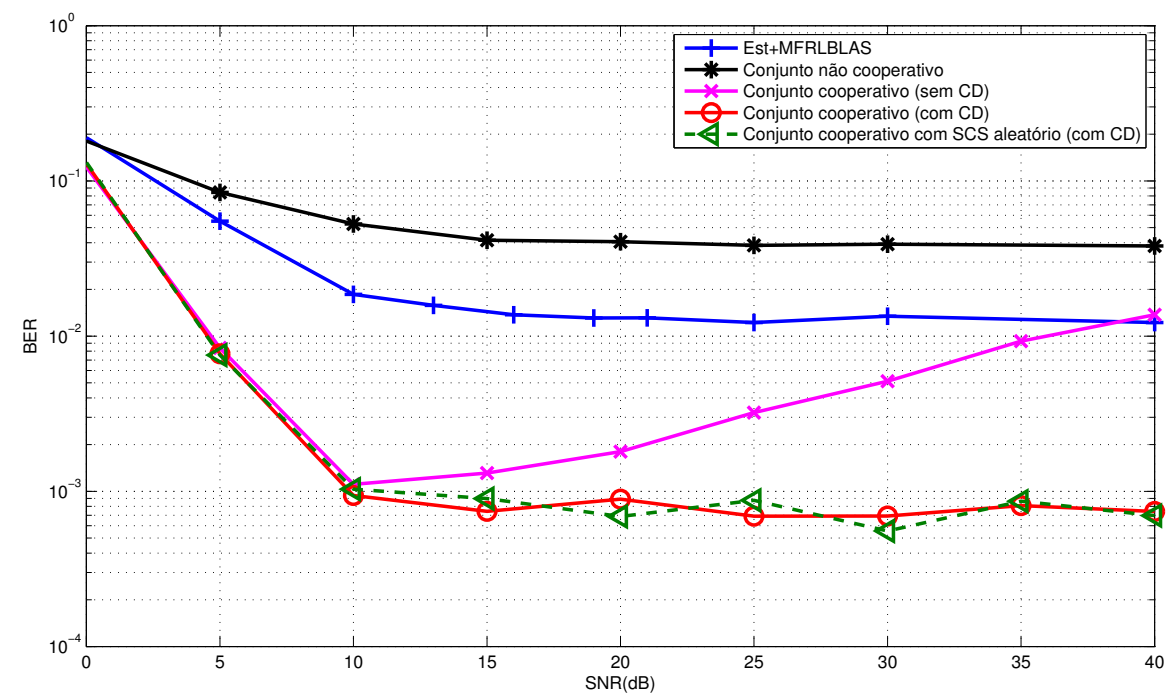

Figura 5.3: Curvas de BER versus SNR para diversas estratégias de estimação e detecção em sistemas MIMO.

contribui para a degradação da BER em relação à estratégia convencional.

Em contrapartida, quando comparam-se os resultados obtidos pela estratégia conjunta cooperativa com os da estratégia convencional, observa-se vantagens significativas no desempenho em termos de BER até valores de SNR próximos a $10 \mathrm{~dB}$. Para valores maiores de SNR, verifica-se que a estratégia sem o carregamento diagonal tem o seu desempenho degradado com o aumento da SNR, devido ao mau-condicionamento da matriz covariância do sinal recebido, conforme discutido anteriormente. De fato, verifica-se ainda a partir da Figura 5.3 que é possível a eliminação da degradação oriunda desse mal-condicionamento por meio da técnica de carregamento diagonal proposta. Apesar disso, não foi possível a eliminação do piso oriundo dos efeitos da contaminação por pilotos. Por fim, esta figura indica que o desempenho em termos de BER do esquema conjunto com SCS aleatório foi o mesmo do esquema conjunto original, porém, conforme será verificado nos resultados apresentados na próxima figura, o esquema com SCS aleatório é menos complexo que o esquema conjunto cooperativo original.

A Figura 5.4 apresenta os resultados de complexidade em termos do número médio por flops por bit transmitido para as estratégias apresentadas anteriormente. Os ganhos oriundos da estratégia conjunta são obtidos com significativo aumento da complexidade computacional, uma vez que esta estratégia envolve operações com toda a matriz de sinais transmitidos, incluindo a necessidade da inversão da matriz covariância do sinal recebido, cujas di- 


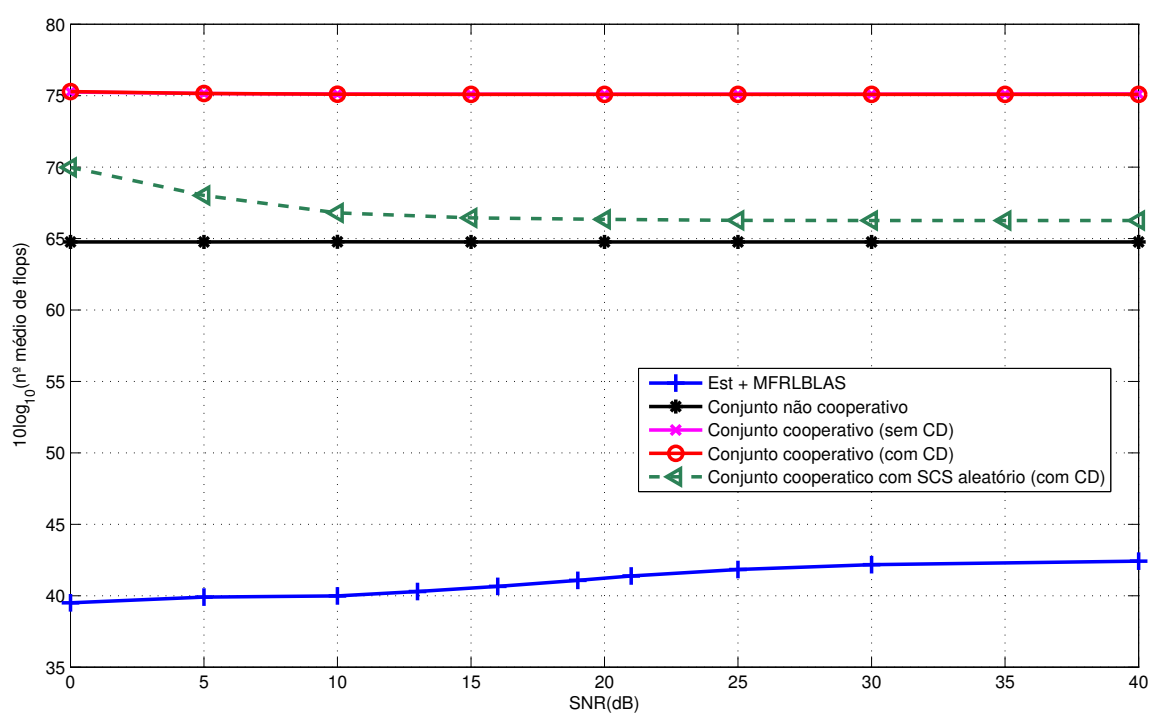

Figura 5.4: Curvas do número médio de flops por bit transmitido versus SNR para diversas estratégias de estimação e detecção em sistemas MIMO.

mensões são $\left(T_{m}+\tau_{p} \times T_{m}+\tau_{p}\right)$, conforme pode ser verificado pelas curvas apresentadas nessa figura. Apesar disso, tendo em vista que a estratégia conjunta provê ganhos significativos na BER mínima alcançável, o emprego da estratégia conjunta cooperativa ainda se mostra uma opção atrativa, especialmente ao se considerar o esquema conjunto cooperativo com SCS aleatório, que atinge valores de número de flops médio próximos ao do esquema não cooperativo.

\section{5}

\section{Conclusões}

Desde o surgimento das propostas de emprego de sistemas MIMO de larga escala, nos quais o número de elementos transceptores aumenta, chegando à ordem das centenas, acreditava-se que o grande limitante do desempenho desses sistemas seria o problema da contaminação por pilotos, oriundo do emprego de sinais pilotos não ortogonais para a estimação dos estados dos canais de comunicação envolvidos nas suas diversas células, mesmo no caso em que o número de antenas nas EB cresce ilimitadamente. Posteriormente, estudos teóricos sobre a capacidade de transmissão desses sistemas e sobre a probabilidade de erro símbolo a símbolo mostraram que, sob determinadas condições, é possível eliminar os efeitos da contaminação por pilotos.

Neste trabalho, baseado no estudo teórico realizado em [16], em especial na métrica ML de um decodificador ideal que efetua a decodificação dos sinais 
transmitidos em todas as células com base nos sinais de treino transmitidos e no sinal recebido, sem que haja a necessidade da estimação prévia das matrizes de coeficientes de canais, foi proposto um detector para o canal reverso de sistemas MIMO multicelulares que visa mitigar os efeitos da contaminação por pilotos. Este detector opera da mesma forma que o detector ideal de [16], i.e., realiza a detecção dos símbolos transmitidos sem a necessidade da estimação prévia dos canais envolvidos.

Resultados de simulação foram apresentados e, por meio deles, pôdese observar os ganhos na BER oriundos do emprego da estratégia conjunta proposta. Naturalmente, esses ganhos são acompanhados de um aumento na complexidade computacional da detecção desses sinais, o que pode ser impactante para o caso de sistemas MIMO de larga escala.

No próximo capítulo um sumário dos trabalhos realizados, as principais contribuições efetuadas e as conclusões gerais da presente tese são apresentados. Além disso, sugestões de trabalhos futuros são consideradas, uma vez que o tema abordado nesta tese está longe de ser esgotado e diversos avanços na área da detecção em sistemas MIMO de larga escala ainda podem ser obtidos. 


\section{6}

\section{Conclusões e Trabalhos Futuros}

\section{1}

\section{Conclusões}

O presente trabalho teve por objetivo o estudo do problema de deteç̧ão no canal reverso em sistemas MIMO multiusuários de larga escala, em especial no que diz respeito à complexidade computacional dos algoritmos empregados para essa deteç̧ão.

Os sistemas MIMO de larga escala, ou massivos, são caracterizados pelo grande número de antenas de transmissão e recepção dos seus elementos componentes. Diversos trabalhos que tratam do assunto defendem com propriedade ganhos expressivos na capacidade de transmissão desses sistemas quando o número de antenas nas suas $\mathrm{EB}$ cresce ilimitadamente enquanto o número de antenas dos usuários permanece inalterado, ou cresce a uma taxa menor que o número de antenas das EB. É demonstrado nesses trabalhos que os efeitos deletérios do ruído de recepção e do desvanecimento rápido podem ser eliminados, a energia mínima por bit para a transmissão pode ser reduzida arbitrariamente e a eficiência espectral do sistema torna-se independente da largura de banda empregada. Além disso, o processamento linear, tanto na transmissão quanto na recepção torna-se ótimo no sentido da menor BER.

Apesar desses ganhos, questões de ordem prática permanecem desafiadoras para a implementação de tais sistemas, dentre elas a complexidade computacional dos detectores empregados, tendo em vista a necessidade de processamento de vetores de dimensões elevadas, referentes ao emprego da grande quantidade de antenas de recepção e transmissão. Sendo assim, este trabalho abordou inicialmente os dois seguintes subtemas:

a) Proposição de detector para o canal reverso de sistemas MIMO multiusuários de baixa complexidade computacional;

b) Análise e proposta de esquema de deteç̧ão e decodificação em sistemas MIMO multiusuários considerando a relação complexidade computacional versus desempenho em termos de BER. 
Em relação ao primeiro subtema, escolheu-se a família de detectores LAS como base de análise, tendo em vista seus excelentes resultados em termos da relação complexidade-desempenho. Como consequência, a primeira contribuição da presente tese foi a proposta do algoritmo de detecção MFRLB-LAS, que superou as métricas de desempenho e de complexidade em todos os casos analisados. Ressalta-se, entretanto, que durante a maior parte do corpo desta tese, foram apresentadas comparações deste algoritmo apenas com outros algoritmos da família de detectores baseados na estratégia LAS. Apesar disso, o detector MF-RLB-LAS, juntamente com outros detectores para sistemas MIMO massivos, como os detectores baseados nos algoritmos de busca tabu reativa (Reactive Tabu Search - RTS), foram objeto de estudo da Dissertação de mestrado intitulada Deteç̧ão de sinais em sistemas MIMO massivos [72]. Nesta dissertação foi derivado um novo detector baseado no MF-RLB-LAS, que obteve resultados melhores do que o MF-RLB-LAS, porém com maior complexidade, sendo indicado, dessa forma, para situações em que a complexidade computacional não é o fator mais relevante, o que não se enquadra no caso dos sistemas de larga escala. Além disso, as comparações realizadas na referida dissertação indicaram o detector MF-RLB-LAS como sendo o que alcançou melhores resultados com menor complexidade quando são considerados cenários realistas, como o descrito pelo cenário B do Capítulo 2 da presente tese.

Ainda acerca do algoritmo MF-RLB-LAS aqui desenvolvido, em particular em relação ao seu critério de parada (e escolha do número de iterações necessárias), destaca-se que este critério pode ser empregado em diversas outras aplicações que necessitam de um número, aleatório ou não, de processos equivalentes para a consolidação de uma decisão final. Este critério foi empregado com sucesso em outros trabalhos promovidos pelo grupo de sistemas de comunicações do Centro de Estudos em Telecomunicações (CETUC) da PUC-Rio, como os realizados em [73] e [74].

Sobre o segundo subtema mencionado anteriormente, buscou-se uma estratégia eficiente de codificação/decodificação a ser aplicada em sistemas MIMO. Com base na pesquisa bibliográfica, verificou-se que as estratégias IDD haviam sido aplicadas com sucesso em diversas situações, como a detecção de usuários em sistemas CDMA [59]. A contribuição referente ao presente trabalho foi a adequação dessa estratégia para os sistemas MIMO de larga escala, com a proposição de um detector de entradas e saídas suaves de baixa complexidade como alternativa ao detector MAP empregado nas estratégias IDD.

Após tratar da detecção propriamente dita e de esquemas de codificação em sistemas MIMO, os trabalhos desta tese voltaram-se para sistemas multi- 
celulares e o problema da contaminação por pilotos, que refere-se à degradação de desempenho dos sistemas MIMO multicelulares oriunda das interferências causadas pelos sinais pilotos dos diversos usuários das células componentes do sistema durante a estimação dos canais de comunicação envolvidos. Nesse sentido, optou-se por investigar a estratégia de estimação e detecção conjunta dos sinais dos diversos usuários do sistema, uma vez que essa detecção realizada com a estimação implícita dos canais envolvidos pode mitigar os efeitos da contaminação por pilotos. De fato, com base nos detectores propostos na fase inicial desta tese, propôs-se um algoritmo de estimação/detecção conjunta cooperativo que foi capaz de obter melhores resultados de BER do que a estratégia convencional na qual se realiza a estimação dos coeficientes de canal e, em seguida, a detecção dos usuários é efetuada.

\section{2}

\section{Propostas para trabalhos futuros}

Dentro dos três subtemas abordados na presente tese, existem diversas questões que podem ser melhor exploradas ou desenvolvidas. A seguir, serão mencionadas algumas propostas de trabalhos em cada subtema passível de estudos suplementares:

\subsection{1 \\ Detector MF-RLB-LAS}

No caso do detector MF-RLB-LAS, o algoritmo proposto pode ser aprimorado no sentido de diminuir ainda mais a sua complexidade computacional.

1. No que se refere à busca LAS efetuada em cada iteração do algoritmo, o símbolo candidato escolhido é aquele que gera o maior aumento na métrica ML empregada. Dessa forma, todos os símbolos componentes da modulação empregada devem ser avaliados a fim de se escolher o símbolo que efetivamente será escolhido como símbolo substituto. Para constelações com elevada eficiência espectral, esta busca exaustiva pode ser problemática. Dessa forma, propõem-se o emprego de esquemas de restrições ao conjunto de símbolos testados como forma de redução de complexidade do algoritmo, como, por exemplo, testar apenas os símbolos adjacentes ao símbolo atual. Sendo assim, o impacto da imposição dessas restrições no algoritmo RLB-LAS deve ser investigado a fim de verificar a sua aplicabilidade;

2. Outra questão interessante é a expressão empregada no cálculo do número de iterações necessárias para o algoritmo MF-RLB-LAS. Nesse 
sentido, o emprego do custo ML padronizado deve ser mantido, porém a função linear desse custo para a obtenção do número de iterações a serem realizadas pode ser revista. Além disso, o parâmetro $c_{1}$, equação (3-25), deve ser otimizado e não escolhido de forma arbitrária, como realizado neste trabalho;

3. Pode-se investigar o desempenho do detector MF-RLB-LAS em cenários mais gerais, incluindo situações em que cada usuário emprega esquemas de modulações distintas ou, até mesmo, estratégias de modulações adaptativas, em que a modulação empregada varia de acordo com as condições de propagação do canal de comunicações;

4. Almeja-se, ainda, a obtenção de expressões analíticas, mesmo que aproximadas, para o desempenho, em termos de BER e de complexidade computacional, para o referido detector.

\section{2 .2}

\section{Esquema de Detecção e Decodificação Iterativo}

Em relação a esse tema, os trabalhos realizados focaram-se na comprovação da viabilidade do uso das estratégias IDD. Apesar disso, propõe-se o emprego de codificadores mais eficientes do que o utilizado nas análises efetuadas, como, por exemplo, esquemas de codificação turbo. Dessa forma, espera-se a obtenção de resultados muito mais expressivos aos obtidos neste trabalho.

\subsection{3}

\section{Estimação e Detecção conjuntas cooperativa em sistemas MIMO multi- celulares}

Apesar dos ganhos obtidos com o algoritmo proposto para a estimação/detecção conjunta em sistemas MIMO multicelulares, o piso encontrado para a curva de BER não foi eliminado para o caso analisado, constituído por um sistema com $L=4$ células interferentes, cada uma munida com uma EB com $N_{r}=16$ antenas receptoras e $K=4$ usuários por célula. Nesse cenário foi mostrado que a matriz de correlação do vetor de símbolos recebidos se aproxima de uma matriz singular com o aumento da SNR, justificando assim o emprego da técnica de carregamento diagonal para contornar o problema de mau-condicionamento dessa matriz.

Dessa forma não ficou claro se a estagnação da BER com o aumento da SNR encontrada foi oriunda do mau-condicionamento da matriz correlação do vetor de sinal recebido ou dos efeitos da contaminação por pilotos, que não foram completamente eliminados pelo algoritmo proposto. Portanto, propõe- 
se os seguintes estudos como seguimento natural aos trabalhos desta tese referentes a esse subtema:

1. análise de cenários em que a matriz correlação do vetor de sinal recebido não se aproxime de uma matriz singular com o aumento da SNR;

2. emprego de estratégias de busca LAS no processo de estimação/detecção efetuado no algoritmo proposto mais robustas que a estratégia empregada, que foi o LAS sequencial. 


\section{Referências bibliográficas}

[1] KRAEMER, B. P.;LI, S.; HILLMAN, G.; ROSDAHL, J. W.; STEPHENS, A. P.; $E T$ AL.. IEEE standard for information technology telecommunications and information exchange systems - local and metropolitan area networks - specific requirements, part 11: Wireless LAN medium access control (MAC) and physical layer (PHY) specifications, amendment 5: Enhancements for higher throughput (IEEE Std 802.11n-2009). IEEE Standards 1, 536p., IEEE, 2009.

[2] GHOSH, A.; RATASUK, R.; MONDAL, B.; MANGALVEDHE, N. ; THOMAS, T.. Lte-advanced: Next-generation wireless broadband technology. IEEE Transactions on Wireless Communications, 17(3):10-22, Jun 2010.

[3] ABOUL-MAGD, O. S.; KIM, J.; WENTINK, M. M.; STACEY, R.; YANG, D.; $E T$ AL.. IEEE standard for information technology - telecommunications and information exchange between systems local and metropolitan area networks - specific requirements, part 11: Wireless LAN medium access control (MAC) and physical layer (PHY) specifications, amendment 4: Enhancements for very high throughput for operation in bands below $6 \mathrm{ghz}$ (IEEE Std 802.11ac-2013). IEEE Standards 1, 425p., IEEE, 2013.

[4] PERAHIA, E.; STACEY, R. Next Generation Wireless LANS: 802.11n and 802.11ac - 2th ed. Cambridge University Press, 2013.

[5] CISCO. 802.11ac: The fifth generation of Wi-Fi. CISCO Technical White Paper, p. 1-25, Mar 2014.

[6] MARZETTA, T. L. Noncooperative cellular wireless with unlimited numbers of base station antennas. IEEE Transactions on Wireless Communications, 9(11):3590-3600, Nov 2010.

[7] RUSEK, F.; PERSSON, D.; LAU, B. K.; LARSSON, E. G.; MARZETTA, T. L.; EDFORS, O.; TUFVESSON, F. Scaling up MIMO: Opportunities 
and challenges with very large arrays. IEEE Signal Processing Magazine, p. 40-60, Jan 2013.

[8] RAPPAPORT, T. S. Wireless Communications - Principles and Practice. Prentice Hall PTR, 1996.

[9] MARZETTA, T. L. BLAST training: Estimating channel characteristics for high capacity space-time wireless. 37th Annual Allerton Conf. Communications, Control, and Computing, Set 1999.

[10] HASSIBI, B.; VIKALO, H. On the sphere-decoding algorithm i. expected complexity. IIEEE Transactions on Signal Processing, 53(8):28062818, Ago 2005.

[11] VIKALO, H.; HASSIBI, B. On the sphere-decoding algorithm ii. generalizations, second-order statistics, and applications to communications. IIEEE Transactions on Signal Processing, 53(8):2819-2834, Ago 2005.

[12] TSE, D.; VISWANATH, P. Fundamentals of Wireless Communication. Cambridge University Press, 2005.

[13] GOLDEN, G. D.; FOSCHINI, C. J.; VALENZUELA, R. A.; WOLNIANSKY, P. W. Detection algorithm and initial laboratory results using V-BLAST space-time communication architecture. Electronics Letters, 35(1):14-16, Jan 1999.

[14] NGO, H. Q.; LARSSON, E. G. ; MARZETTA, T. L.. Energy and spectral efficiency of very large multiuser mimo systems. IEEE Transactions on Communications, 61(4):1436-1449, Abril 2013.

[15] STUDER, C.; LARSSON E. G. PAR-aware large-scale multi-user mimo-ofdm downlink. IEEE Journal on Selected Areas on Communications, 31(2):303-313, Fev 2013.

[16] WANG, H.; PANAND, P.; SHEN, L.; ZHAO, Z. On the pair-wise error probability of a multi-cell MIMO uplink system with pilot contamination. IEEE Transactions on Wireless Communications, 13(10):5797-5811, Out 2014.

[17] KRISHNAN, N.; YATES, R. D.; MANDAYAM, N. B. Uplink linear receivers for multi-cell multiuser MIMO with pilot contamination: Large system analysis. IEEE Transactions on Wireless Communications, 13(8):4360-4373, Ago 2014. 
[18] ZHANG, Q.; JIN, S.; HUANG, Y.; ZHU, H. Uplink rate analysis of multicell MIMO systems in ricean fading. Globecom 2014 - Signal Processing for Communications Symposium, p. 3279-3283, Dez 2014.

[19] JOSE, J.;ASHIKHMIN, A.; MARZETTA, T. L.; VISHWANATH, S. Pilot contamination and precoding in multi-cell TDD systems. IEEE Transactions on Wireless Communications, 10(8):2640-2651, 2011.

[20] VARDHAN, K. V.; MOHAMMED, S. K.;CHOCKALINGAM, A.; RAJAN, B. S. A low-complexity detector for large MIMO systems and multicarrier CDMA systems. IEEE Journal on Selected Areas in Communications, 26(3):473-485, Abr 2008.

[21] MOHAMMED, S. K.; CHOCKALINGAM, A.; RAJAN, B. S. A lowcomplexity near-ML performance achieving algorithm for large MIMO detection. IEEE International Symposium on Information Theory, p. 2012-2016, Jul 2008.

[22] LI, P.; MURCH, R. D. Multiple output selection-LAS algorithm in large MIMO systems. IEEE Communications Letters, 14(5):2012-2016, Maio 2010.

[23] KNIEVEL,C.; NOEMM, M.; HOECHER, P. A. Low-complexity receiver for large-MIMO space-time coded systems. IEEE Vehicular Technology Conference - VTC2011-Fall, Set 2011.

[24] FUKUDA, W.; ABIKO, T.; NISHIMURA, T.; OHGANE, T.; OGAWA, Y.; OHWATARI, Y.; KISHIYAMA, Y. Low-complexity detection based on belief propagation in a massive MIMO system. IEEE Vehicular Technology Conference - VTC2013-Spring, p. 1-5, 2013.

[25] MOREIRA, J. C.; FARREL, P. G. Essentials of error-control coding. John Wiley \& Sons Ltd, Chichester, 2006.

[26] SRINIDHI,N.; MOHAMMED, S. K.; CHOCKALINGAM, A.; RAJAN, B. $S$. Low-complexity near-ML decoding of large non-orthogonal STBCs using reactive tabu search. International Symposium on Information Technology - ISIT 2009, p. 1993-1997, Jul 2009.

[27] GLOVER, F. Tabu search - part i. ORSA journal on computing, p. 190-206, Ago 1989.

[28] GLOVER, F. Tabu search - part ii. ORSA journal on computing, p. 4-32, 1990. 
[29] BATTITI, R.; TECCHIOLLI, G. The reactive tabu search. ORSA journal on computing, 6(2):126-140, 1994.

[30] PEREIRA JR, A. A.; SAMPAIO_NETO, R. A random-list based LAS algorithm for near-optimal detection in large-scale uplink multiuser MIMO systems. 19th International ITG Workshop on Smart Antennas - WSA 2015, p. 1-5, Mar 2015.

[31] PEREIRA JR, A. A.; SAMPAIO_NETO, R. Near ML uplink detection for large scale MIMO systems. XXXIII Simpósio Brasileiro de Telecomunicações - SBrT2015, p. 216-220, Set 2015.

[32] HOCHWALD B. M.; BRINK S. Achieving near-capacity on a multipleantenna channel. IEEE Transactions on Communications, 51(3):389-399, 2003.

[33] HAGENAUER, J.; OFFER, E.; PAPKE, L. Iterative decoding of binary block and convolutional codes. IEEE Transactions on Communications, 42(2):429-445, 1996.

[34] YANG, D. W.; LIN, J. S.; FANG, S. H.; LIN, C. F.; SHIEH, M. D. Highperformance turbo-MIMO system design with iterative softdetection and decoding. Asia-Pacific Signal \& Information Processing Association Annual Summit and Conference (ASIPA ASC), p. 1-4, Dez 2012.

[35] ARÉVALO, L.; DE LAMARE, R. C.; SAMPAIO_NETO, R. Iterative multibranch lattice reduction-aided successive interference cancellation for multiuser mimo systems. 19th International ITG Workshop on Smart Antennas - WSA, p. 1-5, Mar 2015.

[36] SHIN, S. S.; CHOI, H.; JANG, J. E.; CHOI, J. W. A low complexity iterative MIMO detection and decoding scheme using dimension reduction. Transactions on Emerging Telecommunications Technologies, 27(1):136-145, 2016.

[37] COX, D. C.; MURRAY, R.; NORRIS, A. $800 \mathrm{MHz}$ attenuation measured in and around suburban houses. AT\&T Bell laboratory technical journal, 673(6), Julho 1984.

[38] BERNHARDT, R. C. Macroscopic diversity in frequency reuse system. IEEE journal on selected areas in communications, SAC-5:862-878, Junho 1987. 
[39] SKLAR, B. Rayleigh fading channel in mobile digital communications systems - part I: characterization. IEEE communications magazine, 35(7):90-100, Julho 1997.

[40] SHANNON,C. E. A mathematical theory of communication. Bell System Technical Journal, 27:379-423, Julho 1948.

[41] COVER, T. M.; THOMAS, J. A. Elements of Information Theory 2nd ed. John Wiley \& Sons, 2006.

[42] TELATAR, I. E. Capacity of multi-antenna gaussian channels. European Transactions on Telecommunications, 10:585-595, 1999.

[43] KERMOAL, J. P.; SCHUMACHER, L.; PERDERSEN, K. I. A stochastic MIMO radio channel model with experimental validation. IEEE Journal on Selected Areas in Communications, 20(6):1211-1226, Ago 2002.

[44] KAY, S. M. Fundamentals of Statistical Signal Processing: Estimation Theory. Prentice Hall, 1993.

[45] PROAKIS, J. G.; SALEHI, M. Digital Communications - 5th ed. McGraw Hill, 2008.

[46] TREES, H. L. V. Detection, Estimation and Modulation Theory Part I - Detection, Estimation and Linear Modulation Theory. John Wiley \& Sons, 2001.

[47] ARÉVALO, L.; DE LAMARE, R. C.; ZU, K.; SAMPAIO_NETO, R. Multibranch lattice reduction successive interference cancellation detection for multiuser MIMO systems. 11th International Symposium on Wireless Communications Systems (ISWCS) - 2014, p. 219-223, Ago 2014.

[48] DE LAMARE, R. C.; SAMPAIO_NETO, R. Minimum mean-squared error iterative successive parallel arbitrated decision feedback detectors for DS-CDMA systems. IEEE Transactions on Communications, 56(5):778-789, Maio 2008.

[49] DELGADO, K. K. The complex gradient operator and the CRcalculus. Disponível em: http://arxiv.org/pdf/0906.4835.pdf, 2009.

[50] MINKA, T. The UpshapeLightspeed UpshapeMatlab Toolbox, Efficient Operations for UpshapeMatlab Programming, version 2.2. Microsoft Corporation, 2007.

[51] VERDU, S. Multiuser Detection. Cambridge University Press, 1998. 
[52] DATTA, T.; KUMAR, N. A.; CHOCKALINGAM, A.; RAJAN, B. S. A novel MCMC algorithm for near-optimal detection in largescale uplink mulituser MIMO systems. IEEE Information Theory and Applications Workshop (ITA), p. 69-77, Fev 2012.

[53] PATEL, P.; HOLTZMAN, J. Analysis of a simple successive interference cancellation scheme in a DS/CDMA systems. IEEE Journal on Selected Areas in Communications, 12(5):796-807, 1994.

[54] FA, R.; DE LAMARE, R. C. Multi-branch successive interference cancellation for MIMO spatial multiplexing systems: design, analysis and adaptive implementation. IET Communications, 5(4):484-494, 2011.

[55] HAN, S.; TELLAMBURRA, C.; CUI, T. SNR-dependent radius control sphere detection for MIMO systems and relay networks. Transactions on Emerging Telecommunications Technologies, 26(3), Mar 2013. doi 10.1002/ett. 2620 .

[56] FINCKE, U.; POHST, M. Improved methods for calculating vectors of short length in a lattice, including complexity analysis. Mathematics of Computation, 44:463-471, 1985.

[57] DAMEN, M. O.; CHKEIF, A.; BELFIORE, J. C. Lattice code decoder for space-time codes. IEEE Communications Letters, 4:161-163, 2000.

[58] DE LAMARE, R. C; SAMPAIO_NETO, R. Adaptive reduced-rank processing based on joint and iterative interpolation, decimation, and filtering. IEEE Transactions on Signal Processing, 57(7):2503-2514, 2009.

[59] WANG X.; POOR, H. V. Iterative (turbo) soft interference cancellation and decoding for coded CDMA. IEEE Transactions on Communications, 47(7):1046-1061, 1999.

[60] BAHL, L. R.; COCKE, J.; JELINEK, F.; RAVIV, J. Optimal decoding of linear codes for minimizing symbol error rate. IEEE Transactions on Information Theory, 20:284-287, 1974.

[61] MOREIRA, J. C.; FARRELL, P. G. Essentials of Error-Control Coding. John Wiley \& Sons, 2006.

[62] FERNANDES, F.; ASHIKHMIN, A.; MARZETTA, T. Interference reduction on cellular networks with large antenna arrays. IEEE International Conference on Communications - ICC, Maio 2012. 
[63] SARKER, A. L.; LEE, M. H. A fast channel estimation and the reduction of pilot contamination problem for massive MIMO based on a diagonal jacket matrix. International workshop on fiber optics in access network - FOAN, p. 26-30, Set 2013.

[64] WANG, R.; CHEN, Y.; TAN, H. Data-assisted channel estimation for uplink massive MIMO systems. IEEE global communications conference - globecom, p. 3766-3771, Dez 2014.

[65] LIU, F.; MENG, Q.; ZOU, Y.; PANG F.; ZHONG, S. An approach to reduce pilot contamination in large-scale MIMO systems. IEEE International Conference on Communications - ICC, p. 813-816, Out 2015.

[66] MA, S.; JIANG, S.; LONG, T. Pilot contamination reduction based on improved power control in M-MIMO systems. International Conference on Wireless Communications, Networking and Mobile Computing - WiCOM, p. 1-6, Set 2015.

[67] ZHU, X.; WANG, Z.; DAI, L.; QIAN, C. Smart pilot assignment for massive mimo. IEEE Communications Letters, p. 1644-1647, Set 2015.

[68] YIN, H.; GESBERT, D.; FILIPPOU, M.; LIU, Y. A coordinated approach to channel estimation in large-scale multiple-antenna systems. IEEE Journal on Selected Areas in Communications, 31(2):264-273, Fev 2013.

[69] ASHIKHMIN, A.; MARZETTA, T. Pilot contamination precoding in multi-cell large scale antenna systems. IEEE International Symposium on Information Theory - ISIT2012, p. 1137-1141, Jul 2012.

[70] VIKALO, H.; HASSIBI, B.; STOICA, P. Efficient joint maximumlikelihood channel estimation and signal detection. IEEE Transactions on Wireless Communications, 5(7):1838-1845, jul 2006.

[71] JOSE, J.; ASHIKHMIN, A.; MARZETTA, T. ; VISHWANATH, S.. Pilot contamination problem in multi cell tdd systems. UCSD Information Theory \& Applications Workshop, Fev 2009.

[72] ORTEGA, A. J. Detecção de sinais em sistemas MIMO massivos. Dissertação de Mestrado - PUC-RJ, 2015.

[73] BRAZ, J. C.; SAMPAIO_NETO, R. Projection-based list detection in generalized spatial modulation MIMO systems. IEEE Communications Letters, 19(7):1145-1148, May 2015. 
[74] ARÉVALO, L.; DE LAMARE, R. C.; SAMPAIO_NETO, R. Variable list detection for multiuser MIMO systems. IEEE Transactions on Vehicular Technology, 2016. doi 10.1109/TVT.2016.2586942. 
A

\section{Demonstrações por indução}

A seguir serão apresentadas as demonstrações por indução matemática das equações (4-10) e (4-14). Pela definição de $\tilde{\alpha}^{t}$, temos que:

$$
\tilde{\alpha}^{1}(\mathbf{w})=c_{1}+\alpha^{1}(\mathbf{w})
$$

Considerando que $\tilde{\alpha}^{t-1}(\mathbf{w})=\sum_{i=1}^{t-1} c_{i}+\alpha^{t-1}(\mathbf{w})$, de (4-7) e (4-8), temos que:

$$
\begin{aligned}
& \tilde{\alpha}^{t}(\mathbf{w})=c_{t}+\log \left(\sum_{\mathbf{w}^{\prime}} \exp \left\{\tilde{\alpha}^{t-1}\left(\mathbf{w}^{\prime}\right)+\log \left(P\left[\mathbf{b}^{t}\left(\mathbf{w}^{\prime}, \mathbf{w}\right)\right]\right)\right\}\right) \\
& =c_{t}+\log \left(\sum_{\mathbf{w}^{\prime}} \exp \left\{\sum_{i=1}^{t-1} c_{i}+\alpha^{t-1}(\mathbf{w})+\log \left(P\left[\mathbf{b}^{t}\left(\mathbf{w}^{\prime}, \mathbf{w}\right)\right]\right)\right\}\right) \\
& =c_{t}+\log \left(\sum_{\mathbf{w}^{\prime}} \exp \left\{\sum_{i=1}^{t-1} c_{i}\right\} \cdot \exp \left\{\alpha^{t-1}(\mathbf{w})+\log \left(P\left[\mathbf{b}^{t}\left(\mathbf{w}^{\prime}, \mathbf{w}\right)\right]\right)\right\}\right) \\
& =c_{t}+\log \left(\exp \left\{\sum_{i=1}^{t-1} c_{i}\right\} \sum_{\mathbf{w}^{\prime}} \exp \left\{\alpha^{t-1}(\mathbf{w})+\log \left(P\left[\mathbf{b}^{t}\left(\mathbf{w}^{\prime}, \mathbf{w}\right)\right]\right)\right\}\right) \\
& =c_{t}+\sum_{i=1}^{t-1} c_{i}+\log \left(\sum_{\mathbf{w}^{\prime}} \exp \left\{\alpha^{t-1}(\mathbf{w})+\log \left(P\left[\mathbf{b}^{t}\left(\mathbf{w}^{\prime}, \mathbf{w}\right)\right]\right)\right\}\right) \\
& =\sum_{i=1}^{t} c_{i}+\alpha^{t}(\mathbf{w})
\end{aligned}
$$

em que a última igualdade vem da definição de $\alpha^{t}(\mathbf{w})$ em (4-5). Sendo assim, considerando (A-1) e (A-2), por indução, temos que:

$$
\tilde{\alpha}^{t}(\mathbf{w})=\sum_{i=1}^{t} c_{i}+\alpha^{t}(\mathbf{w}) \triangleq C^{t}+\alpha^{t}(\mathbf{w}), \quad t=1, \cdots, \tau
$$

Analogamente, pela definição de $\tilde{\beta}^{t}(\mathbf{w})$, temos que:

$$
\tilde{\beta}^{\tau-1}(\mathbf{w})=c_{\tau-1}+\beta^{\tau-1}(\mathbf{w})
$$

Considerando que $\tilde{\beta}^{t+1}(\mathbf{w})=\sum_{i=t+1}^{\tau-1} c_{i}+\beta^{t+1}(\mathbf{w})$, de $(4-12)$ e $(4-13)$, temos 
que:

$$
\begin{aligned}
& \tilde{\beta}^{t}(\mathbf{w})=c_{t}+\log \left(\sum_{\mathbf{w}^{\prime \prime}} \exp \left\{\tilde{\beta}^{t+1}\left(\mathbf{w}^{\prime \prime}\right)+\log \left(P\left[\mathbf{b}^{t+1}\left(\mathbf{w}, \mathbf{w}^{\prime \prime}\right)\right]\right)\right\}\right) \\
& =c_{t}+\log \left(\sum_{\mathbf{w}^{\prime \prime}} \exp \left\{\sum_{i=t+1}^{\tau-1} c_{i}+\beta^{t+1}\left(\mathbf{w}^{\prime \prime}\right)+\log \left(P\left[\mathbf{b}^{t+1}\left(\mathbf{w}, \mathbf{w}^{\prime \prime}\right)\right]\right)\right\}\right) \\
& =c_{t}+\log \left(\sum_{\mathbf{w}^{\prime \prime}} \exp \left\{\sum_{i=t+1}^{\tau-1} c_{i}\right\} \cdot \exp \left\{\beta^{t+1}\left(\mathbf{w}^{\prime \prime}\right)+\log \left(P\left[\mathbf{b}^{t+1}\left(\mathbf{w}, \mathbf{w}^{\prime \prime}\right)\right]\right)\right\}\right) \\
& =c_{t}+\log \left(\exp \left\{\sum_{i=t+1}^{\tau-1} c_{i}\right\} \sum_{\mathbf{w}^{\prime \prime}} \exp \left\{\beta^{t+1}\left(\mathbf{w}^{\prime \prime}\right)+\log \left(P\left[\mathbf{b}^{t+1}\left(\mathbf{w}, \mathbf{w}^{\prime \prime}\right)\right]\right)\right\}\right) \\
& =c_{t}+\sum_{i=t+1}^{\tau-1} c_{i}+\log \left(\sum_{\mathbf{w}^{\prime \prime}} \exp \left\{\beta^{t+1}\left(\mathbf{w}^{\prime \prime}\right)+\log \left(P\left[\mathbf{b}^{t+1}\left(\mathbf{w}, \mathbf{w}^{\prime \prime}\right)\right]\right)\right\}\right) \\
& =\sum_{i=t}^{\tau-1} c_{i}+\beta^{t}(\mathbf{w})
\end{aligned}
$$

em que a última igualdade vem da definição de $\beta^{t}(\mathbf{w})$ em (4-6). Sendo assim, considerando (A-4) e (A-5), por indução, temos que:

$$
\tilde{\beta}^{t}(\mathbf{w})=\sum_{i=t}^{\tau-1} c_{i}+\beta^{t}(\mathbf{w}) \triangleq D^{t}+\beta^{t}(\mathbf{w}), \quad t=\tau-1, \cdots, 0
$$

Aplicando a equação (A-3) e a definição de $c_{t}$, conforme equação (4-9), em (4-7) e (4-8), temos que:

$$
\begin{aligned}
\tilde{\alpha}^{t}(\mathbf{w})=c_{t}+\hat{\alpha}^{t}(\mathbf{w}) \\
=-\log \left(\sum_{\mathbf{w}} \sum_{\mathbf{w}^{\prime}} \exp \left\{\tilde{\alpha}^{t-1}\left(\mathbf{w}^{\prime}\right)+\log \left(P\left[\mathbf{b}^{t}\left(\mathbf{w}^{\prime}, \mathbf{w}\right)\right]\right)\right\}\right) \\
\quad \log \left(\sum_{\mathbf{w}^{\prime}} \exp \left\{\tilde{\alpha}^{t-1}\left(\mathbf{w}^{\prime}\right)+\log \left(P\left[\mathbf{b}^{t}\left(\mathbf{w}^{\prime}, \mathbf{w}\right)\right]\right)\right\}\right) \\
=\log \left\{\frac{\sum_{\mathbf{w}^{\prime}} \exp \left\{C^{t-1}+\alpha^{t-1}\left(\mathbf{w}^{\prime}\right)+\log \left(P\left[\mathbf{b}^{t}\left(\mathbf{w}^{\prime}, \mathbf{w}\right)\right]\right)\right\}}{\sum_{\mathbf{w}} \sum_{\mathbf{w}^{\prime}} \exp \left\{C^{t-1}+\alpha^{t-1}\left(\mathbf{w}^{\prime}\right)+\log \left(P\left[\mathbf{b}^{t}\left(\mathbf{w}^{\prime}, \mathbf{w}\right)\right]\right)\right\}}\right\} \\
=\log \left\{\frac{\sum_{\mathbf{w}^{\prime}} \exp \left\{\alpha^{t-1}\left(\mathbf{w}^{\prime}\right)+\log \left(P\left[\mathbf{b}^{t}\left(\mathbf{w}^{\prime}, \mathbf{w}\right)\right]\right)\right\}}{\sum_{\mathbf{w}} \sum_{\mathbf{w}^{\prime}} \exp \left\{\alpha^{t-1}\left(\mathbf{w}^{\prime}\right)+\log \left(P\left[\mathbf{b}^{t}\left(\mathbf{w}^{\prime}, \mathbf{w}\right)\right]\right)\right\}}\right\} \\
=\log \left\{\sum_{\mathbf{w}^{\prime}} \exp \left\{\alpha^{t-1}\left(\mathbf{w}^{\prime}\right)+\log \left(P\left[\mathbf{b}^{t}\left(\mathbf{w}^{\prime}, \mathbf{w}\right)\right]\right)\right\}\right\} \\
\quad-\log \left\{\sum_{\mathbf{w}} \sum_{\mathbf{w}^{\prime}} \exp \left\{\alpha^{t-1}\left(\mathbf{w}^{\prime}\right)+\log \left(P\left[\mathbf{b}^{t}\left(\mathbf{w}^{\prime}, \mathbf{w}\right)\right]\right)\right\}\right\}
\end{aligned}
$$




$$
\begin{aligned}
& =\alpha^{t}(\mathbf{w})-\log \left(\sum_{\mathbf{w}} \exp \left\{\alpha^{t}(\mathbf{w})\right\}\right) \\
& =\log \left\{\frac{\exp \left\{\alpha^{t}(\mathbf{w})\right\}}{\sum_{\mathbf{w}} \exp \left\{\alpha^{t}(\mathbf{w})\right\}}\right\}
\end{aligned}
$$

